\author{
Universidade de São Paulo \\ Faculdade de Saúde Pública
}

\title{
Perfil de morbidade da população indígena infantil referenciada para a Casa de Saúde Indígena (CASAI) de Rio Branco
}

Fernanda Lage Lima Dantas

\author{
Dissertação apresentada \\ ao Programa de Pós- \\ Graduação em Saúde \\ Pública para obtenção de \\ título de Mestre em Saúde \\ Pública. \\ Área de concentração: \\ Saúde, Ciclos de Vida e \\ Sociedade. \\ Orientador: Prof. Dr. \\ Paulo Rogério Gallo. \\ Tutor: Prof. Dr. Pascoal \\ Torres Muniz
}

Rio Branco - ACRE

2010 


\section{Perfil de morbidade da população indígena infantil referenciada para a Casa de Saúde Indígena (CASAI) de Rio Branco}

Fernanda Lage Lima Dantas

Dissertação apresentada ao Programa de PósGraduação em Saúde Pública para obtenção de título de Mestre em Saúde Pública.

Área de concentração: Saúde, Ciclos de Vida e Sociedade.

Orientador: Prof. Dr. Paulo Rogério Gallo.

Tutor: Prof. Dr. Pascoal Torres Muniz

Rio Branco - ACRE 
É expressamente proibida a comercialização deste documento, tanto na sua forma impressa como eletrônica. Sua reprodução total ou parcial é permitida exclusivamente para fins acadêmicos e científicos, desde que na reprodução figure a identificação do autor, título, instituição e ano da dissertação. 
À minha mãe, professora doutora e pesquisadora, minha maior inspiração acadêmica, que sempre me estimulou a estudar e ser aplicada, fazendo sempre o mais perfeito possível.

Ao meu amor e meu marido, Thor Oliveira Maia Dantas, professor doutor e pesquisador, também inspiração e estímulo para minha vida acadêmica. Ao nosso amor, Helena Lage Maia Dantas, por ter que me dividir com a dissertação logo tão no início de sua vida. Obrigada pela paciência nas ausências.

À minha família, pais, irmãos e agregados, por serem a base da minha existência, tão importante para os passos futuros.

E a todas as crianças do mundo, que elas possam ter uma vida plena e digna.

Dedico este trabalho. 
O êxito na realização de um trabalho complexo como este é, invariavelmente, fruto de um esforço coletivo. Devo os mais profundos e sinceros agradecimentos a:

O Prof. Dr. Paulo Rogério Gallo, meu orientador, professor dedicado não só na orientação da pesquisa e da dissertação, mas orientador na postura acadêmica, na organização da vida para conseguir realizar tantos sonhos e desejos, e até nos cuidados com a minha filha! Muito obrigada pela dedicação e pela paciência neste momento tão importante.

Meu marido Thor Oliveira Maia Dantas e minha mãe Lana Lage da Gama Lima, pelas sugestões, revisões e contribuições tanto com no projeto como na dissertação.

A Faculdade de Saúde Pública da Universidade de São Paulo, seus docentes e funcionários, por me proporcionarem tão elevado nível de aprendizagem. Em especial os Professores Doutores Cláudio Leone, Ana Cristina Tanaka, Néia Schor, Délsio Natal, Arlindo Philippi Jr e Maria do Carmo Avamilano Alvarez.

O Professor Pascoal Torres, Vice reitor da UAFC, pelo empenho em trazer esse curso de pós graduação para o Acre. E também pelo estímulo e ajuda no início da caminhada.

Nailton Cardoso Leitão, fiel escudeiro durante o mestrado, muito obrigada por tantas ajudas. Obrigada a Leandro Cleto, pela ajuda e acolhimento em São Paulo. 
Os funcionários da FUNASA, em especial os gestores Gelcimar Mota da Cruz e José Carlos Pereira Lima, além de Cleudo José Augusto Gadelha, pela disponibilização dos dados sobre o Dsei do Alto Rio Purus.

Aos funcionários da CASAI pela acolhida carinhosa durante o período da pesquisa de campo, sempre solícitos e atenciosos.

A Assessoria Especial dos Povos Indígenas do Acre, principalmente o Secretario Francisco Pianko e o antropólogo Marcelo Iglesias Piedrafita, pela disponibilização dos dados sobre as populações indígenas do estado, além da ajuda para contato com as lideranças indígenas.

As lideranças indígenas por autorizarem a utilização dos dados de seu povo para o trabalho. Espero poder contribuir para a melhoria das condições de vida, principalmente das crianças.

O antropólogo Txai Terri Aquino, por me ajudar no contato com as lideranças, e por me estimular a trabalhar com os povos indígenas.

A Aline Barros e Pamela Peres, alunas de medicina da UFAC, muito obrigada pela ajuda com os dados e pelo incentivo.

E principalmente aos povos indígenas da Amazônia Ocidental, espero estar contribuindo para melhoria da qualidade de vida e da saúde de sua população.

Obrigada. 
DANTAS, F. L. L. Perfil de morbidade da população indígena infantil referenciada para a Casa de Saúde Indígena (CASAI) de Rio Branco. 2010. 136 p. Dissertação (Mestrado em Saúde Pública) - Faculdade de Saúde Pública, Universidade de São Paulo, São Paulo.

\section{RESUMO}

Pouco se conhece sobre o perfil epidemiológico da população indígena infantil, principalmente na Amazônia Ocidental. $O$ conhecimento das morbidades e da demanda aos serviços auxilia na estruturação dos sistemas de saúde. A Casa de Saúde Indígena (CASAI) funciona como unidade de apoio, recebendo os indígenas referenciados para tratamento de saúde na rede do Sistema Único de Saúde. A CASAI de Rio Branco atende aos indígenas dos Distritos Sanitários Especiais Indígenas (Dsei) do Alto Rio Purus e do Alto Rio Juruá. Com o objetivo de traçar o perfil epidemiológico das crianças indígenas referenciadas no Estado do Acre e adjacências, foram avaliados todos os prontuários das crianças menores de 10 anos de idade que passaram pela CASAI de Rio Branco entre janeiro de 2003 e dezembro de 2007. As causas mais freqüentes de internação na CASAI foram as doenças infecciosas e parasitárias (cap. I do CID 10) com 19\%, seguidas das doenças do aparelho respiratório (cap. $\mathrm{X}$ do CID 10) com $16,5 \%$. A malária foi a quinta causa mais encontrada. Em $23 \%$ dos casos não foi encontrado registro sobre a causa da internação. Houve aumento na participação das malformações congênitas (cap. XVII do CID 10) 
nos anos finais do estudo, sugerindo um processo de transição epidemiológica. Observou-se predominância de crianças menores de dois anos de idade (44\%), principalmente no primeiro ano de vida $(26,5 \%)$, com poucos recém nascidos (3,9\%). Quase a totalidade das crianças atendidas (95\%) era moradora de aldeias. As diferenças culturais entre as etnias e a dificuldade de acesso às aldeias foram os principais fatores determinantes da demanda e do tipo de morbidade que chega a CASAI.

Descritores: saúde da criança, morbidade, perfil de saúde, população indígena, demanda. 
DANTAS, F. L. L. Morbidity profile of indigenous children referred to the Indigenous Nursing House (CASAI) of Rio Branco. 2010. 136 p. Dissertation (Master's degree in Public Health) - Faculdade de Saúde Pública, Universidade de São Paulo, São Paulo.

\begin{abstract}
There is little information available about the epidemiological profile of the indigenous children population, mainly in the Western Amazon Region. Knowledge about morbidity and demand to health services assists in the structuring of health systems. The Indigenous Nursing House (CASAI) works as a support unit, receiving the indigenous people referred for health treatment in the network of the Brazilian Public Health System (SUS). The CASAI of Rio Branco serves the indigenous population from two Special Indigenous Sanitary Districts (DSEI): Alto Rio Purus and Alto Rio Jurua. Aiming to outline the epidemiological profile of referred indigenous children in Acre and nearby areas, we evaluated medical records of all children under 10 years of age who have passed the CASAI of Rio Branco from January 2003 to December 2007. The most frequent causes of hospitalization in the CASAI were infectious and parasitic diseases (Chapter I of International Classification of Diseases - $10^{\circ}$ edition) with $19 \%$, followed by respiratory diseases (chapter X of the ICD-10) with $16.5 \%$. Malaria was the fifth most frequent cause. In $23 \%$ of cases the
\end{abstract}


cause of hospitalization was not found on records. There was an increased participation of congenital malformations (Chapter XVII of ICD-10) in the final years of the study, suggesting an epidemiological transition process. A high prevalence of children under two years of age (44\%) was observed, mainly in the first year of life (26.5\%), with few newborns (3.9\%). Almost all the children enrolled $(95 \%)$ were resident in villages in the forest. Cultural differences between ethnic and difficult access to villages were the main determinants of demand and the type of morbidity that comes to CASAI.

Keywords: child health, morbidity, health profile, indigenous population, demand. 


\section{ÍNDICE}

1. INTRODUÇÃO

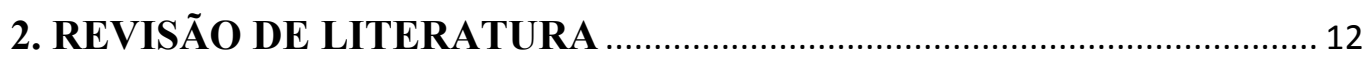

2.1 HISTÓRICO DA POLÍTICA DE SAÚDE INDÍGENA .......................... 12

2.2 ORGANIZAÇÃO DA ASSISTÊNCIA À SAÚDE INDÍGENA NO

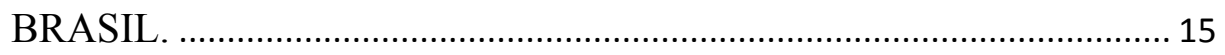

2.3 A ASSISTÊNCIA Á SAÚDE INDÍGENA NO ACRE .......................... 21

2.4 SISTEMA DE INFORMAÇÃO DA ASSISTÊNCIA Á SAÚDE

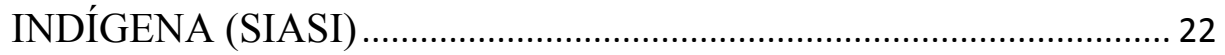

2.5 POVOS INDÍGENAS DO BRASIL ………………………………….... 24

2.6 PERFIL EPIDEMIOLÓGICO DOS POVOS INDÍGENAS DO

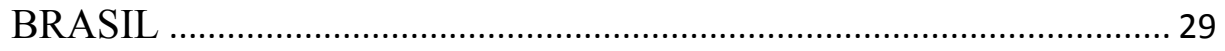

2.7 DISTRITOS SANITÁRIOS INDÍGENAS DO ACRE............................. 37

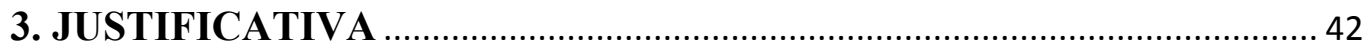

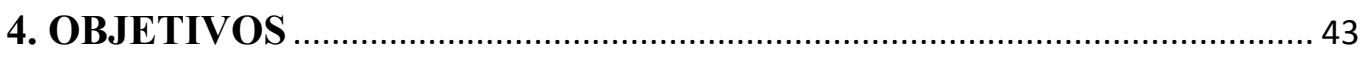

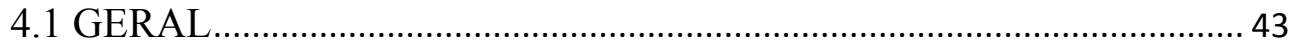

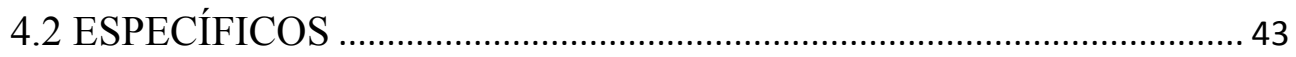

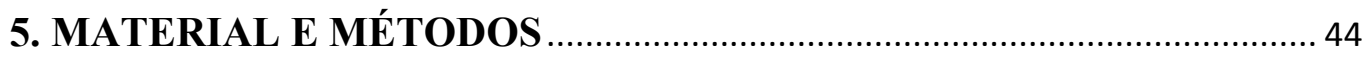

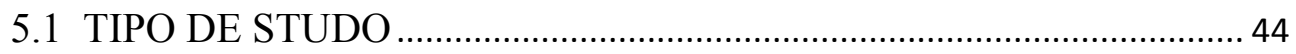

5.2 POPULAÇÃO DE ESTUDO …………………………………………... 44

5.3 COLETA DOS DADOS ………………………………………………...... 45

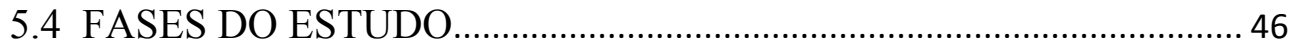

5.5 ANÁLISE DOS DADOS ............................................................................ 48

5.6 CONSIDERAÇÕES ÉTICAS ............................................................... 50

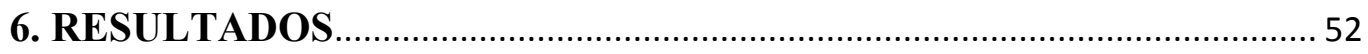

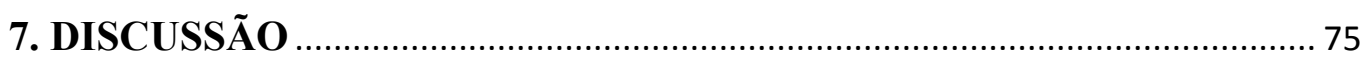

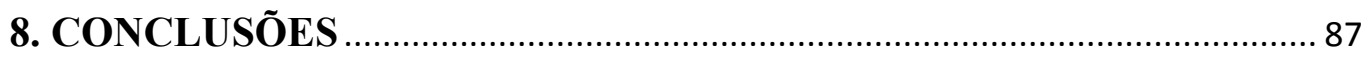


9. REFERÊNCIAS BIBLIOGRÁFICAS 89 ANEXOS

ANEXO 1 - Prontuário da Casa de Saúde Indígena de Rio Branco. 102

ANEXO 2 - Ficha do Pesquisador 107

ANEXO 3 - Parecer do Conselho Nacional de Ética em Pesquisa 109

ANEXO 4 - Termo de Consentimento Livre e Esclarecido assinado pelas lideranças indígenas 111

ANEXO 5 - Tabela com todos os códigos da Classificação Internacional de Doenças 10 revisão - CID 10 encontrados na pesquisa 113 ANEXO 6 - Tabela com todas as aldeias encontradas na pesquisa. 116

ANEXO 7 - Tabelas bivariadas de causa de internação por etnia . 119

ANEXO 8 - Tabelas bivariadas de causa de internação por Pólo-base 125 


\title{
Lista de abreviaturas e siglas
}

\author{
AIS Agentes Indígenas de Saúde \\ CASAI Casa de Saúde Indígena \\ CEP Comitê de Ética em Pesquisa \\ CONEP Conselho Nacional de Ética em Pesquisa
}

Dsei Distrito Sanitário Especial Indígena

FUNAI Fundação Nacional do Índio

FUNASA Fundação Nacional de Saúde

FUNTAC Fundação Tecnológica do Acre

IAB-PI Incentivo de Atenção Básica aos Povos Indígenas

IAE-PI Incentivo para a Atenção Especializada aos Povos Indígenas

IBGE Instituto Brasileiro de Geografia e Estatística

MS Ministério da Saúde

OMS Organização Mundial de Saúde

ONG Organização Não-Governamental

OPAS Organização Pan-Americana de Saúde

PPTAL Projeto Integrado de Proteção às Populações e Terras Indígenas da Amazônia Legal

RN Recém nascidos

SAS/MS Secretaria da Assistência à Saúde /Ministério da Saúde

SASI Sistema de Atenção à Saúde Indígena 
SIASI Sistema de Informação da Saúde Indígena

SPI Serviço de Proteção ao Índio

SPILTN Serviço de Proteção aos Índios e Localização de Trabalhadores Nacionais

SUS Sistema Único de Saúde

UNI União das Nações Indígenas do Acre e Sul do Amazonas

VIGISUS Projeto de Vigilância e Controle de Doenças 


\section{INTRODUÇÃO}

Conforme ressalta CARVALHO et al. (1994), há um interesse crescente no conhecimento do perfil epidemiológico das populações para adequação das práticas de saúde, visando orientar o planejamento e a programação das ações em saúde. Além das análises de mortalidade, tradicionalmente utilizadas para subsidiar o planejamento em saúde, o conhecimento das morbidades é de suma importância, por englobar também as doenças sem risco de morte eminente, porém que levam a uma demanda para os serviços de saúde (Moriyama, 1979 apud LAURENTI, 2004). Esses estudos de morbidade podem ser realizados tanto com dados primários, oriundos de inquéritos domiciliares, em locais de trabalho ou escolas; quanto com dados secundários disponíveis nos prontuários das instituições (CARVALHO et al., 1994).

O Estado do Acre possui quase $15 \%$ de sua extensão territorial reconhecida como Terras Indígenas pelo Governo Federal, e 2,4\% de sua população é composta por indígenas, divididos em 14 etnias além dos índios isolados (ACRE, 2008). Esses indígenas residem principalmente em aldeias. Seu território engloba os Distritos Sanitários Especiais Indígenas (Dsei) do Alto Rio Purus e do Alto Rio Juruá, sendo que o primeiro atende também parte dos Estados do Amazonas e de Rondônia, englobando mais três etnias (FUNASA, 2006). Não existem estudos sobre a saúde da população indígena da região, sabendo-se apenas que a mortalidade infantil do Dsei do Alto Rio Juruá é uma das mais altas do país (GARNELO et al., 2005). 
A Casa da Saúde Indígena (CASAI) é parte integrante do Subsistema de Atenção à Saúde Indígena (SASI), sendo responsável por dar apoio ao indígena durante seu período de tratamento nos hospitais referenciados da rede do Sistema Único de Saúde (SUS), localizando-se geralmente na principal cidade da região. Nela ficam hospedados os pacientes que buscam cuidados de saúde de média e alta complexidade. Principalmente nas aldeias de difícil acesso, é comum que os casos mais graves cheguem a óbito antes de alcançar atendimento médico. Os casos mais simples são atendidos nos Pólos-base localizados nos municípios. A CASAI de Rio Branco atende aos indígenas dos Dsei do Alto Rio Purus e do Alto Rio Juruá (FUNASA, 2006a).

A população indígena brasileira apresenta um quadro de saúde caracterizado pela alta ocorrência de doenças infecto-contagiosas e relacionadas às baixas condições de saneamento ambiental, trabalho, moradia; assim como alta prevalência de anemia e desnutrição (COIMBRA JUNIOR e SANTOS, 2001).

De uma forma geral, os trabalhos de pesquisa em saúde com populações indígenas são difíceis de serem conduzidos e pouco numerosos, sendo raros os artigos na literatura, a maioria relacionada a inquéritos de prevalência de doenças infecciosas (GUERRA et al., 2004; BASTA et al., 2006; ISHAK M. e ISHAK R., 2001; SOBRAL et al., 2005) ou status nutricional (GUGELMIN et al., 2001; ORELLANA e COIMBRA JUNIOR, 2006). Poucos trabalhos foram realizados com os índios da Amazônia Ocidental, principalmente com a população indígena infantil (SANTOS e COIMBRA JUNIOR, 2003). 
Segundo BUCHILLET (1995), para atender às demandas, expectativas e necessidades em matéria de saúde das populações, em particular das comunidades indígenas, há necessidade do conhecimento acurado de seu perfil epidemiológico e sanitário. CESAR et al. (1996) ressaltam a importância dos estudos sobre o perfil de morbidade da população, assim como sobre o padrão de utilização dos serviços de saúde, com intuito de auxiliar na estruturação de sistemas de saúde regionalizados e hierarquizados, num cenário de municipalização e integração das atividades preventivas e curativas.

Nesse contexto, o presente estudo se propõe a descrever o perfil epidemiológico das crianças indígenas referenciadas para a CASAI de Rio Branco para tratamento de saúde na rede do SUS, principalmente nos níveis de média e alta complexidade. Trata-se de um estudo de morbidade por demanda, através da utilização de dados secundários dos prontuários da referida CASAI, buscando auxiliar no planejamento de políticas públicas de saúde para o atendimento dessa população, de modo que o SUS possa melhor incluí-las, visando diminuir as desigualdades e contribuir para um atendimento universal e satisfatório. 


\section{REVISÃO DA LITERATURA}

\subsection{HISTÓRICO DA POLÍTICA DE SAÚDE INDÍGENA}

O termo política indigenista compreende todas as intervenções que o Estado brasileiro vem efetuando, desde o início do século $\mathrm{XX}$, junto aos grupos étnicos originais que habitam os limites do território brasileiro. Sua organização se deu em 1910, com a fundação do Serviço de Proteção aos Índios e Localização de Trabalhadores Nacionais (SPILTN), criado com o propósito de minimizar os inevitáveis conflitos gerados pela ocupação de territórios indígenas pelos diversos agentes econômicos em expansão, como fazendeiros, madeireiros, garimpeiros, agroempresas e outros. Apesar de visar, em tese, à proteção dos indígenas, a atuação do SPILTN acabou acarretando para essa população graves perdas de território e a piora das condições de vida (GARNELO et al., 2003). O SPILTN passou a ser conhecido como Serviço de Proteção ao Índio (SPI) a partir de 1918 (LIMA, 1995).

Ao ser concebida, a política indigenista brasileira partia do princípio de que os índios eram povos primitivos, que deveriam evoluir para se aproximar da sociedade brasileira. Isso contribuiu para que a cultura e os saberes dessa população fossem desqualificados, e também impulsionou o aculturamento e a incorporação dos indígenas como mão de obra agrícola no processo de ocupação do território brasileiro (GARNELO et al., 2003). 
Em 1916, o código civil brasileiro considerava os indígenas como incapazes de compreender seus direitos e responsabilidades legais e, portanto, de responder judicialmente por seus atos, instituindo a tutela como figura jurídica reguladora desses povos. Assim, aos órgãos indigenistas cabia tutelar essa população, responsabilizando-se pela gestão financeira e administrativa dos bens e recursos naturais existentes dentro das reservas indígenas. Essa condição facilitou a subordinação dos indígenas a agentes econômicos que visavam à exploração de sua mão-de-obra e das riquezas naturais de seus territórios (GARNELO et al., 2003).

Em 1967, o SPI foi substituído pela Fundação Nacional do Índio (FUNAI), mas permaneceu a figura jurídica da tutela, e foi mantido o caráter vertical e pouco participativo da política indigenista. Em 1973, em pleno regime militar, foi promulgado o Estatuto do Índio, regulamentando a intervenção do Estado brasileiro junto aos indígenas, considerados então como o principal obstáculo ao desenvolvimento da Amazônia e outras regiões de fronteira. Com relação às políticas de saúde e educação, a política indigenista foi marcada pela idéia de que a ação nesse campo deveria ser auto-sustentável, e que os órgãos indigenistas deveriam financiar suas ações com recursos advindos da exploração das riquezas naturais das terras indígenas (GARNELO et al., 2003).

Em 1988, no contexto dos avanços democráticos, estabeleceu-se com a nova constituição uma relação diferente entre o Estado e os povos indígenas, cabendo ao primeiro o papel de suprir suas necessidades básicas, como saúde e educação; e de prover apoio e fomento para a implantação de políticas setoriais de geração 
de renda, gestão territorial, ambiental e preservação das culturas tradicionais nas áreas demarcadas. Os indígenas foram reconhecidos como co-responsáveis pelo desenvolvimento de políticas públicas de seu interesse (GARNELO et al., 2003). $\mathrm{Na}$ década de 90, foi criado o Projeto Integrado de Proteção às Populações e Terras Indígenas da Amazônia Legal (PPTAL). A elaboração do PPTAL foi marcada pela participação dos grupos indígenas e pela parceria com entidades de apoio à sua causa, resultando numa efetiva contribuição para a organização dessas populações na região. Mas, somente em 2002 a tutela foi substituída por um novo dispositivo legal, garantindo aos indígenas $\mathrm{o}$ direito à autorepresentação jurídico-política (ATHIAS e MACHADO, 2001; GARNELO et al., 2003).

A atual Política Nacional de Atenção à Saúde dos Povos Indígenas apresenta como objetivo garantir:

acesso à atenção integral à saúde, de acordo com os princípios e diretrizes do Sistema Único de Saúde, contemplando a diversidade social, cultural, geográfica, histórica e política de modo a favorecer a superação dos fatores que tornam essa população mais vulnerável aos agravos à saúde de maior magnitude e transcendência entre os brasileiros, reconhecendo a eficácia de sua medicina e o direito desses povos à sua cultura (BRASIL, 2002a, p.13).

A forma de organização dos serviços de saúde para as áreas indígenas nasceu das Conferências Nacionais de Saúde, no contexto da Reforma Sanitária do início da década de noventa, sendo referendado pelo movimento indígena na II Conferência Nacional de Saúde para os Povos Indígenas (II CNSPI) de 1993, assim como pelos profissionais de saúde que trabalhavam com essa população (ATHIAS e MACHADO, 2001). 
Desde 1999, a atenção à saúde da população indígena do Brasil é organizada pelo Subsistema de Atenção à Saúde Indígena (SASI), articulado ao Sistema Único de Saúde (SUS), sendo de responsabilidade da Fundação Nacional de Saúde (FUNASA), órgão executivo do Ministério da Saúde, que assumiu a responsabilidade pela assistência à saúde indígena, até então atribuída à FUNAI (BRASIL, 2008). Em 17 de outubro de 2007 foi publicada a Portaria 2656, dispondo sobre as responsabilidades na prestação de atenção à saúde indígena, e regulamentando os Incentivos de Atenção Básica e Especializada aos Povos Indígenas.

\subsection{ORGANIZAÇÃO DA ASSISTÊNCIA À SAÚDE} INDÍGENA NO BRASIL

O Subsistema de Atenção à Saúde Indígena (SASI) está organizado na forma de trinta e quatro Distritos Sanitários Especiais Indígenas (Dsei), conforme explicitado na figura 1, responsáveis pelo atendimento básico, e articulados ao SUS quando são necessários procedimentos mais complexos. O modelo de assistência proposto para os Dsei caracteriza-se pela ênfase na promoção da saúde, pela oferta ininterrupta de serviços nas aldeias, pela adoção de demanda programada e pela utilização das estratégias de programas nacionais de prevenção e controle de agravos (GARNELO et al., 2003).

A noção de Distrito Sanitário Indígena está centrada na idéia de que a organização da prestação de serviços de saúde deve ser pertinente a cada 
realidade étnica, de forma que as ações sejam eficazes para determinada população indígena, sendo fundamental a participação das diversas instâncias organizativas indígenas na formulação das políticas do setor. Assim, os Distritos contemplam as características peculiares de cada área indígena, e são diferentes nas diversas regiões do Brasil, de acordo com o nível de organização dessa população.

As rotinas distritais cobrem uma gama de serviços voltados para a assistência e para o desenvolvimento de atividades programáticas, que visam principalmente ao controle dos agravos mais freqüentes, como malária, tuberculose, desnutrição e doenças imunopreveníveis (GARNELO et al., 2005).

O Dsei é uma unidade organizacional da FUNASA, criado como uma extensão territorial e populacional definidas, de responsabilidade sanitária identificada. Seus limites não correspondem à divisão geográfica de Estados e Municípios da União, mas foram determinados de acordo com critérios técnicooperacionais, levando em consideração a distribuição geográfica tradicional dos povos indígenas e as relações culturais e políticas existentes. Possui uma equipe mínima necessária para execução de suas ações, e está sob controle social por intermédio dos Conselhos Local e Distrital de Saúde (BRASIL, 2010).

O mapa a seguir indica a distribuição dos 34 Distritos Sanitários Especiais Indígenas (Dsei) no território brasileiro: 


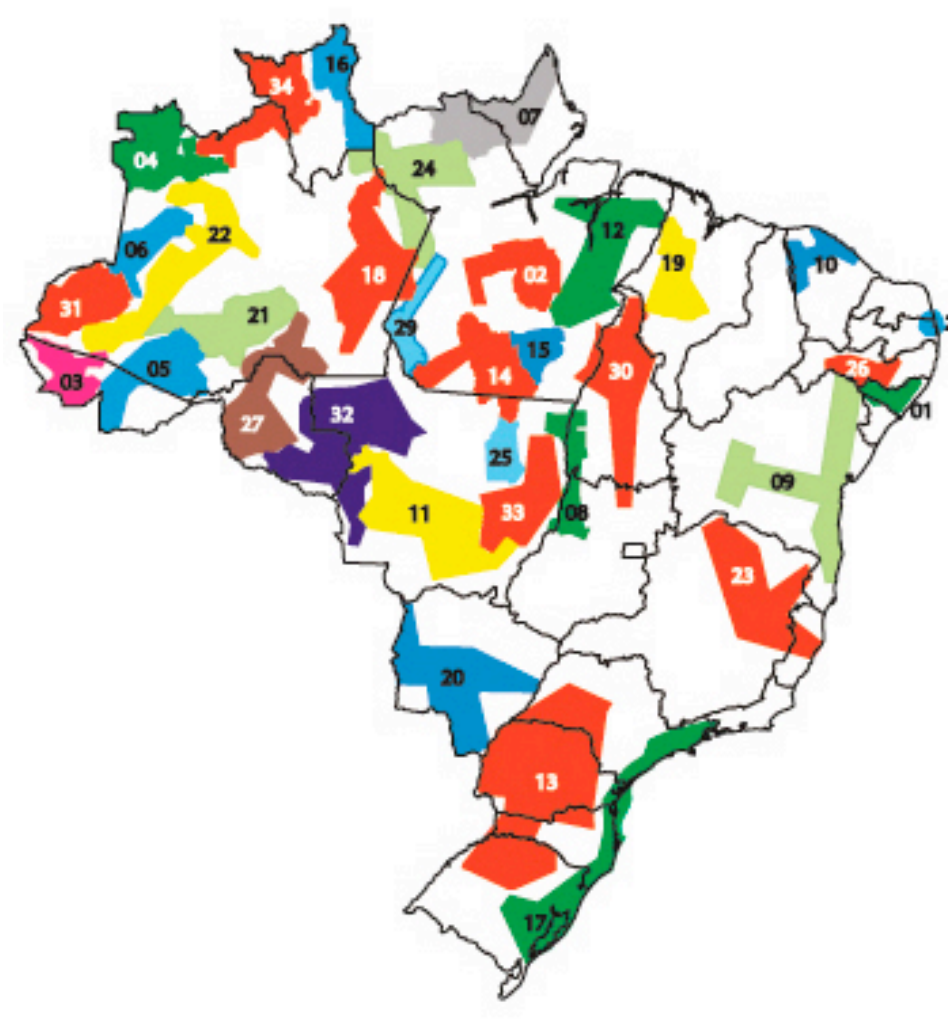

FONTE: Desai/Funasa/MS, setembro de 2003

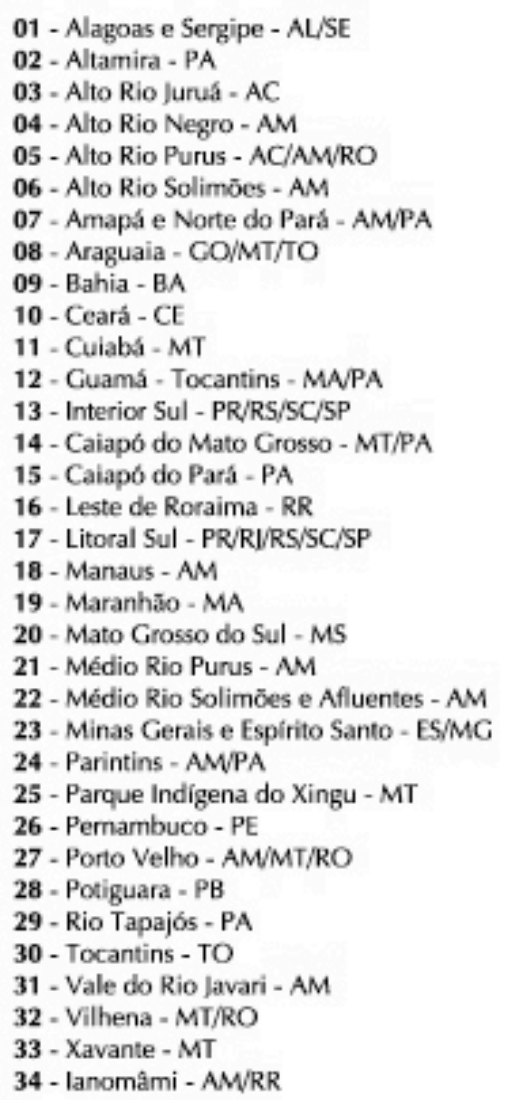

01 - Alagoas e Sergipe - AL/SE

03 - Alto Rio Juruá - AC

04 - Alto Rio Negro - AM

05 - Alto Rio Purus - AC/AMRO

07 - Amapá e Norte do Pará - AM/PA

08 - Araguaia - GO/MT/TO

12 - Guamá - Tocantins - MAPA

13 - Interior Sul - PR/RS/SC/SP

14 - Caiapó do Mato Grosso - MT/PA

15 - Caiapó do Pará - PA

17 - Litoral Sul - PR/RI/RS/SC/SP

18 - Manaus - AM

19 - Maranhw̃o - MA

- Mato Cirosso do Sul - MS

22 - Médio Rio Solimōes e Afluentes - AM

23 - Minas Gerais e Espírito Santo - ES/MG

25 - Parque Indigena do Xingu - MT

26 - Pemambuco - PE

27 - Porto Velho - AMMT/RO

28 - Potiguara - PB

31 - Vale do Rio Javari - AM

33 - Xavante - MT

34 - lanomâmi - AM/RR

Figura 1: Distribuição dos 34 Distritos Sanitários Especiais Indígenas no território brasileiro. Fonte: FUNASA, 2008.

Segundo o desenho do Dsei (Figura 2) cada comunidade indígena possui um posto de saúde do tipo I ou II, onde atuam respectivamente o Agente Indígena de Saúde e auxiliares de enfermagem. Os postos de saúde estão ligados aos respectivos Pólos-base do Município ou da microrregião, os quais contam com equipe de enfermagem permanente e recebe visitas periódicas do médico e do odontólogo. Nele são realizados procedimentos e atendimento de baixa complexidade. Além de prestar assistência à saúde, o Pólo-base realiza a capacitação e supervisão dos agentes indígenas de saúde (AIS), devendo operar 
de forma integrada e obedecer aos mecanismos de referência e contra-referência de pacientes e informações.

Os Pólos-base têm referência direta à Casa de Saúde Indígena (CASAI) e à rede do SUS, para realização de procedimentos de média e alta complexidade. O grau de resolubilidade proposto para os Dsei se resume à prestação da atenção básica, sendo necessária referência para a rede do SUS no caso de procedimentos de maior complexidade (GARNELO et al., 2003).

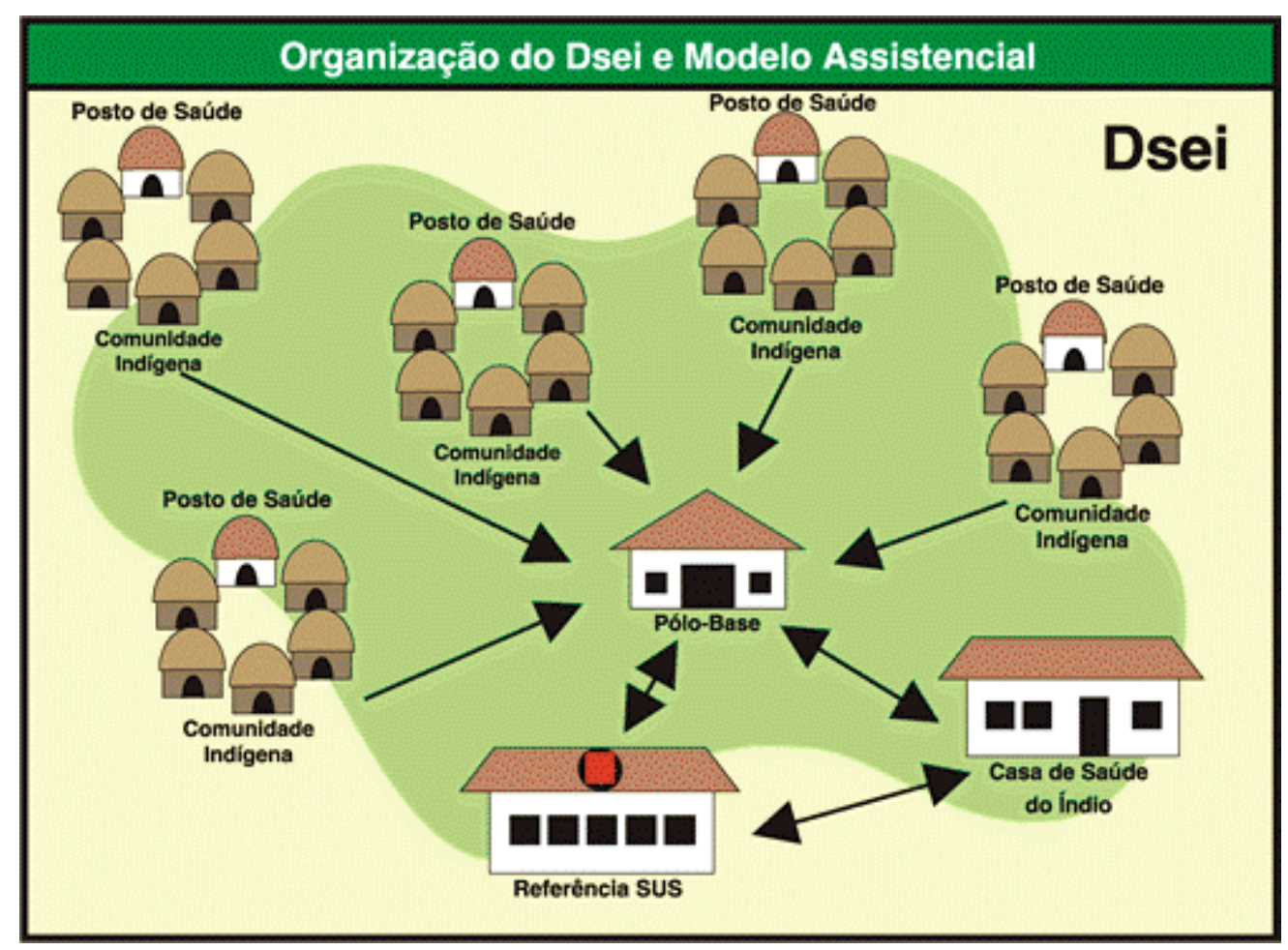

Figura 2: Desenho organizacional do Distrito Sanitário Especial Indígena (Dsei). Fonte: FUNASA, 2008.

A CASAI, que se localiza geralmente na capital do Estado ou região do Dsei, serve como apoio para a população indígena durante o período de tratamento fora da aldeia. Ela facilita o acesso aos serviços de saúde do SUS e a locomoção 
dos pacientes para as unidades hospitalares, assim como desenvolve atividades de educação em saúde e vigilância de agravos. Também pode funcionar como apoio para indígenas que precisam resolver questões sociais e jurídicas na cidade.

A CASAI tem como funções receber os pacientes encaminhados pelo Pólobase; alojar e alimentar pacientes e seus acompanhantes durante o período de tratamento; estabelecer os mecanismos de referência e contra-referência com a rede do SUS; prestar assistência de enfermagem aos pacientes póshospitalização e em fase de recuperação; acompanhar os pacientes para consultas, exames subsidiários e internações hospitalares; fazer a contrareferência com os Distritos Sanitários e articular o retorno dos pacientes e acompanhantes aos seus domicílios, por ocasião da alta. Algumas contam também com leitos para internação, atendimento médico de baixa complexidade e assistência odontológica (BRASIL, 2002a).

De acordo com o que trata o inciso $2^{\circ}$ da Lei 9863/1999, o SUS serve de retaguarda e referência ao Subsistema de Atenção à Saúde Indígena, mediante a realização de atendimento ambulatorial e hospitalar, clinico/cirúrgico e laboratorial, na assistência de média e alta complexidade. Para isso ocorre uma comunicação de forma articulada e intersetorial com a Secretaria de Estado de Saúde, que recebe incentivo financeiro da União para priorizar esses atendimentos. $\mathrm{O} 3^{\circ}$ inciso dessa mesma lei determina que as populações indígenas devem ter acesso garantido ao SUS, em âmbito local, regional e de centros especializados, de acordo com suas necessidades, compreendendo a 
atenção primária, secundária e terciária à saúde, e respeitando sua realidade étnico-cultural (FUNASA, 2006a).

Até 2007, o modelo administrativo adotado pela FUNASA para gestão do SASI apresentava duas vertentes. Na primeira, as Coordenações Regionais da FUNASA atuavam como ordenadoras de despesa e controlavam os recursos financeiros destinados aos distritos. Na segunda, o nível central da FUNASA celebrava convênios com organizações indígenas, organizações não governamentais (ONG), secretarias de saúde e universidades para a execução das ações de saúde nas áreas indígenas (ATHIAS e MACHADO, 2001).

Em outubro de 2007, por meio da Portaria 2656, houve uma normatização do modelo de assistência. A FUNASA continuou responsável pelo “planejamento, a coordenação e a execução das ações de atenção à saúde às comunidades indígenas, em estreita articulação com a Secretaria da Atenção à Saúde (SAS) do Ministério da Saúde, e complementarmente pelas Secretarias Estaduais e Municipais de Saúde". A execução das ações básicas de saúde pelos Municípios passou a ser financiada pelo Incentivo de Atenção Básica aos Povos Indígenas (IAB-PI), e o Estado passou a receber o Incentivo para a Atenção Especializada aos Povos Indígenas (IAE-PI) para a "implementação qualitativa e equânime da assistência ambulatorial, hospitalar e de apoio diagnóstico complementar". Os recursos do IAB-PI e IAE-PI são transferidos ao respectivo gestor, na modalidade fundo a fundo, mediante pactuação (BRASIL, 2007). 


\subsection{A ASSISTÊNCIA À SAÚDE INDÍGENA NO ACRE}

A Coordenação Regional da FUNASA do Acre, que até 2004 mantinha um convênio com a União das Nações Indígenas do Acre e Sul do Amazonas (UNI) para prestação de assistência à saúde, hoje apresenta um modelo híbrido de administração. A contratação de profissionais de saúde é realizada por meio das Prefeituras dos Municípios onde estão localizados os Pólos-base e a Casa de Saúde do Índio (CASAI). Os recursos são oriundos da Secretaria da Assistência à Saúde (SAS/MS), repassados diretamente, fundo a fundo, para pagamento das Equipes Multidisciplinares de Saúde Indígena, da equipe da CASAI, e também de parte da gerência técnica da sede do Dsei. Os recursos administrados diretamente pela FUNASA, referentes ao teto do Distrito e recursos do Projeto de Vigilância e Controle de Doenças (VIGISUS), são utilizados para capacitação das equipes multidisciplinares, dos Agentes Indígenas de Saúde, para manutenção da CASAI e para aquisição de insumos necessários para as condições de trabalho das Equipes Multidisciplinares de Saúde Indígena (FUNASA, 2006a).

A CASAI de Rio Branco foi fundada em 14 de julho de 1992, por meio de um projeto da Fundação Tecnológica do Acre (FUNTAC) em convênio com Ministério da Justiça / FUNAI. Funciona como um serviço de apoio aos pacientes de média e alta complexidade, encaminhados pelos Pólos-Base dos municípios de referência dos Distritos Sanitários Especiais Indígenas do Alto Rio Purus e Alto Rio Juruá para atendimento na rede do SUS. 
Os indígenas podem dar entrada na CASAI Rio Branco por dois caminhos diferentes. No primeiro caso o indígena vem referenciado diretamente do PóloBase para a CASAI com atendimento já agendado no SUS, sendo admitido na CASAI antes de passar pela rede ambulatorial e hospitalar. Já os casos de urgências e emergência são encaminhados dos Pólos-Base diretamente para o Pronto-Socorro, sendo o paciente referenciado para a CASAI após a alta hospitalar, para cuidados de enfermagem, até que possa retornar a sua moradia. Portanto, todos os indígenas referenciados para tratamento de saúde na rede do SUS acabam passando pela CASAI, seja antes de ir para o hospital, seja depois, antes do retorno para o domicílio (FUNASA, 2006a).

2.4 SISTEMA DE INFORMAÇÃO DA ASSISTÊNCIA À SAÚDE INDÍGENA

O Sistema de Informação da Assistência à Saúde Indígena (SIASI) da FUNASA foi iniciado em 2000, e ainda não está totalmente implementado. A coleta de dados é feita manualmente no plano local, estando sujeita a muitas falhas, o que torna difícil uma análise comparativa ou mesmo uma visão de conjunto. Os levantamentos são realizados geralmente com dados incompletos, baseados em suposição e não em contagem direta. A situação torna-se ainda mais complicada quando se pretende discutir perfis de mortalidade, fecundidade, migração ou crescimento populacional (COIMBRA JUNIOR e SANTOS, 2001), já que para isso é necessária a contabilização da população. A maioria das 
informações disponíveis é sobre morbidade, sendo derivadas dos atendimentos dos agentes de saúde, existindo poucos dados sobre os casos que geraram internação hospitalar (GARNELO et al., 2003).

Apesar dos avanços representados pela implantação do Subsistema de Atenção à Saúde Indígena, ainda existem diversos problemas que devem ser equacionados; dentre eles a precariedade do sistema de informação, que não supre as equipes de saúde com informações consistentes e congruentes com as necessidades e peculiaridades da população atendida (GARNELO et al., 2005). Mesmo quando são dados resultantes de contagem direta, geralmente os recenseadores não dominam a linguagem, não entendem a organização social nem a dinâmica espacial e sazonal das sociedades indígenas, produzindo, portanto informações inconsistentes e totais errados para mais ou para menos (RICARDO, 1996). Outra questão importante sobre a demografia dos povos indígenas diz respeito à metodologia de análise demográfica utilizada nos estudos, que é adequada para populações de grande porte, porém tem falhas quando aplicada a populações menores, caso da maior parte dos povos indígenas do Brasil (ISA, 2008). Estatísticas vitais, tais como coeficiente de mortalidade infantil, esperança de vida ao nascer, e taxas brutas de natalidade e mortalidade, essenciais para monitorar o perfil de saúde/doença e planejar ações de saúde e educação, não são disponíveis para a ampla maioria dos grupos (COIMBRA JUNIOR e SANTOS, 2001). Segundo Coimbra Junior e Santos, a divulgação dos dados referentes à saúde da população indígena é importante na busca da equidade entre as condições de saúde, o que é chamado por eles de "danosa 
invisibilidade demográfica e epidemiológica”. A coleta e a sistematização dos dados demográficos dos povos indígenas são de responsabilidade da FUNAI, porém na prática esses bancos de dados inexistem ou não se revestem de confiabilidade, por não serem coletados e atualizados de forma sistemática. Apenas em 1991 foi introduzido no censo nacional um ítem de classificação específico para os índios no quesito “cor”. Até então eles eram contabilizados na categoria dos "pardos". Porém não se especifica a etnia a qual eles pertencem. Além disso, somente são recenseadas as pessoas residentes próximo aos postos da FUNAI ou em missões indígenas, excluindo-se da contagem um contingente significativo de indígenas que vivem em regiões de difícil acesso (COIMBRA JUNIOR e SANTOS, 2001). Isso causa disparidades entre os dados sobre o contingente numérico de indígenas no Brasil de acordo com a fonte consultada, como veremos a seguir.

\subsection{POVOS INDÍGENAS DO BRASIL}

A população indígena do Brasil é estimada pela FUNASA em aproximadamente 400.000 indivíduos, distribuídos por cerca de 215 povos diferentes em 3.225 aldeias, falando em torno de 170 línguas distintas. Na sua maioria, os índios brasileiros estão concentrados nos Estados do Amazonas, Acre, Pará, Mato-Grosso, Rondônia e Roraima. As diferentes etnias indígenas têm experiências de interação com a sociedade nacional bem distintas, encontrando-se desde alguns grupos vivendo relativamente isolados na 
Amazônia até outros com significativa parcela de sua população vivendo em zonas urbanas (COIMBRA JUNIOR e SANTOS, 2001).

Mas, de acordo com a fonte consultada, o contingente numérico indígena relatado pode ser bem diferente. O censo populacional do Instituto Brasileiro de Geografia e Estatística (IBGE) de 2000 contabilizou 734 mil indígenas autodeclarados, enquanto a FUNASA contabilizou no mesmo período 400 mil indígenas cadastrados por suas equipes, como foi mencionado. Estes dados denotam, por um lado, uma possível superestimação dos auto-declarados indígenas pelo IBGE, resultado de um reconhecido movimento de resgate da auto-estima e valorização dos povos indígenas. Por outro lado, é provável uma subestimação no cadastramento da FUNASA, conseqüente ao baixo registro de nascimentos e óbitos e a particularidades geográficas de sua moradia, com grande dificuldade de acesso a alguns povos mais isolados. Já o Instituto Socioambiental estima a existência de 600 mil indígenas no país, distribuídos em 231 povos, falantes de mais de 180 línguas diferentes. Destes, 450 mil viveriam em Terras Indígenas ou núcleos urbanos próximos, e 150 mil residiriam em grandes cidades pelo país. Essa disparidade nos números denota a dificuldade de mensuração desta população específica, que deve corresponder a aproximadamente $0,2 \%$ da população total do país (ISA, 2008).

Quanto ao contingente populacional segundo etnia, a maioria dos indígenas se enquadra em micro-sociedades, ou seja, aquelas constituídas por 500 ou menos indivíduos (RICARDO, 1996). As seis etnias nacionais com maior contingente populacional, apresentando mais de 10.000 pessoas, são os Guarani, 
Kainngáng, Makuxi, Guajajára-tenetehára, Térena e Tikúna, que somam conjuntamente cerca de $40 \%$ dos indígenas do Brasil. A posse dos territórios indígenas também varia muito conforme as regiões, sendo que aproximadamente $40 \%$ da população indígena do Brasil se localiza nas regiões Nordeste, Sudeste e Sul, nas quais estão situados apenas $2 \%$ dos territórios indígenas (RICARDO, 1996).

Estima-se que, em 1500, quando os portugueses chegaram ao Brasil, a população indígena brasileira chegasse aos seis milhões de índios (CUNHA, 1992). Epidemias de doenças infecciosas, massacres e trabalho escravo foram as principais causas de despovoamento. Entre as décadas de 1950 e 1970 foram correntes os prognósticos sombrios sobre o futuro dos povos indígenas no Brasil, porém, da década de 1980 para cá, há fortes indícios de que certas populações indígenas vêm crescendo continuamente (GOMES, 1988).

A pirâmide populacional indígena tem um desenho diferente daquela referente à população total do Brasil, exibindo a base mais ampla e o topo menor, o que explicita uma população mais jovem. É encontrado elevado índice de natalidade, sendo que aproximadamente $50 \%$ da população indígena têm menos que 15 anos de idade (PAGLIARO et al., 2005; GARNELO et al., 2003). Para o país como um todo, esta porcentagem se aproxima de $33 \%$ da população nacional. 
Pirâmide populacional da população brasileira

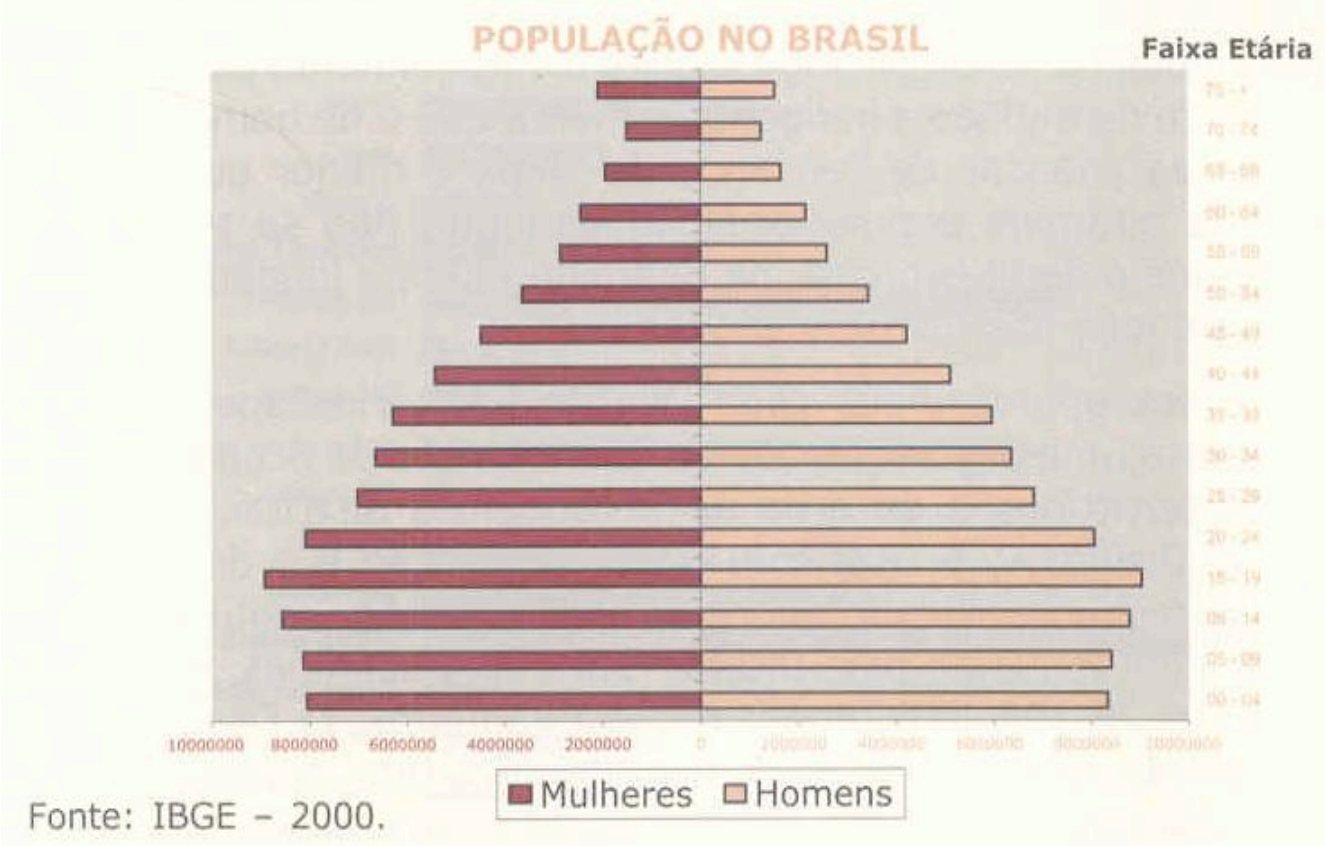

Figura 3: Pirâmide populacional brasileira.

\section{Pirâmide populacional dos povos indígenas do Brasil}

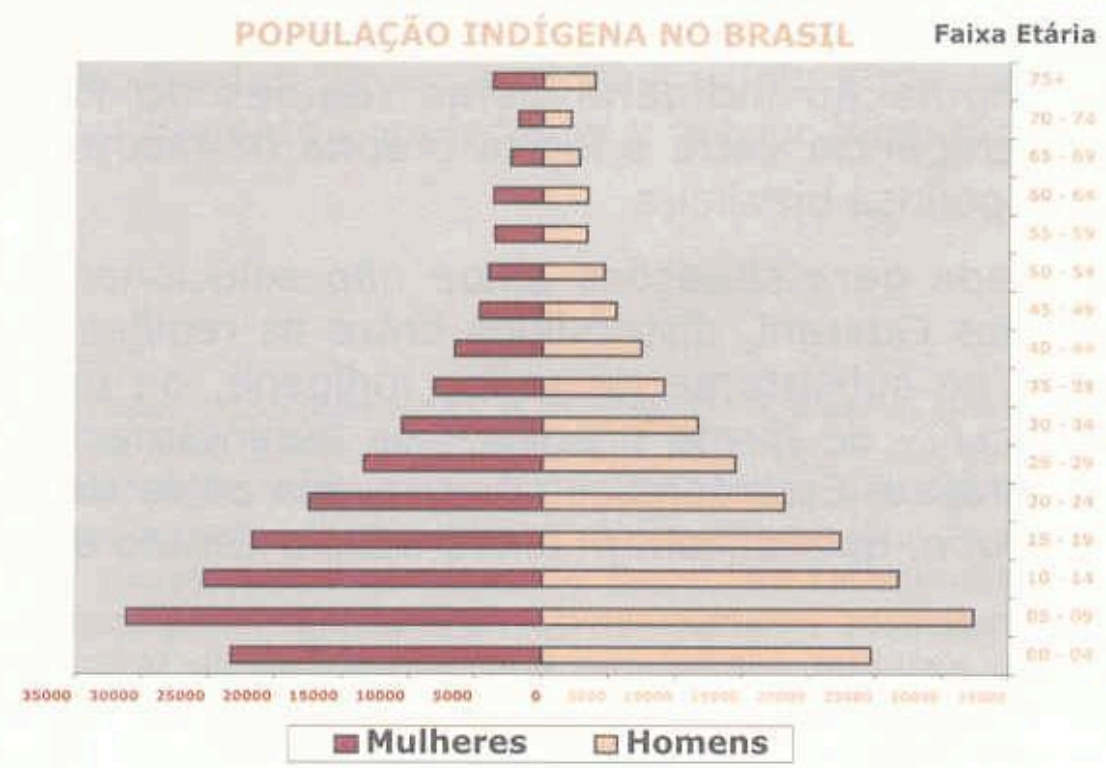

Fonte: Gráfico elaborado pela equipe do Desai, 2002.

Figura 4: Pirâmide populacional dos Povos Indígenas do Brasil. 
Estimava-se, em 2007, que no Acre viviam aproximadamente 14.450 indígenas, distribuídos em cerca de 146 aldeias e 14 etnias diferentes, apresentando densidade demográfica bastante variada (ACRE, 2008). Neste Estado também são encontrados índios "ressurgidos", ou seja, de etnias consideradas extintas, e índios sem contato nenhum com a sociedade brasileira, chamados de índios "isolados". Em maio de 2008 foram divulgadas imagens dos índios isolados localizados no rio Envira, próximo à fronteira com o Peru. Os antropólogos acreditam que pertençam a quatro etnias, num total de aproximadamente 750 indivíduos, que vieram do Peru expulsos pelos madeireiros que atuam na região.

Hoje são encontradas então 14 etnias no Acre, mais os índios isolados, com um total aproximado de 16.331 indígenas, o que corresponde a 2,4\% da população total do Estado. Estes indígenas estão distribuídos em 182 aldeias, localizadas em 35 Terras Indígenas reconhecidas pelo governo federal, com extensão territorial estimada em 2.320.232 hectares, o equivalente a $14 \%$ da extensão do estado (16.519.263 ha), situadas em 11 municípios. Das 35 Terras Indígenas, 70\% estão localizadas no Vale do Juruá (ACRE, 2008). Acredita-se que, antes do contato com os brancos, existissem 50 povos indígenas no Acre (UCHÔA, 2003).

Os indígenas do Acre pertencem a três troncos lingüísticos: Pano, Aruak e Arawá, contendo o primeiro o maior número de etnias. As etnias Aruak são tradicionais da região Amazônica e habitam principalmente a bacia do rio Purus, e as do tronco lingüístico Pano são originárias da região andina, que migraram 
para a bacia amazônica após os sucessivos confrontos com os espanhóis em suas terras, e estão mais concentrados no território do Juruá. Os povos encontrados no Estado do Acre são: Kaxinawá (Huni Kui), Ashaninka (Kampa), Manchineri, Kulina (Madijá), Katikina, Jaminawa, Shanenawa, Yawanawá, Jaminawa-Arara (ressurgido), Arara (Shawãdawa), Poyanawa, Nukini, Nawa (ressurgido) e Apolina-Arara (ressurgido); mais os índios isolados que vivem e transitam pela região de fronteira com o Peru. Como se pode observar, algumas etnias tem mais de uma nomeclatura, sendo uma denominada pelo branco e outra geralmente como o povo se auto-define. As duas são amplamente utilizadas. Os Kaxinawá correspondem a $57 \%$ dos indivíduos indígenas do Acre, e estão dispostos em diversas terras indígenas pelo Estado (UCHOA, 2003).

No Estado do Amazonas, perto da fronteira com o Acre, são encontradas as etnias Jamamadi e Apurinã; e em Rondônia, também próximo a fronteira com o Acre, o povo Kaxarary. Essas três etnias citadas, apesar de não pertencerem ao território do Acre, são atendidas pelos serviços do Estado pela proximidade geográfica e cultural.

\subsection{PERFIL EPIDEMIOLÓGICO DOS POVOS INDÍGENAS DO BRASIL}

O perfil epidemiológico dos povos indígenas no Brasil é muito pouco conhecido, em decorrência da precariedade das informações sobre morbidades, mortalidade e cobertura vacinal (COIMBRA JUNIOR e SANTOS, 2000). Mesmo assim, restam poucas dúvidas de que as condições de saúde dos povos 
indígenas são precárias, colocando-os em desvantagem em relação a outros segmentos da sociedade nacional. Tal situação de marginalidade é recorrente nas mais diferentes regiões das Américas. (COIMBRA JUNIOR et al., 1996; OPAS, 1998).

O complexo quadro de saúde indígena está diretamente correlacionado a processos históricos de mudanças sociais, econômicas e ambientais, atreladas à expansão de frentes demográficas e econômicas nas diversas regiões do país ao longo do tempo. Tais frentes exerceram importante influência sobre os fatores determinantes e o perfil das morbidades, seja pela introdução de novos patógenos, que causaram graves epidemias; seja pela usurpação de território, levando a mudanças nos modos de vida e de subsistência destas populações; seja pela perseguição e morte direta de indivíduos ou mesmo comunidades inteiras. Estas situações perduram até hoje, em diferentes regiões do país (COIMBRA JUNIOR e SANTOS, 2001).

Os indicadores de saúde da população indígena mostram em geral números sensivelmente piores que os da população nacional, principalmente de mortalidade infantil, mortalidade por doenças infecciosas e alcoolismo (SANTOS e COIMBRA JUNIOR, 2003). A mortalidade infantil indígena é mais elevada que a média da população brasileira, sendo que o censo do IBGE de 2000 mostra coeficiente de mortalidade de $31,8 / 1000$ nascidos vivos para os não indígenas e 74,6/1000 nascidos vivos para a população indígena (GARNELO et al., 2003). Mesmo entre os distintos distritos do SASI, os indicadores de saúde variam de acordo com a região estudada. No Acre, os indicadores encontrados 
no Dsei do Alto Rio Juruá são piores que os do Alto Rio Purus. A mortalidade infantil do Dsei do Alto Purus, em 2005, foi de 76/1000 nascidos vivos, enquanto no Juruá, no mesmo período, foi de 177/1000 (FUNASA, 2006a; FUNASA, 2006b), mostrando ambos os Dseis indicadores mais alarmantes que os da população indígena como um todo.

Estes indicadores exemplificam a condição de marginalidade socioeconômica a que os indígenas estão relegados, da qual uma das facetas se expressa pelas precárias condições de saneamento de suas aldeias e inadequação do atendimento à saúde.

Historicamente, as sociedades indígenas dependem, em menor ou maior medida, da agricultura, caça, pesca e coleta para subsistência. A interação com as frentes de expansão, a instalação de novos regimes econômicos e a diminuição dos limites territoriais levaram, entre outros fatores, a drásticas alterações na economia de subsistência, ocasionando empobrecimento e carência alimentar (COIMBRA JUNIOR e SANTOS, 2001). Além disso, a posse da terra significa não só a subsistência propriamente dita, mas corresponde também a um elo fundamental na continuidade étnica e tradições.

A avaliação da situação nutricional das crianças é um instrumento útil na aferição das condições de vida de uma população, porque está intimamente relacionado com a alimentação, saneamento e assistência à saúde. Em geral os estudos apontam para elevadas freqüências de déficit para o indicador estatura / idade, o que é interpretado como desnutrição crônica. Vale salientar que há uma discussão, em curso na literatura, acerca da validade de utilizar os pontos de 
corte preconizados por organismos internacionais na avaliação nutricional das crianças indígenas, já que os mesmos foram baseados em populações com outra compleição física. Assim, a freqüência de desnutrição descrita para determinada população deve ser analisada cautelosamente, pois se baseia nestes limites internacionais (SANTOS, 1993).

A anemia é outro problema nutricional importante nas populações indígenas, afetando sobretudo crianças e mulheres em idade reprodutiva. Além da ingestão insuficiente de determinados nutrientes, como por exemplo o ferro, a ocorrência de anemia também está relacionada com parasitoses endêmicas como a ancilostomose e a malária. Os estudos mostram ocorrência de anemia em $60 \%$ a 70\% das crianças indígenas (COIMBRA JUNIOR e SANTOS, 2001).

Historicamente, o perfil de morbi-mortalidade indígena do Brasil tem sido dominado pelas doenças infecciosas e parasitárias, e até recentemente epidemias de gripe e sarampo exterminavam aldeias quase inteiras, comprometendo a continuidade cultural e social dos grupos atingidos. A raridade de tais eventos no presente não elimina o peso das doenças infecciosas no cotidiano da maioria da população indígena, porém a ausência de informações impede a análise detalhada da epidemiologia deste grupo de doenças nessa população. Quando se observa o risco de adoecimento por tuberculose, malária e risco de morte na infância, verificamos que a população indígena apresenta valores muito superiores à população não-indígena da mesma região, demonstrando que este segmento está muito mais exposto aos agravos à saúde, além de ter piores condições sanitárias (GARNELO et al., 2005). 
As principais morbidades apresentadas pela população indígena, em ordem decrescente de prevalência, são verminoses, infecção de vias aéreas superiores, anemias, doenças diarréicas agudas e doenças das vias aéreas inferiores; sendo a população infantil a mais acometida. O percentual de óbitos nos menores de 10 anos representa $50 \%$ do total de óbitos entre os indígenas (FUNASA, 2006a; FUNASA 2006b).

Uma característica marcante da grande maioria das aldeias é a precariedade do saneamento ambiental, com ausência de infra-estrutura destinada à coleta dos dejetos e a inexistência de água potável. Isso permite que as parasitoses intestinais sejam amplamente disseminadas. Em geral, as espécies de helmintos mais prevalentes são o Ascaris lumbricoides, Trichuris trichiura, Strongyloides stercoralis e ancilostomídeo, e um quadro comum é de mais de $50 \%$ da população acometida por mais de uma espécie de parasita (RIOS et al, 2007). Os estudos também revelam prevalência variável de infecção por protozoários intestinais, como Giardia lamblia e Entamoeba hystolitica (COIMBRA JUNIOR e SANTOS, 2001). Essas condições ambientais precárias favorecem também a contaminação da água de consumo e dos alimentos por enterobactérias e rotavírus. Em certas situações, as infecções gastrointestinais chegam a corresponder à quase metade das internações hospitalares das crianças indígenas, e ser responsáveis por quase $60 \%$ das mortes em menores de um ano, como sugerem dados dos Xavante (IANELLI et al., 1996).

A presença diária, e nos mais variados horários, de famílias indígenas às margens de cursos d'água no entorno das aldeias, inclusive nos picos de 
atividade do Anopheles darlingi, expõe os indivíduos de ambos os sexos e todas as idade ao risco de infecção por malária. O risco é maior em locais sob a influência de fluxos migratórios, atividades de mineração e implantação de projetos de desenvolvimento.

As hepatites também constituem importante causa de morbi-mortalidade entre os indígenas, sendo que os inquéritos sorológicos revelam elevada prevalência de hepatite B e também relevante co-infecção pelo vírus Delta (COIMBRA JUNIOR et al., 1996). Chamam atenção as inúmeras práticas culturais e de cunho ritualístico, cosmético e curativo que podem estar relacionadas à transmissão dos vírus das hepatites $\mathrm{B}$ e $\mathrm{D}$ em sociedades indígenas. Além disso, a interação com garimpeiros, militares e outros agentes das frentes de expansão facilitam a disseminação de doenças sexualmente transmissíveis.

Entre as morbidades que provavelmente acometem grande número de indígenas, porém que possuem poucos registros, podem ser ressaltadas leishimaniose, oncocercose, esquistossomose, tracoma, hanseníase, e problemas ginecológicos (COIMBRA JUNIOR e SANTOS, 2001).

Uma dimensão pouco conhecida da epidemiologia dos povos indígenas diz respeito à emergência de doenças crônico-degenerativas como obesidade, hipertensão arterial e diabetes mellitus. Essas doenças são diretamente relacionadas às modificações na dieta e na atividade física desta população, decorrentes de mudanças sócio-culturais e econômicas resultantes da interação com a sociedade nacional (SANTOS e COIMBRA JUNIOR, 2003). A 
incidência de doenças cardiovasculares aumenta com a introdução de sal, bebidas alcoólicas destiladas, e gorduras saturadas na dieta, somado à diminuição na atividade física. É também observado aumento de ocorrência de transtornos psiquiátricos como depressão, alcoolismo, drogadicção e suicídio em diversas etnias.

Pode-se dizer, portanto que o perfil epidemiológico dos povos indígenas do Brasil está em transição, porém sem ser verificada ainda uma diminuição na ocorrência de doenças infecto-parasitárias e carências. As precárias condições sócio-econômicas e ambientais, e a ausência de adequada assistência à saúde, levam à perpetuação das doenças infecto-parasitárias e carências; e a mudança nos hábitos alimentares e a diminuição da atividade física levam ao aumento das doenças crônico degenerativas, causando uma superposição de perfis epidemiológicos distintos (SANTOS e COIMBRA JUNIOR, 2003).

Um aspecto que não pode ser esquecido quando se estuda o perfil de morbidade da população indígena é o significado da doença para sua cultura, quais as morbidades são consideradas doenças de índio e são tratadas pelo Pajé na aldeia, e quais são levadas para assistência nos serviços de saúde. Esse aspecto cultural pode levar a mudanças na demanda aos serviços de saúde (FUNASA, 2006b), e pode ter algumas diferenças entre as várias etnias, apesar de se observar um padrão universal (BUCHILLET, 2007). De uma forma geral são entendidas como doenças de índio aquelas existentes desde antes do contato com o homem branco, sendo que os quadros são menos específicos e geralmente associados à feitiçaria e espíritos maus. Os remédios da floresta servem para 
“matar muitas caças”, "ser trabalhador", "não pegar doença”, “ficar feliz de vida", além de outros mais objetivos e diretos como "para dor de dente", queimadura, para "mulher não ter filhos", para "ferradura de arraia", "ferrada de escorpião" (UCHOA, 2003). O estudo deste tema, porém, foge ao escopo deste trabalho.

Também se observa, em alguns estudos qualitativos, uma tendência das comunidades mais próximas das populações urbanas em procurar tratamento de "branco" para algumas doenças que já eram conhecidas e tratadas pela medicina tradicional dos indígenas, com o argumento que o primeiro seria mais "prático" por não exigir dietas e rituais (GONÇALVES, 2007). Algumas etnias perderam o conhecimento dos remédios da floresta por falecimento dos mais idosos e xamãs da comunidade, sem transmissão do conhecimento para gerações mais novas. Outra característica dos povos indígenas é o uso de algumas substâncias alucinógenas, como a ayahuasca, bebida feita de um cipó (Banisteriopsis caapi), que contém alcalóides de beta-carbolina, que são potentes inibidores MAO-A e uma folha (Psychotria viridis ou espécies correlatas), que contém Ndimetiltriptamina - DMT, potente alucinógeno de ação rápida (BRITO, 2002); e o veneno do sapo Kampô em seus rituais, com o objetivo de ficar mais forte e evitar adoecer, além de servir para conexão com os "espíritos da floresta". 


\subsection{DISTRITOS SANITÁRIOS INDÍGENAS DO ACRE}

O Estado do Acre engloba dois Dsei, o do Alto Rio Purus e o do Alto Rio Juruá, com uma população total atendida de 17.758 indígenas, divididos em 205 aldeias, segundo os dados da FUNASA de 2006. O Dsei do Alto Rio Purus atende a uma população de 7.346 indígenas, distribuídos em 99 aldeias, e conta com 6 Pólos-base; e o Dsei do Alto Rio Juruá atende 10.412 indígenas de 106 aldeias, e conta com 7 Pólos-base. Ambos encaminham os pacientes para a CASAI de Rio Branco (FUNASA, 2006a). Os Dsei localizados no Acre atendem a uma população indígena maior que a contabilizada no próprio Estado. Isso se deve ao fato dos limites territoriais dos Dsei não corresponderem à divisão geográfica dos Estados, englobando também parte da população indígena dos Estados do Amazonas e de Rondônia, conforme mostra a figura 1 (página 17).

A região em que esses Dsei estão localizados possui clima equatorial quente e úmido, com temperatura média anual variando entre $24,5^{\circ} \mathrm{C}$ e $32^{\circ} \mathrm{C}$. São identificadas duas estações distintas: a estação da chuva, que corresponde ao inverno Amazônico, e compreende o período entre os meses de novembro e abril, e o período da seca, entre os meses de maio a outubro (ACRE, 2008). No inverno Amazônico são características as chuvas constantes e abundantes, que promovem alagações e transformam o solo de tabatinga das estradas da região em grandes lamaçais, dificultando sobremaneira o acesso por via terrestre, mesmo com veículos com tração nas quatro rodas ou a pé. Por outro lado o acesso via fluvial é facilitado, com rios navegáveis em toda sua extensão. Já na 
época da seca o acesso via terrestre é facilitado, pois as estradas de terra, denominadas ramais na região, se tornam trafegáveis; em contrapartidas os rios ficam com nível de água menor, com áreas de bancos de areia propícias para encalhe das embarcações, tornando a viagem fluvial mais longa e difícil.

Outra característica da estação da seca é o alto índice de queimadas na região, que libera grande quantidade de fumaça na atmosfera e propicia doenças respiratórias. Ocorre um aumento no número de atendimentos nos hospitais da população em geral, principalmente em crianças e idosos, relacionados a problemas respiratórios (SALDANHA et al., 2005). As queimadas são do Estado do Acre, e principalmente das regiões vizinhas da Rondônia e da Bolívia, cuja fumaça se concentra no território.

O Distrito Sanitário Especial Indígena do Alto Rio Purus desenvolve ações de atenção básica à saúde dos povos indígenas que abrangem quatro municípios no Estado do Acre (Assis Brasil, Manuel Urbano, Sena Madureira, Santa Rosa), dois no Amazonas (Boca do Acre e Pauiní) e um em Rondônia (Extrema), com as etnias: Jaminawa, Manchineri, Kulina, Kaxinawá, Kaxararí, Jamamadi e Apurinã (FUNASA, 2006b). Está entre os sete Dsei do país com maior número de notificação de casos de tuberculose, lembrando que alguns Dsei não fazem notificação nem enviam os dados para o SIASI (GARNELO et al., 2005).

O Pólo-base de Assis Brasil atende às aldeias Jaminawá e Manchineri; o Pólo-base de Boca do Acre atende à aldeias Apurinã e Jamamadi; o Pólo-base de Manoel Urbano atende às aldeias Kulina; o Pólo-base de Pauini atende às aldeias Apurinã; e Jamamadi; o Pólo-base de Santa-Rosa atende às aldeias Kaxinawá, 
Kulina, e Jaminawá; e o Pólo-base de Sena Madureira atende às aldeias Jaminawa e Kaxararí, sendo esta última a única etnia entre as citadas não encontrada no Estado do Acre.

Em termos de organização está muito mais evoluído que o Dsei do Alto Rio Juruá, apresentando indicadores de saúde melhores, maior notificação dos agravos e maior infra-estrutura de atendimento. Sua sede se localiza na cidade de Rio Branco, no edifício da Coordenadoria Regional do Acre da FUNASA. Entre os anos de 2004 a 2007 o Dsei do Alto Rio Purus elaborou relatórios anuais digitais com muitos dados demográficos e também sobre a prestação dos serviços de assistência à saúde à população sob sua responsabilidade. Apesar de estarem sujeitos a uma margem de erro, representam uma grande evolução no SIASI. Porém a partir de 2008, segundo informações colhidas com a equipe do referido Dsei, tais relatórios pararam de ser produzidos por termino de contrato do funcionário responsável pelo mesmo. O relatório de 2007 já contém muito menos informações que o anterior.

Segundo dados do relatório de 2006, neste ano específico foram registrados no Dsei do Alto Rio Purus 267 casos de malária nos pólos-base de Sena Madureira, Boca do Acre e Pauini, com incidência de 45,56 casos por 1000 habitantes, sendo maior nos indígenas da etnia Kaxararí. Foram registrados também 427 casos novos de DST, principalmente cervicites e uretrites por tricomonas, clamídia e gonococo; um caso de sífilis vertical; 39 casos novos de hepatite $\mathrm{B}$, sendo cinco deles associados a hepatite $\mathrm{D}$ com uma incidência de 5,3 
casos novos por 1000 habitantes; quatro casos de tuberculose pulmonar e um caso de tuberculose óssea.

O referido relatório também informa um aumento de 46,8\% nos nascimentos entre 2004 e 2006, tendo sido acompanhadas 339 gestantes em 2006 com cobertura de $100 \%$ no pré-natal, e realizados 546 exames de sangue nas mesmas. Foram registrados 319 nascidos vivos e realizados 134 testes do pezinho. 78\% dos partos foram realizados por parteiras indígenas, $21 \%$ nos hospitais e $1 \%$ pelas equipes multidisciplinares de saúde.

Quanto aos dados sobre mortalidade, foram registrados 50 óbitos em 2006, sendo 46\% causados por pneumonia, diarréia e/ou desidratação. Os principais problemas reportados para assistência destes pacientes são a dificuldade de acesso as aldeias, acarretando uma demora no resgate dos casos graves, e também dificuldades relacionadas a questões sócio-culturais.

As dez morbidades mais relatadas nesta população em 2006 foram, em ordem decrescente, verminoses, infecção de vias aéreas superiores, anemias, infecção de vias aéreas inferiores, dermatoses, doenças osteomusculares, doenças do aparelho digestivo e do aparelho genitourinário.

Segundo o mesmo relatório o grau de cobertura vacinal ainda é deficiente, sendo este problema causado principalmente pela dificuldade de acesso as aldeias, e também devido a características nômades de algumas etnias.

O Distrito Sanitário Especial Indígena do Alto Rio Juruá atende 10.412 indígenas de 106 aldeias, e conta com sete Pólos-base, encaminhando seus pacientes também para a CASAI de Rio Branco. Conta com infra-estrutura 
menor que a do Dsei do Alto Rio Purus, apresentando indicadores de saúde muito piores e menos informações sobre a população sob sua responsabilidade. $\mathrm{O}$ acesso à maioria das aldeias indígenas da região é muito dificultado pelas condições geográficas, só sendo possível no período do inverno Amazônico e por via fluvial.

Não foram encontrados relatórios anuais no Dsei do Alto Rio Juruá como os produzidos pelo Dsei do Alto Rio Purus. As informações sobre esta região foram conseguidas junto ao Governo do Estado do Acre, portanto referem-se aos municípios e não aos Pólos-base, não podendo ser utilizada para análise específica dos mesmos. Dessa maneira, não é possível analisar indicadores de produtividade segundo pólo-base (LOTUFO e DUARTE, 1987). De acordo com relatos dos funcionários da CASAI de Rio Branco, apesar de ter um contingente numérico maior, a quantidade de indígenas encaminhados pelos Pólos-base do Dsei de Alto Rio Juruá é menor que aqueles encaminhados pelo Dsei do Alto Rio Purus, pois muitos são atendidos nos hospitais secundários da região, localizados principalmente nos municípios de Cruzeiro do Sul e Mâncio Lima. 


\section{JUSTIFICATIVA}

Diante do exposto, o estudo sobre os agravos à saúde na população indígena infantil referenciada para a CASAI de Rio Branco se justifica por: 1) o reconhecimento da situação epidemiológica particular das populações indígenas brasileiras; 2) a participação importante da faixa etária infantil na pirâmide populacional indígena brasileira; 3) a precariedade do Sistema de Informação sobre a Assistência à Saúde Indígena (SIASI); 4) a carência de estudos epidemiológicos sobre população indígena infantil atendida nos Distritos Sanitários Indígenas do Alto Purus e do Alto Juruá. O estudo proposto nos parece, portanto, oportuno e pertinente na medida em que o resultado refletirá a demanda ao SUS gerada pelas crianças indígenas da área em questão, podendo auxiliar na estruturação dos serviços de saúde. 


\section{OBJETIVOS}

\subsection{GERAL}

Analisar o perfil de morbidade na população indígena infantil referenciada para a Casa de Saúde Indígena de Rio Branco.

\subsection{ESPECÍFICOS}

1. Descrever a população estudada mediante aspectos biológicos (sexo, idade) e sócio-culturais (aldeado ou não, etnia, Pólo-base de origem).

2. Descrever a população estudada segundo causa de internação na CASAI, morbidades encontradas e coeficiente de internação por etnia.

3. Classificar as morbidades segundo etiologia (congênita ou adquirida, trauma, infecção ou carencial), e segundo grupos de doenças, conforme Classificação Internacional de Doenças, $10^{\mathrm{a}}$ revisão (CID 10).

4. Analisar as morbidades segundo características biológicas e sócioculturais. 


\section{MATERIAIS E MÉTODOS}

\section{$5.1 \quad$ TIPO DE ESTUDO}

O trabalho é um estudo epidemiológico transversal descritivo, de base institucional, com análise de dados secundários.

\subsection{POPULAÇÃO DE ESTUDO}

A população estudada é composta por todos os indígenas menores de 10 anos, referenciados para a Casa de Saúde Indígena (CASAI) de Rio Branco para tratamento de saúde no período de janeiro de 2003 até dezembro de 2007. A idade adotada para a análise e seleção das crianças foi aquela registrada no livro de admissão na CASAI no momento da internação. Só foram incluídas no estudo as morbidades referidas até a criança completar 10 anos de idade menos um dia.

A Casa de Saúde Indígena de Rio Branco atende indígenas residentes em todo o Estado do Acre, e também em algumas aldeias dos Estados vizinhos do Amazonas e de Rondônia, assistidos pelos Distritos Sanitários Especiais Indígenas do Alto Rio Purus e do Alto Rio Juruá, conforme figura 1; e que necessitam de tratamento de saúde de média e alta complexidade. 


\subsection{COLETA DOS DADOS}

Analisamos os dados obtidos a partir dos livros de admissão e dos prontuários das crianças menores de 10 anos admitidas na Casa de Saúde Indígena de Rio Branco desde janeiro de 2003 até o final de 2007. Foram identificadas todas as crianças que foram internadas para tratamento de saúde.

Fez parte dos procedimentos de definição da base de coleta dos dados, a análise dos registros da CASAI e também dos registros dos hospitais onde estas crianças foram atendidas, sendo que a idéia inicial era analisar também os prontuários hospitalares em busca de informações mais detalhadas sobre as morbidades e as internações hospitalares. Porém foram localizados menos que 5\% dos prontuários hospitalares destas crianças, optando-se então pela utilização dos prontuários da CASAI (Anexo 1) apenas. Apesar de se ter uma perda no detalhamento das informações conseguiu-se os dados demográficos, e também aqueles referentes à causa da internação na CASAI, da quase totalidade das crianças, sendo estes suficientes para traçar o perfil de morbidade, objetivo principal do estudo.

Os dados foram coletados por meio de instrumento próprio (Anexo 2), sendo possível identificar as seguintes variáveis a partir dos prontuários. Variáveis demográficas: sexo, etnia, data de nascimento, se é morador de aldeia ou da cidade, de qual aldeia, qual Pólo-base de origem e Estado de moradia. Dados sobre as internações na Casa de Saúde Indígena: data e idade de admissão, causa da internação, morbidades associadas, etiologia (a saber: 
congênitas ou adquiridas, se são por trauma, infecção/inflamação ou carenciais), se foi realizada alguma cirurgia e qual o tipo (especialidade).

Foram verificados também dados gerais sobre a população indígena atendida pelos Dsei do Alto Rio Purus e do Alto Rio Juruá tanto na FUNASA como no Governo do Acre. Na FUNASA estes dados estão disponíveis na forma de relatórios anuais apenas para o Dsei do Alto Rio Purus, sendo que estes relatórios incluem dados sobre o contingente populacional de cada aldeia e região, número de nascidos vivos, causa de mortalidade, grau de cobertura vacinal, ocorrência das principais morbidades nas aldeias, número de internações hospitalares na população atendida, dentre outros. Não foram encontrados relatórios do Dsei do Alto Rio Juruá. No governo do Acre foram localizados dados sobre contingente populacional de cada aldeia e Terra Indígena, sem caracterização por faixa etária. Os dados sobre a população nacional foram verificados no banco de dados DATASUS.

\section{$5.4 \quad$ FASES DO ESTUDO}

O estudo foi dividido em quatro fases. A primeira consistiu na coleta dos dados da FUNASA e do Governo do Acre sobre as populações indígenas, e as características dos Dsei do Alto Rio Purus e do Alto Rio Juruá. A segunda fase foi caracterizada pela análise dos livros de entrada da CASAI para seleção de todas as crianças menores de 10 anos de idade na data da admissão, recebidas para tratamento de saúde entre janeiro de 2003 e dezembro de 2007. Foram 
identificados dados como nome, etnia, idade e data de admissão para preenchimento da primeira parte das fichas.

A terceira fase do estudo consistiu na localização e análise dos prontuários destas crianças na CASAI, sendo colhidos dados demográficos, dados sobre as morbidades apresentadas e o tratamento instituído. As morbidades principais, consideradas como sendo a causa de internação na CASAI, foram consensuadas em discussão de equipe caso a caso. Optou-se por aproveitar todo o registro que pudesse trazer informação diagnóstica sobre a causa da internação, mesmo que este não estivesse escrito explicitamente, resgatando-se a informação contida em registros de sinais, sintomas e/ou conduta quando estes deixavam evidente um diagnóstico implícito. Uma vez definida a morbidade principal, a mesma foi classificada de acordo com a Classificação Internacional de Doenças $10^{\mathrm{a}}$ revisão (CID 10), e também por etiologia, a saber, congênitas ou adquiridas, e dentre essas últimas, entre carenciais, traumáticas ou inflamatórias/infecciosas.

Foram considerados sinais e sintomas mal definidos: cefaléia, dor abdominal e febre de origem indeterminada. Dentre os casos classificados como "sem informação" considerou-se aqueles sem prontuário ou sem qualquer tipo de registro no mesmo, e também aqueles em cujo prontuário havia anotações como consulta médica, retorno, tomografia ou outros exames laboratoriais, sem especificações sobre a patologia de base.

Como quase não foram reportadas informações sobre as cirurgias realizadas nos indígenas, mesmo naqueles sabidamente operados, optou-se por não 
trabalhar com estas informações. Também não foram encontradas informações sobre óbito nos prontuários.

Cada ficha correspondeu a uma única internação na CASAI de uma criança específica. $\mathrm{Na}$ análise dos dados coletados é que foram identificadas as reinternações por meio dos nomes das crianças, nome dos pais, e datas de nascimento quando disponíveis.

A quarta fase do trabalho correspondeu à tabulação e análise dos dados obtidos, com elaboração de apreciações sobre os resultados encontrados. A análise foi centrada, principalmente, na internação; buscou-se correlacionar a ocorrências das morbidades com dados demográficos e sócio-culturais, identificando-se possíveis associações entre as variáveis de interesse, conforme especificado abaixo. Após essa etapa, foi realizada a redação final da dissertação.

\subsection{ANÁLISE DOS DADOS}

Foi construído como referência um banco de dados no programa Windows Office Excel, e utilizado o aplicativo específico SPSS versão 13.0 para análise dos mesmos. As variáveis quantitativas foram descritas em termos de média, e as qualitativas, nominais e ordinais, através de proporções. A análise foi centrada principalmente na internação, sendo utilizada a distribuição proporcional por variável. 
Foi buscado diferenciar as morbidades, identificando a magnitude de sua ocorrência na população. Foi buscado descrever a ocorrência desses diferentes aspectos das morbidades identificadas de acordo com idade, etnia, e Pólo-base responsável; identificando seu padrão de ocorrência e eventuais diferenças significativas nessa ocorrência ou associações entre variáveis. As morbidades reportadas foram agrupadas e analisadas conforme capítulo da Classificação Internacional de Doenças $10^{\mathrm{a}}$ revisão (CID 10), para avaliação de sua distribuição proporcional.

Foi determinado o coeficiente de internação por 1.000 crianças segundo etnia, utilizando-se para o cálculo, no denominador, a proporção da pirâmide populacional indígena produzida pela FUNASA em 2002 e divulgada pela Organização Pan-Americana de Saúde (GARNELO et al., 2003), onde 30\% da população indígena têm menos que 10 anos de idade. Não pôde ser utilizada a distribuição real por faixa etária de cada etnia, pois não foi encontrada esta informação nos registros da FUNASA nem da FUNAI, mas apenas o número absoluto de indígenas por etnia, sendo então consideradas como menores que 10 anos de idade $30 \%$ destas pessoas. Essa proporção foi corroborada pelo estudo de Rios e colaboradores, de 2007, com achado de 34,68\% dos indígenas menores de 10 anos entre aqueles residentes no Distrito de Iauaretê, no Município de São Gabriel da Cachoeira, no Amazonas (RIOS et al., 2007).

Como para o Dsei do Alto Rio Juruá não foram localizadas informações sobre o contingente populacional sob responsabilidade de cada Pólo-base, não pode ser realizado o cálculo de coeficiente de internação por 1.000 crianças 
relativo a cada Pólo-base. Nesse caso trabalhou-se apenas com a proporção de freqüências para a análise comparativa dos mesmos.

Foi realizada também análise dos resultados com base anual, com a construção de uma série histórica englobando os cinco anos analisados no estudo, buscando identificar tendências e alterações no padrão de ocorrências das morbidades.

As fichas foram aplicadas por internação na CASAI, e depois foi realizada a análise da magnitude da ocorrência das re-internações nas crianças.

\subsection{CONSIDERAÇÕES ÉTICAS}

O estudo obedeceu aos princípios éticos contidos nas diretrizes das resoluções 196/96 e 304/00 do Conselho Nacional de Saúde sobre pesquisa envolvendo seres humanos. Por consistir basicamente no levantamento de informações secundárias, a partir de revisão de prontuários, foi considerado de risco mínimo, sendo identificado como potencialmente importante aquele relacionado com sigilo e confidencialidade das informações coletadas. O projeto foi submetido e aprovado pelo Comitê de Ética em Pesquisa da instituição responsável pela condução da pesquisa (COEP/USP), e por se tratar de um estudo sobre a população indígena, também pelo Conselho Nacional de Ética em Pesquisa (CONEP), anexo 3. Foi tomada autorização das lideranças indígenas através do Termo de Consentimento Livre e Esclarecido, anexo 4, e também do Coordenador Regional da FUNASA para acesso aos dados da CASAI. 
Os resultados encontrados serão colocados à disposição da FUNASA, buscando contribuir com a atenção à saúde dos povos indígenas; e diretamente para os indígenas com divulgação dos resultados para as lideranças. Os resultados serão disponibilizados também para a para a Assessoria Especial dos Povos Indígenas do Acre, para a Secretaria de Estado de Saúde do Acre, e para as secretarias municipais de saúde, visando auxiliar no planejamento da assistência à saúde, já que os dados refletem a demanda gerada ao SUS por esta população específica. 


\section{RESULTADOS}

Foram identificadas no livro de admissão 695 internações de crianças indígenas menores que 10 anos na Casa de Saúde Indígena - CASAI de Rio Branco no período entre 01 de janeiro de 2003 e 31 de dezembro de 2007. Estas internações corresponderam a 507 crianças, com número variado de re-internações.

Das 507 crianças estudadas, $231(45,6 \%)$ eram do sexo feminino e 274 (54\%) do sexo masculino, sendo que em duas crianças $(0,4 \%)$ não se obteve informação do sexo, observando-se leve predomínio do sexo masculino. Quanto à situação de moradia 484 crianças $(95,5 \%)$ residiam em aldeias e 22 crianças $(4,3 \%)$ residiam nas cidades, e em uma criança $(0,2 \%)$ não se obteve esta informação, como se percebe ao analisar o gráfico 1 . 
Gráfico 1 - Distribuição percentual das crianças indígenas menores que 10 anos de idade encaminhadas para CASAI para tratamento de saúde, segundo local de moradia - Rio Branco - AC, 2003 - 2007.

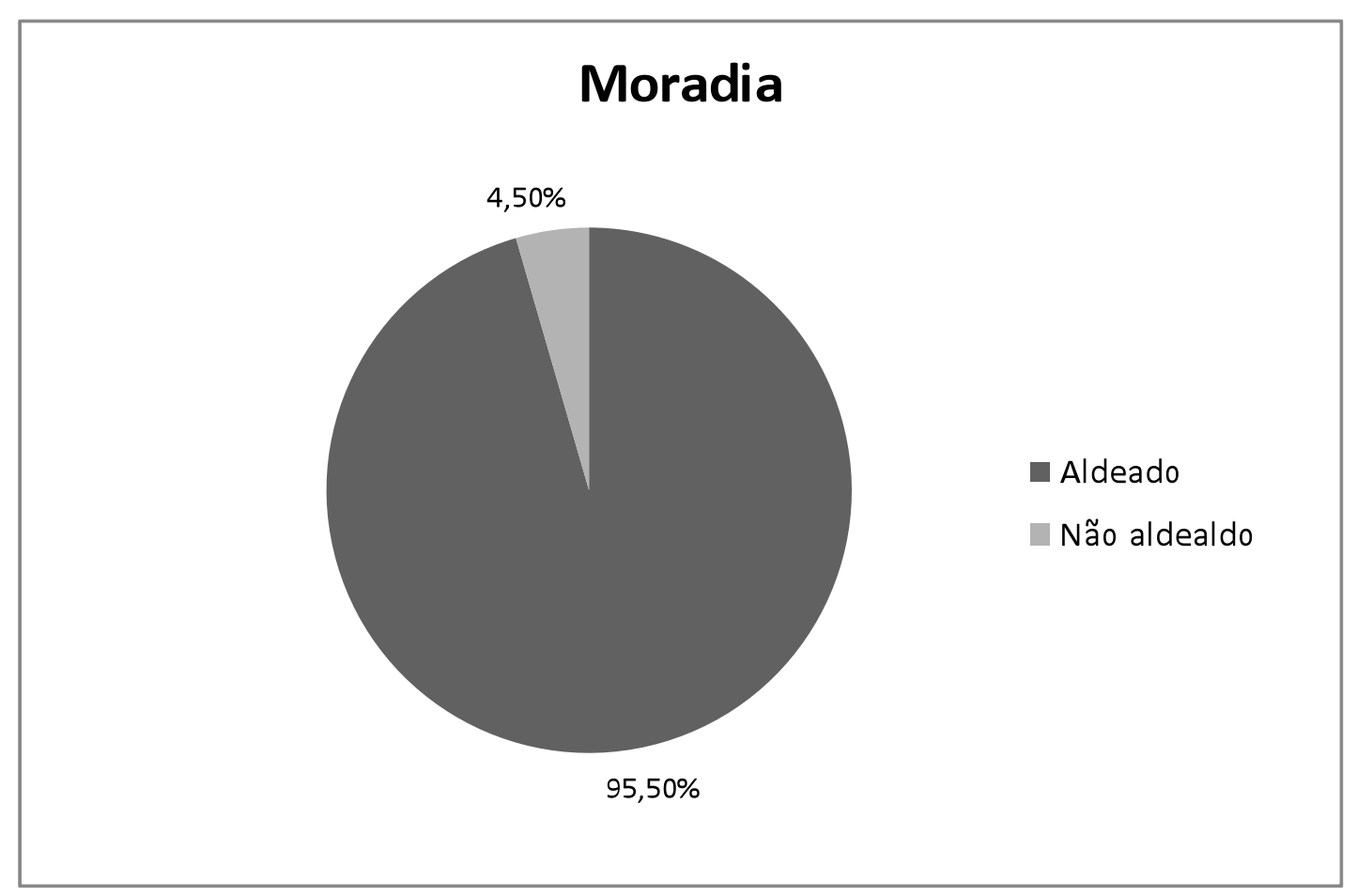

Como se pode observar no gráfico 2 , apenas $54,6 \%$ das crianças atendidas na CASAI possuíam prontuário na instituição, e mesmo dentre aquelas com prontuário, o mesmo não se encontrava completo, com todas as informações sobre as morbidades e as internações. 
Gráfico 2 - Distribuição percentual das crianças indígenas menores que 10 anos de idade encaminhadas para CASAI para tratamento de saúde, segundo presença de prontuário na instituição - Rio Branco - AC, 2003 - 2007.

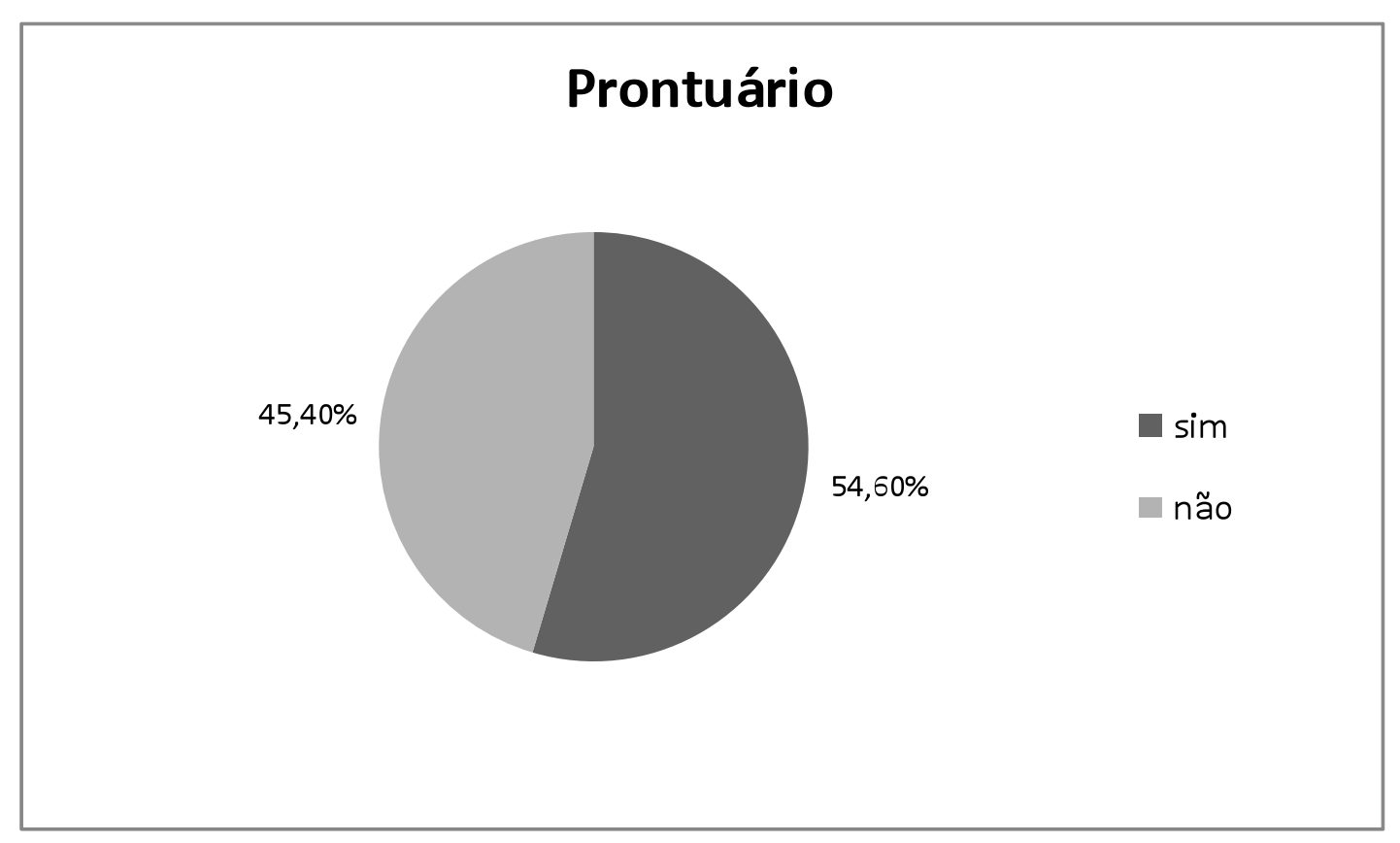

Quanto às internações, unidade básica de análise eleita na presente dissertação, percebe-se que das 695 identificadas, $336(48,3 \%)$ correspondiam a crianças do sexo feminino, e $357(51,4 \%)$ a crianças do sexo masculino, sendo duas internações $(0,3 \%)$ sem esta informação. Com relação à faixa etária, 184 (26,5\%) eram menores que 1 ano, 318 (45,8\%) entre 1 e 5 anos, e 193 (27,8\%) entre 5 e 10 anos. O gráfico 3 mostra a proporcionalidade das faixas etárias entre os sexos, observando-se que o sexo masculino é predominante nas internações em menores de um ano e maiores que cinco anos, sendo a diferença mais importante no primeiro extrato. 
Gráfico 3 - Distribuição percentual das internações em crianças indígenas menores que 10 anos de idade encaminhadas para a CASAI para tratamento de saúde, segundo sexo e faixa etária - Rio Branco - AC, 2003 - 2007.

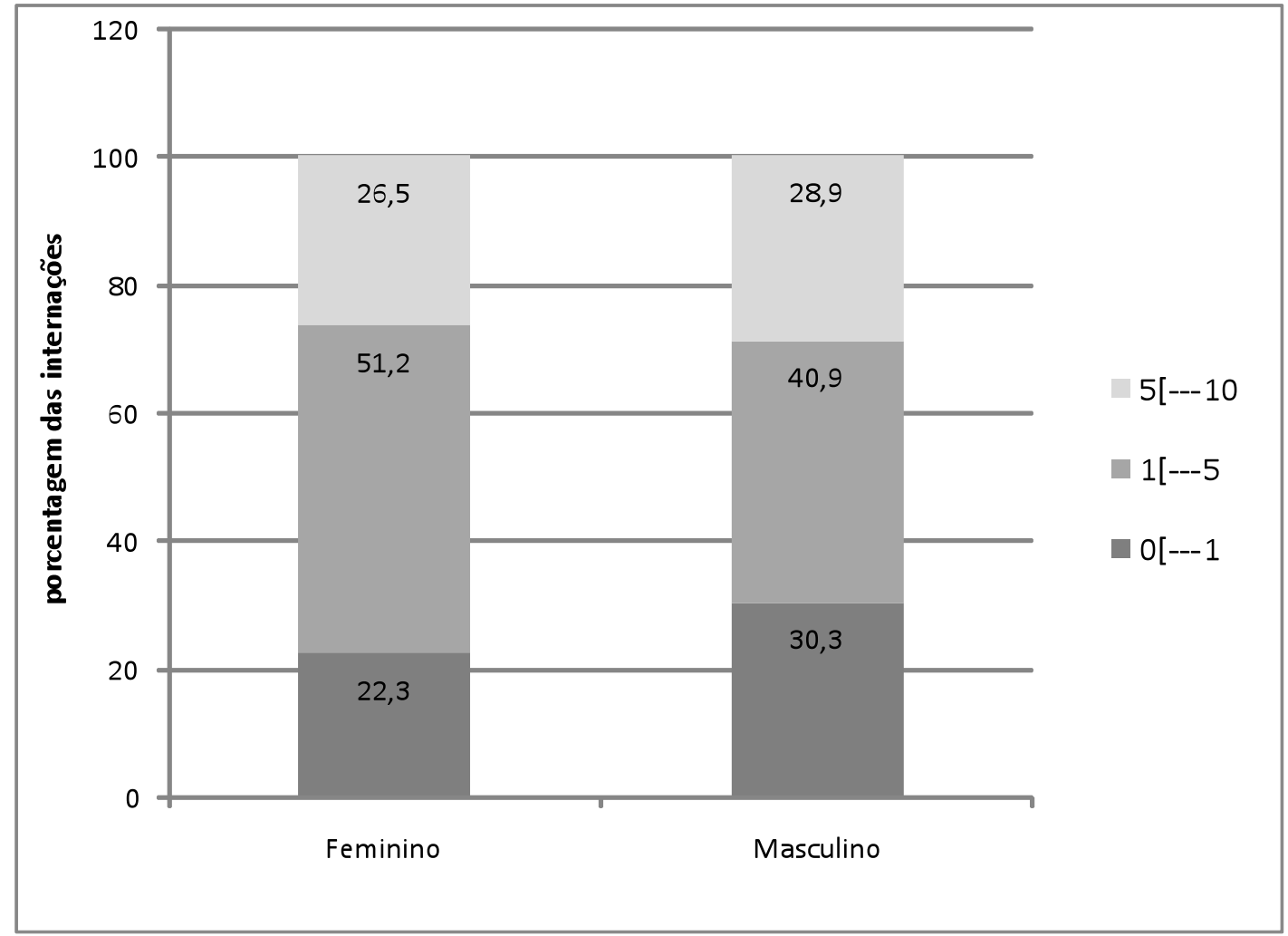

Subdividindo-se em mais categorias a variável faixa etária, para permitir análise mais específica, observa-se no gráfico 4 que 306 (44\%) internações correspondem a crianças menores que dois anos de idade, enquanto 389 (66\%) são de crianças entre dois e 10 anos de idade. 
Gráfico 4 - Distribuição percentual das internações em crianças indígenas menores que 10 anos de idade encaminhadas para CASAI para tratamento de saúde, segundo faixa etária - Rio Branco - AC, 2003 - 2007.

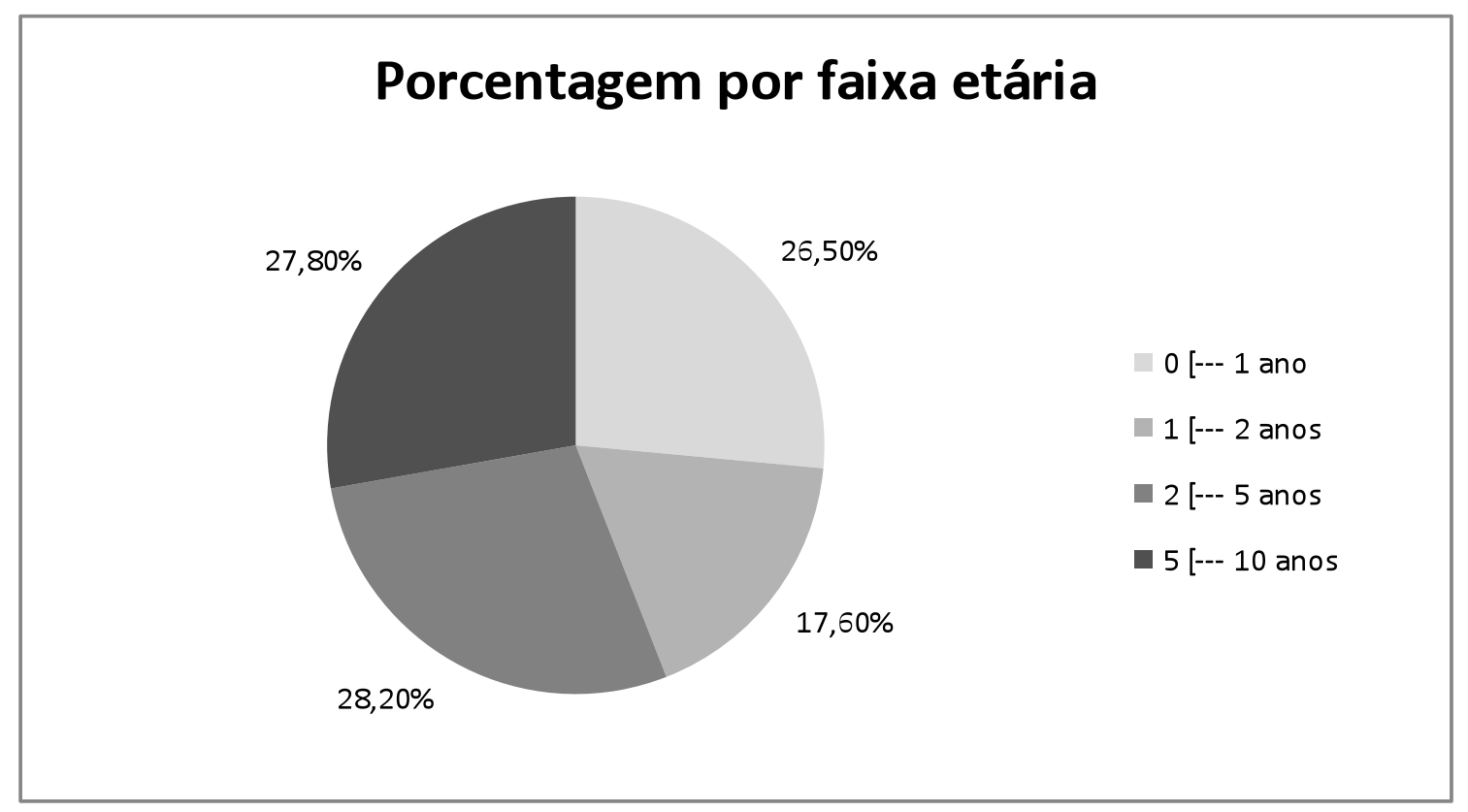

O gráfico 5 especifica a idade da criança em anos completos de vida na época da internação. Nota-se uma tendência decrescente da proporção das internações com o aumento da faixa etária, com uma leve oscilação no quinto ano de vida, fazendo com que o menor percentual de internação $(3,6 \%)$ seja em crianças de nove anos de idade. 
Gráfico 5 - Distribuição percentual das internações em crianças indígenas menores que 10 anos de idade encaminhadas para CASAI para tratamento de saúde, segundo anos completos de vida - Rio Branco - AC, 2003 - 2007.

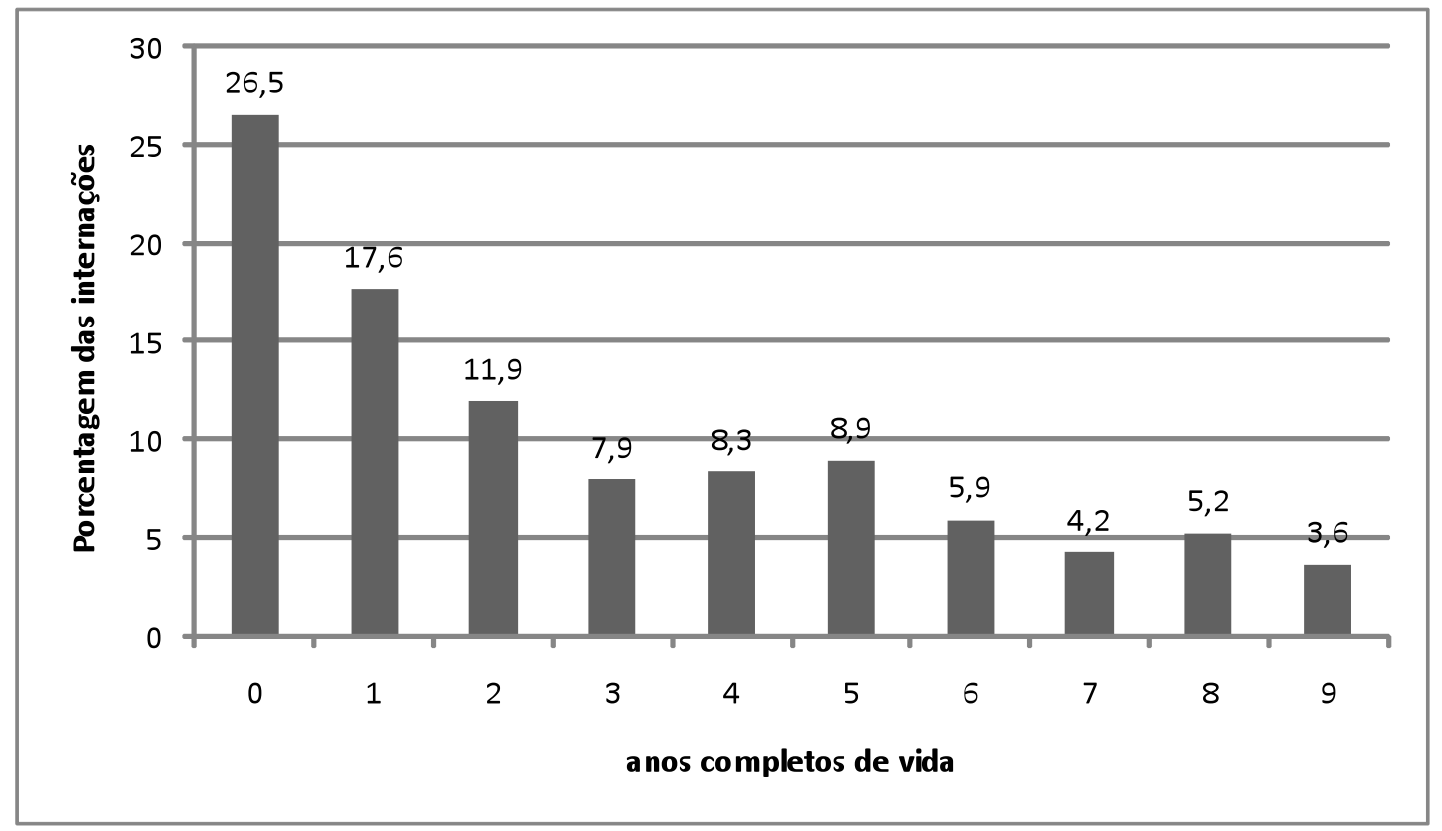

Quanto à análise das internações em crianças recém-nascidas, nota-se que apenas $27(3,9 \%)$ internações representaram essa categoria, com consequente 668 $(96,1 \%)$ internações se dando em crianças das demais faixas etárias. Dentre as 27 internações em recém-nascidos o percentual maior foi em crianças na primeira semana de vida (período neonatal precoce), com 10 (37\%) internações; também se observou a mesma tendência decrescente conforme vai aumentando a idade das crianças, como mostrado na tabela 1. 
Tabela 1 - Distribuição percentual das internações em crianças indígenas recém nascidas encaminhadas para CASAI para tratamento de saúde, segundo dias de vida Rio Branco - AC, 2003 - 2007.

\begin{tabular}{lcc}
\hline Idade em dias & $\mathbf{N}^{\mathbf{0}}$ episódios de internação & $\mathbf{\%}$ \\
\hline 0 [---] 7 & 10 & $37,0 \%$ \\
$8[---] 14$ & 6 & $22,2 \%$ \\
$15[---] 21$ & 6 & $22,2 \%$ \\
$22[---] 28$ & 5 & $18,5 \%$ \\
\hline Total & 27 & $100,0 \%$ \\
\hline
\end{tabular}

A análise da média de internações por criança por ano mostra uma diferença muito pequena entre os anos de início e do final do estudo, oscilando entre 1,4 e 1,5 internações por criança por ano em 2003 e 2007 respectivamente.

Como se pode observar no gráfico 6 , a maioria $(72,9 \%)$ das internações na CASAI correspondeu a primeira internação. Cento e oitenta e oito $(27,1 \%)$ foram reinternações, e destas o percentual maior, 94 (13,5\%), foi segunda internação. Relativamente poucas internações, 94 (13,5\%), corresponderam à terceira ou mais internação. 
Gráfico 6 - Distribuição percentual das internações em crianças indígenas menores de 10 anos de idade encaminhadas para CASAI para tratamento de saúde, segundo ordem de internações - Rio Branco - AC, 2003 - 2007.

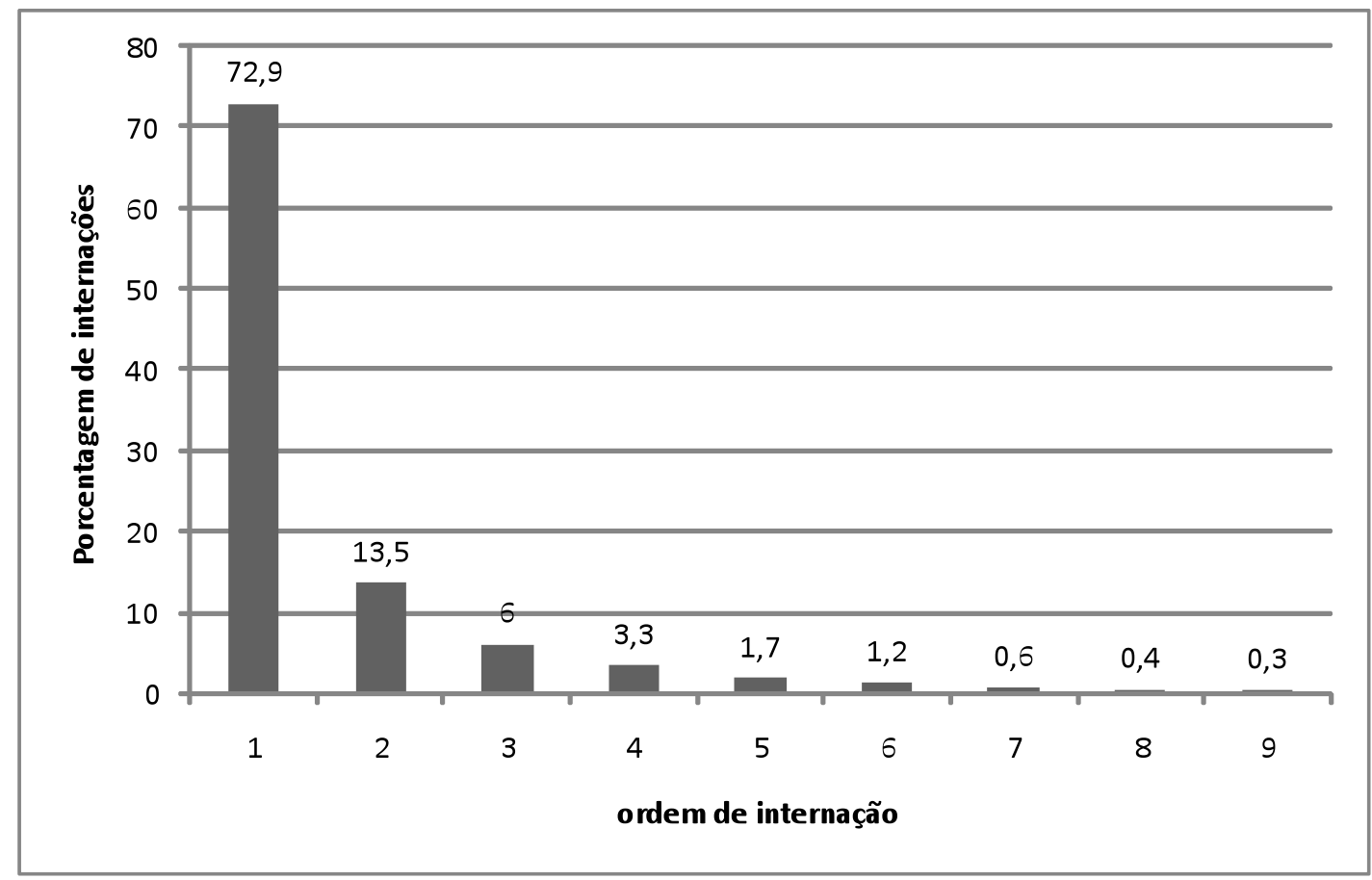

Das 17 etnias existentes no território dos dois Dsei estudados, foram verificadas internações de crianças pertencentes a 14 delas. Não foi identificada nenhuma criança das etnias Nawa, Jaminawa-arara e Apolina-arara. A etnia mais freqüente na CASAI foi a dos indígenas Kaxinawá (25,2\%), que também corresponde à etnia mais freqüente no Estado do Acre (41\%). O gráfico 7 mostra a distribuição percentual das etnias entre as internações na CASAI. 
Gráfico 7 - Distribuição percentual das internações em crianças indígenas menores que 10 anos de idade encaminhadas para tratamento de saúde na CASAI, segundo etnia - Rio Branco - AC, 2003 - 2007.

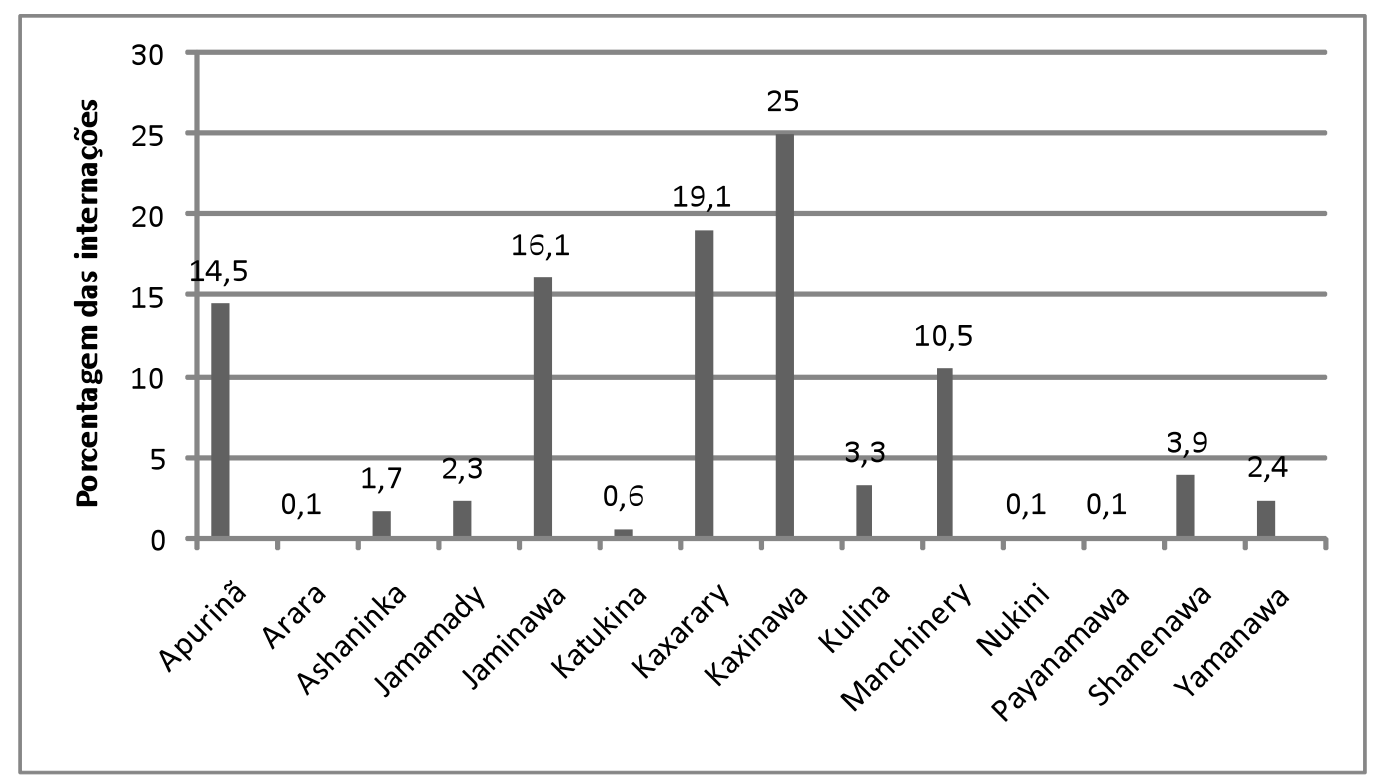

Um dado que chama atenção ao se analisar o gráfico 7 é o valor apresentado pelos indígenas da etnia Kaxararí, residentes no Estado de Rondônia e atendidos no Pólo-base de Sena Madureira, no Dsei do Alto Rio Purus. Apesar de numericamente poucos, com população total de 334 indígenas, apresentaram 88 crianças internadas e contribuíram com 133 internações, o que corresponde a 19,1\% das internações. É importante destacar que a etnia Kaxararí possuía, na ocasião do estudo, aproximadamente 100 crianças menores de 10 anos em sua população. Isso implica que quase a totalidade das crianças desta etnia foi atendida com algum tipo de morbidade na CASAI. O coeficiente de internação na CASAI por 1000 crianças, explicitado no gráfico 8 , mostra a grande disparidade desta etnia com relação às outras. 
Gráfico 8 - Coeficiente de internação na CASAI por 1.000 crianças, em crianças indígenas menores que 10 anos de idade encaminhadas para CASAI para tratamento de saúde, segundo etnia - Rio Branco - AC, 2003 - 2007.

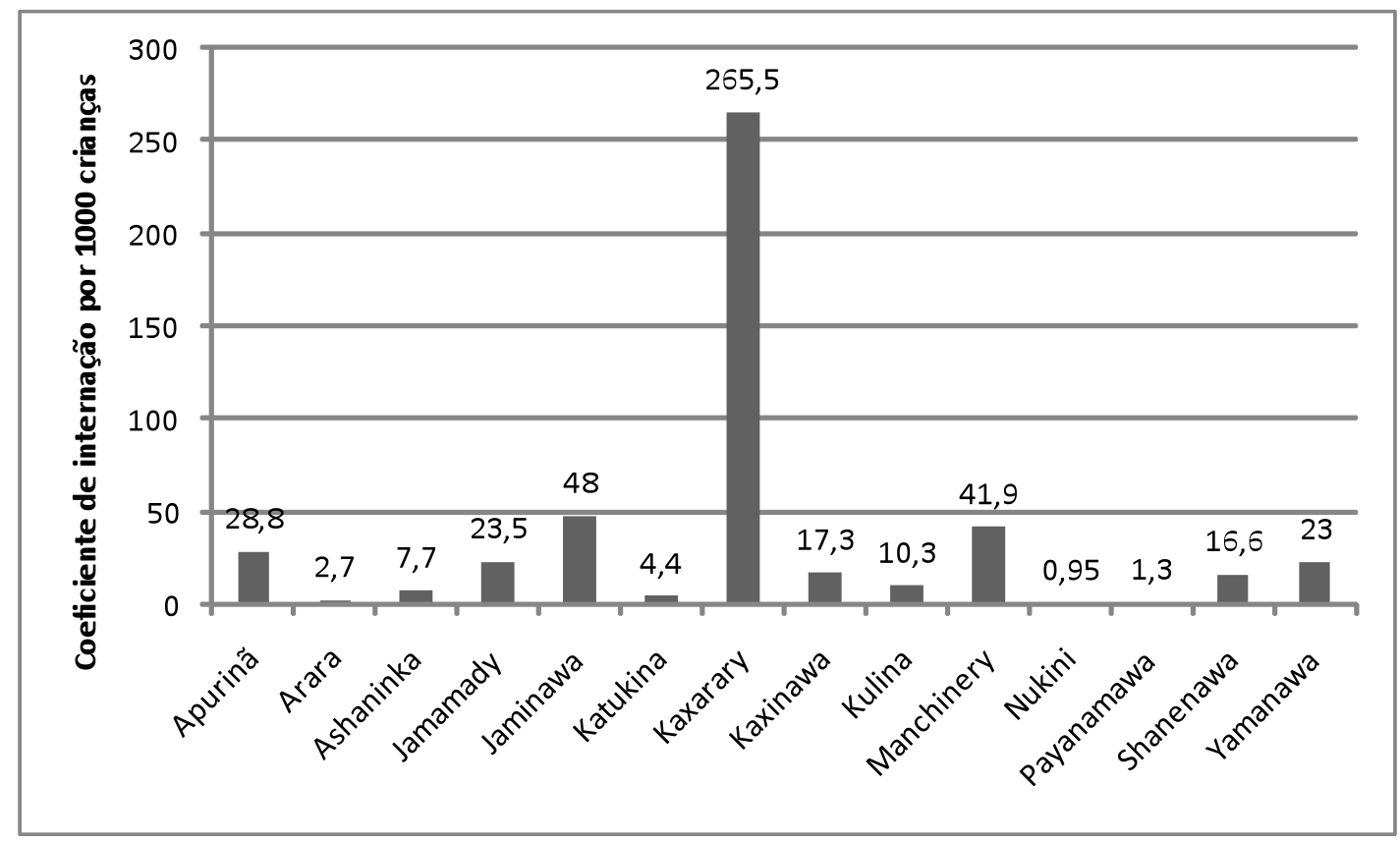

O gráfico 9 mostra a distribuição percentual das internações conforme o Pólobase que encaminhou a criança para a CASAI. Chama atenção a porcentagem elevada de crianças encaminhadas pelo Pólo-base de Sena Madureira; 189 (27,2\%) internações são oriundas deste Pólo-base, que atende os indígenas da etnia Kaxararí além de possuir o acesso mais fácil a Rio Branco por estrada de boas condições. Com exceção de Santa Rosa, os outros quatro Pólos-base mais freqüentes (Sena Madureira, Assis Brasil e Boca do Acre) tem acesso direto por carro à CASAI.

Não foi possível o cálculo do coeficiente de internação por Pólo-base devido à ausência de dados do contingente populacional específico de cada um, realizando-se o indicador apenas para os dois Dseis estudados. O Dsei do Alto Rio Purus 
apresentou 58 internações por 1000 crianças e o Dsei do Alto Rio Juruá 7,7 internações por 1000 crianças.

Gráfico 9 - Distribuição percentual das internações em crianças indígenas menores que 10 anos de idade encaminhadas para CASAI para tratamento de saúde, segundo Pólo-base de origem - Rio Branco - AC, 2003 - 2007.

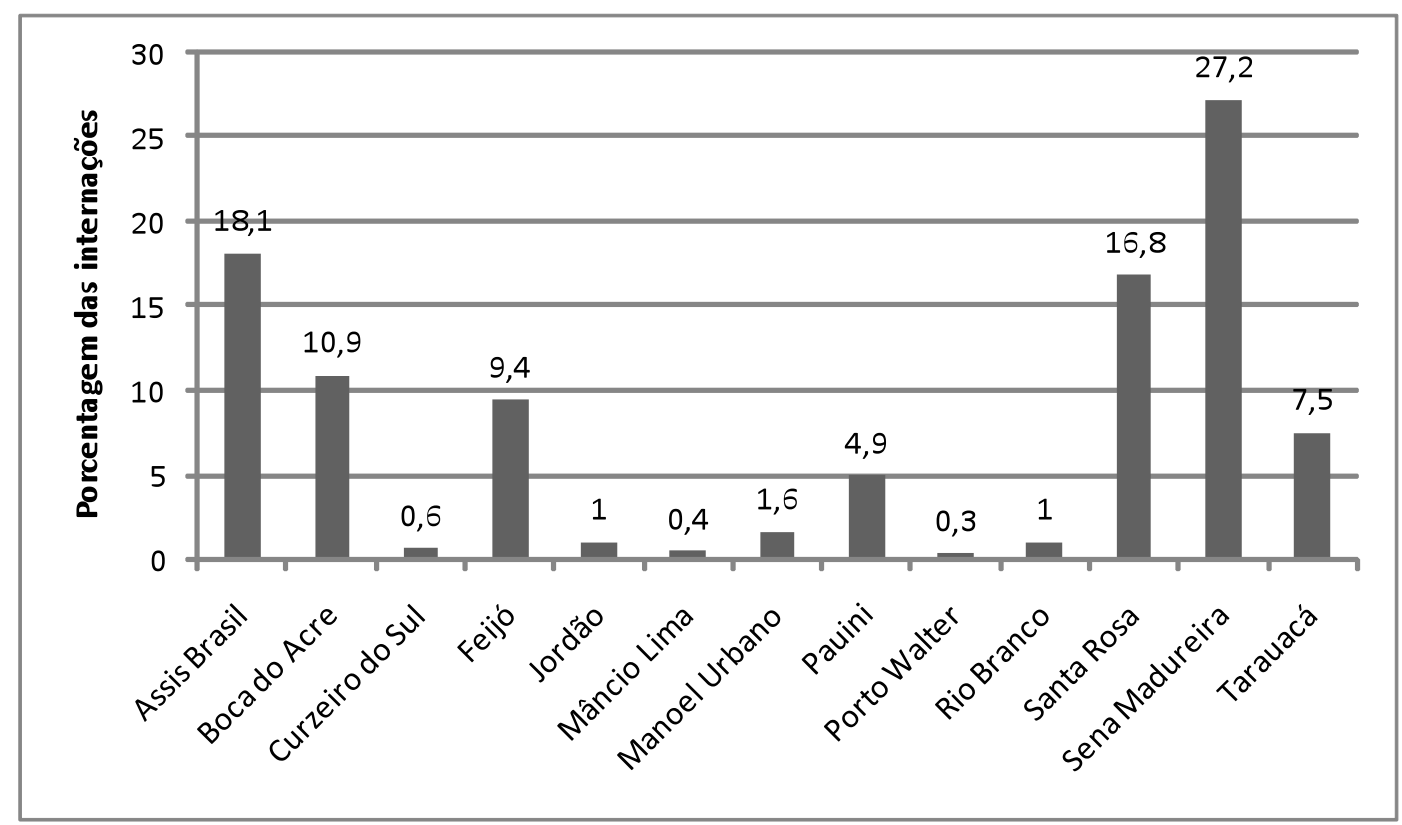

Quando se observa o gráfico 10, que distribui proporcionalmente as internações conforme o mês do ano, nota-se leve preponderância de internações nos meses de setembro, outubro e novembro, final do período de seca, época que tradicionalmente ocorrem as queimadas na região. Já nos meses de dezembro, janeiro, fevereiro e março, auge do período de chuvas, observam-se menos internações na CASAI entre os indígenas até 10 anos de idade. 
Gráfico 10 - Distribuição percentual das internações em crianças indígenas menores de 10 anos de idade encaminhadas para CASAI para tratamento de saúde, segundo mês de internação - Rio Branco - AC, 2003 - 2007.

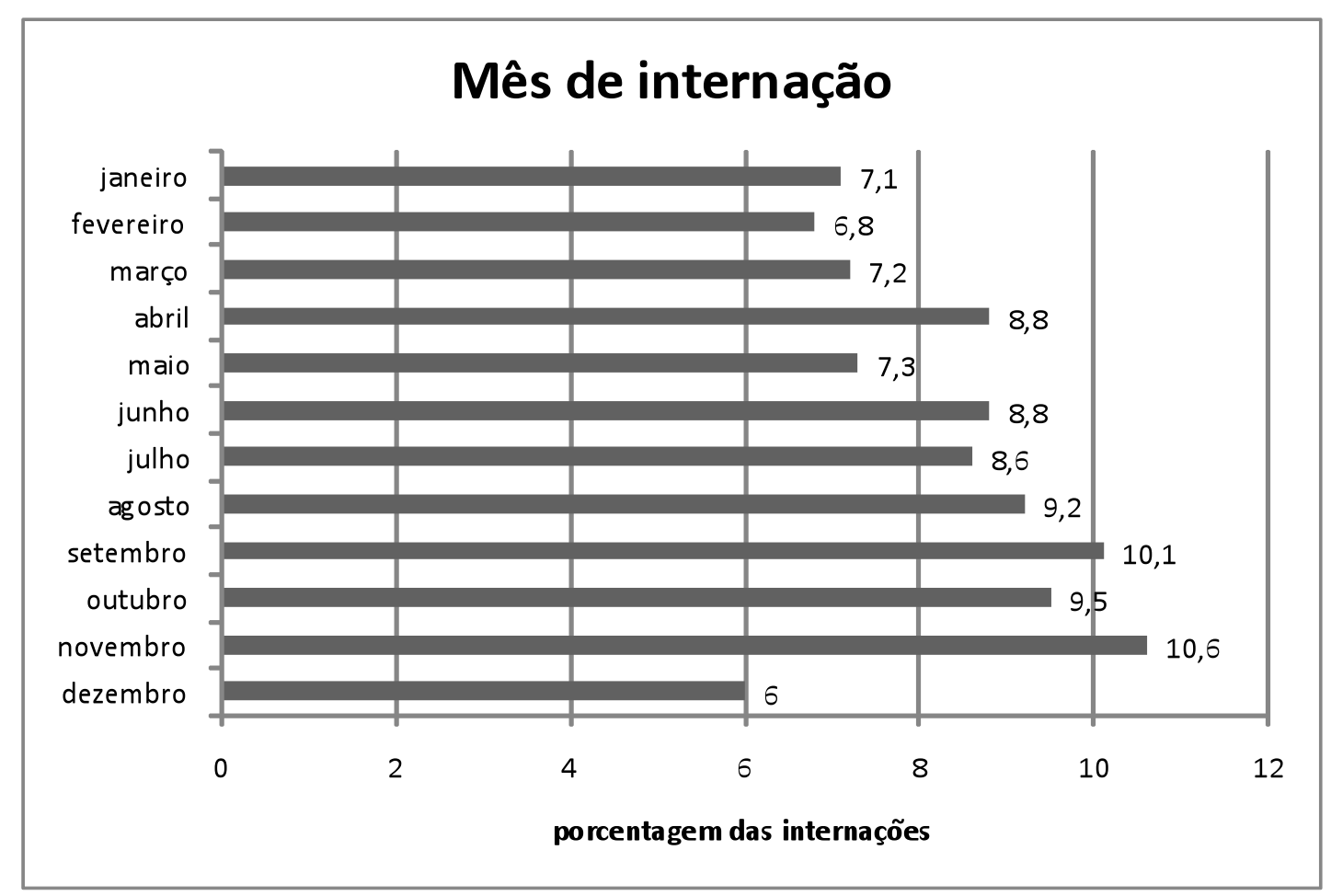

No período das chuvas, entre novembro e abril, observou-se um total de 323 (46,5\%) internações. Já no período da seca, entre os meses de maio e outubro, observou-se $372(53,5 \%)$ internações.

No gráfico 11 observa-se, como causa de internação na CASAI, uma predominância das doenças infecciosas e parasitárias, cap. I, com 132 (19\%) internações, seguida por doenças do aparelho respiratório, cap. X, com 115 (16,5\%) internações. É importante ressaltar também a proporção de internações sem informação sobre a morbidade, $161(23,2 \%)$, o que pode ser relacionado à grande proporção de crianças sem prontuário na CASAI. Depois se destacam as 
malformações congênitas, cap. XVII, com 61 (8,8\%), e as causas externas, cap. IX, com $36(5,2 \%)$ internações. Em terceiro plano chamam atenção as doenças do sangue, cap. III, e as doenças do sistema nervoso, cap. VI, com $26(3,7 \%)$ internações cada uma, as doenças da pele, cap.XII, com $25(3,6 \%)$ e as doenças endócrinas, nutricionais e metabólicas, cap. IV, com 24 (3,5\%) internações.

Gráfico 11 - Distribuição percentual das internações em crianças indígenas menores de 10 anos de idade encaminhadas para CASAI para tratamento de saúde, segundo causa de internação, utilizando a Classificação Internacional de Doenças, $10^{\mathrm{a}}$ revisão (CID 10) - Rio Branco - AC, 2003 - 2007.

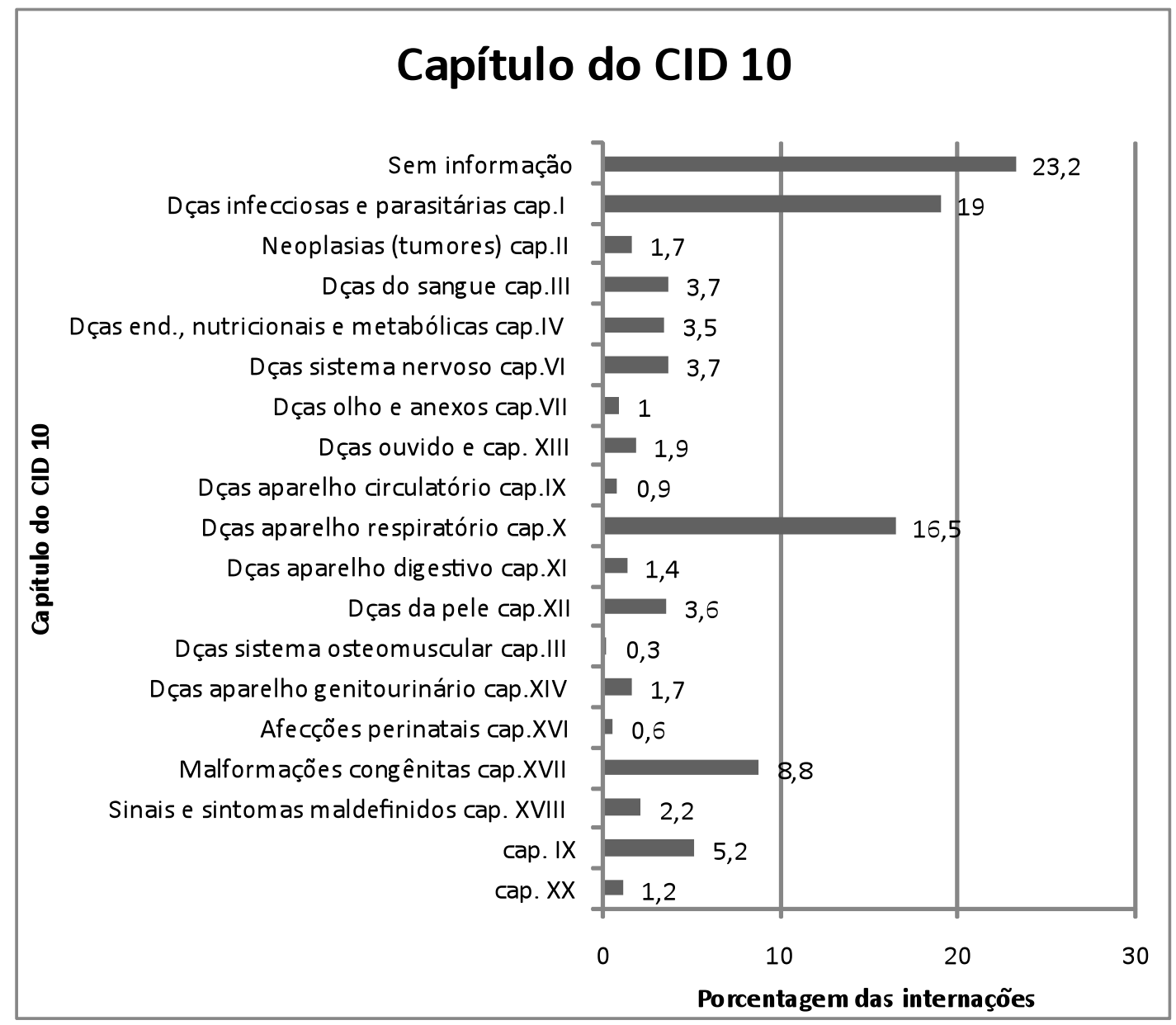


Quando se agrupam as morbidades em grupos de causas afins para uma análise mais detalhada, como exposto na tabela 2 , nota-se um predomínio das infecções respiratórias com $110(15,8 \%)$ internações, seguido de malformações congênitas com $61(8,8 \%)$ e diarréia com $53(7,6 \%)$. Chama ainda atenção o trauma com 33 (4,7\%), malária com 29 (4,2\%) e anemia com 21 (3\%) internações. Também foi muito frequente a proporção de internações sem causa conhecida, correspondendo a $161(23,2 \%)$ internações.

Das 695 internações se obteve informação sobre morbidade principal em 534 (76,8\%). Deste total de 534 causas conhecidas, $473(88,6 \%)$ podem ser classificadas conforme as causas descritas abaixo, sendo as restantes $61(11,4 \%)$ morbidades que só apareceram uma única vez como causa de internação, e podem ser encontradas descritas conforme o código do CID10 no anexo 5 . 
Tabela 2 - Distribuição proporcional das causas de internação em crianças indígenas menores que 10 anos de idade encaminhadas para CASAI para tratamento de saúde, segundo grupo de doenças afins - Rio Branco - AC, 2003 - 2007.

\begin{tabular}{lcc}
\hline Grupo de doenças afins & \multicolumn{2}{c}{ Frequência } \\
\cline { 2 - 3 } & Número internações & Percentual \\
\hline Infecção respiratória & 110 & $15,8 \%$ \\
Malformação congênita & 61 & $8,8 \%$ \\
Diarréia & 53 & $7,6 \%$ \\
Trauma & 33 & $4,7 \%$ \\
Malária & 29 & $4,2 \%$ \\
Anemia & 21 & $3,0 \%$ \\
Desnutrição & 17 & $2,4 \%$ \\
Parasitose & 15 & $2,2 \%$ \\
Sinais e sintomas gerais & 15 & $2,2 \%$ \\
Otite & 13 & $1,9 \%$ \\
Paralisia cerebral & 13 & $1,9 \%$ \\
Lesão infecciosa de pele & 12 & $1,7 \%$ \\
Pênfigo & 12 & $1,7 \%$ \\
Papiloma vírus humano (HPV) & 10 & $1,4 \%$ \\
Epilepsia & 10 & $1,4 \%$ \\
Neoplasia & 10 & $1,4 \%$ \\
Hepatite viral & 8 & $1,2 \%$ \\
Infecção trato urinário & 6 & $0,9 \%$ \\
Conjuntivite & 5 & $0,7 \%$ \\
Tuberculose & 5 & $0,7 \%$ \\
Hérnias da parede abdominal & 4 & $0,6 \%$ \\
Lesão por arma branca & 3 & $0,4 \%$ \\
Lesão por arma de fogo & 695 & $0,4 \%$ \\
Queimadura & 3 & $0,4 \%$ \\
Acidente ofídico & 3 & $0,3 \%$ \\
Outros & $23,2 \%$ \\
Sem informação & $3 \% 0 \%$ \\
\hline Total & $3 \%$ \\
\hline & 31 & \\
\hline
\end{tabular}

A tabela 3 mostra a distribuição percentual da morbidade principal, segundo capítulo do CID 10, fazendo-se uma série histórica dos cinco anos analisados no estudo. Observa-se, durante todo o período, uma freqüência baixa das doenças do sistema osteomuscular, cap.XIII, com apenas dois casos no ano de 2005; das doenças 
originadas no período neonatal, cap.XVI, com quatro casos distribuídos nos anos de 2004, 2006 e 2007; das doenças do aparelho circulatório, cap.IX, com seis casos distribuídos em 2004, 2005 e 2007; e das neoplasias, com três casos em 2004, sete casos em 2005 e dois casos em 2007. Entre os capítulos mais freqüentes, chama atenção a participação das doenças infecciosas e parasitárias, cap.I, como causa de internação em 2003, com 29,9\% das internações, sendo 2,4 vezes maior que a encontrada em 2007, quando contribuiu com apenas 12,5\% das internações. Pode-se notar uma tendência decrescente de sua importância no período analisado. Outro dado que chama atenção é a participação crescente das malformações congênitas, cap.XVII, como causa de internação, que parte de $3 \%$ no ano de 2003 para $12,5 \%$ no ano de 2007 apresentando um aumento de 4,2 vezes. Nota-se também uma tendência crescente na participação das doenças endócrinas, metabólicas e nutricionais cap.IV, com 1,2\% das internações em 2003 e 6,5\% em 2007.

Quanto às internações sem informação, podemos observar uma contribuição expressiva em todos os anos do estudo, variando de um sexto a um terço das internações. A freqüência mais elevada foi observada no último ano estudado, 2007, quando não se obteve causa de internação em quase $30 \%$ das internações, contrastando com o ano de 2004 onde apenas 15\% das internações não possuíam registro da informação. 
Tabela 3 - Série histórica da distribuição percentual das causas de internação em crianças indígenas menores que 10 anos de idade encaminhadas para CASAI para tratamento de saúde, segundo grupo de doenças da Classificação Internacional de Doenças $10^{\mathrm{a}}$ revisão (CID 10), por ano - Rio Branco - AC, 2003 - 2007.

\begin{tabular}{|c|c|c|c|c|c|c|c|c|c|c|}
\hline \multirow[t]{2}{*}{ CID10 } & \multicolumn{2}{|c|}{2003} & \multicolumn{2}{|c|}{2004} & \multicolumn{2}{|c|}{2005} & \multicolumn{2}{|c|}{2006} & \multicolumn{2}{|c|}{2007} \\
\hline & $\mathbf{N}$ & (\%) & $\mathbf{N}$ & (\%) & $\mathbf{N}$ & $(\%)$ & $\mathbf{N}$ & $(\%)$ & $\mathbf{N}$ & $(\%)$ \\
\hline Cap.I & 49 & $(29,9)$ & 18 & $(16,2)$ & 22 & $(20,2)$ & 20 & $(15,7)$ & 23 & $(12,5)$ \\
\hline Cap.X & 29 & $(17,7)$ & 26 & $(23,4)$ & 11 & $(10,1)$ & 21 & $(16,5)$ & 28 & $(15,2)$ \\
\hline $\begin{array}{l}\text { Cap.XIX e } \\
\text { XX }\end{array}$ & 12 & $(7,3)$ & 8 & $(7,2)$ & 6 & $(5,5)$ & 10 & $(7,9)$ & 8 & $(6,1)$ \\
\hline Cap.XII & 9 & $(5,5)$ & 4 & $(3,6)$ & 4 & $(3,7)$ & 3 & $(2,4)$ & 5 & $(2,7)$ \\
\hline Cap.VI & 7 & $(4,3)$ & 3 & $(2,7)$ & 2 & $(1,8)$ & 5 & $(3,9)$ & 9 & $(4,9)$ \\
\hline Cap.VIII & 5 & $(3,0)$ & 1 & $(0,9)$ & 3 & $(2,8)$ & 1 & $(0,8)$ & 3 & $(1,6)$ \\
\hline Cap.XVII & 5 & $(3,0)$ & 11 & $(9,9)$ & 10 & $(9,2)$ & 12 & $(9,4)$ & 23 & $(12,5)$ \\
\hline Cap.III & 3 & $(1,8)$ & 6 & $(5,4)$ & 1 & $(0,9)$ & 7 & $(5,5)$ & 3 & $(4,9)$ \\
\hline Cap.XI & 3 & $(1,8)$ & 2 & $(1,8)$ & - & (0) & 4 & $(3,1)$ & 1 & $(0,5)$ \\
\hline Cap.IV & 2 & $(1,2)$ & 2 & $(1,8)$ & 4 & $(3,7)$ & 4 & $(3,1)$ & 12 & $(6,5)$ \\
\hline Cap.VII & 2 & $(1,2)$ & 1 & $(0,9)$ & 1 & $(0,9)$ & 2 & $(1,6)$ & 1 & $(0,5)$ \\
\hline Cap.XIV & 2 & $(1,2)$ & 2 & $(1,8)$ & 4 & $(3,7)$ & 2 & $(1,6)$ & 2 & $(1,1)$ \\
\hline Cap.XVIII & 2 & $(1,2)$ & 3 & $(2,7)$ & 4 & $(3,7)$ & 4 & $(3,1)$ & 2 & $(1,1)$ \\
\hline Cap.II & - & (0) & 3 & $(2,7)$ & 7 & $(6,4)$ & - & (0) & 2 & $(1,1)$ \\
\hline Cap.IX & - & (0) & 2 & $(1,8)$ & 2 & $(1,8)$ & - & (0) & 2 & $(1,1)$ \\
\hline Cap.XIII & - & (0) & - & (0) & 2 & $(1,8)$ & - & (0) & - & (0) \\
\hline Cap.XVI & - & $(0)$ & 2 & $(1,8)$ & - & $(0)$ & 1 & $(0,8)$ & 1 & $(0,5)$ \\
\hline $\begin{array}{l}\text { Sem } \\
\text { informação }\end{array}$ & 34 & $(20,7)$ & 17 & $(15,3)$ & 26 & $(23,9)$ & 31 & $(24,4)$ & 53 & $(28,8)$ \\
\hline Total & 164 & (100) & 111 & (100) & 109 & (100) & 127 & (100) & 184 & $(100)$ \\
\hline
\end{tabular}

Cap. I: Dças infecciosas e parasitárias; Cap. II: Neoplasias; Cap III: Dças sangue e imunitárias; Cap IV: Dças endócrinas, metabólicas e nutricionais; Cap VI: Dças sistema nervoso; Cap VII: Dças olho e anexos; Cap VIII: Dças ouvido, apófise e mastóide; Cap IX: Dças aparelho circulatório; Cap X: Dças aparelho respiratório; Cap XI: Dças aparelho digestivo; Cap XII: Dças pele e tecido celular subcutâneo; Cap XIII: Dças sistema osteomuscular; Cap XIV: Dças aparelho genitourinário; Cap XVI: Dças originadas no período neonatal; Cap XVII: Malformações congênitas e anormalidades cromossômicas; Cap XVIII: Sinais e sintomas; Cap XIX: Causas externas; Cap XX: Causas externas.

$\mathrm{Na}$ análise da etiologia da morbidade, explicitada no gráfico 13, observa-se uma predominância das morbidades de causa infecciosa, com 331 (44,7\%) internações, seguida pelas morbidades de etiologia congênita com $122(17,6 \%)$, os traumas com $47(6,8 \%)$ e as doenças carenciais com 38 (5,5\%) internações, sendo as neoplasias menos freqüentes, contribuindo com apenas $10(1,4 \%)$ internações. 
Novamente chama atenção a proporção de internações sem causa registrada, 167 $(24 \%)$.

Gráfico 13 - Distribuição percentual das causas de internação em crianças indígenas menores que 10 anos de idade encaminhadas para CASAI para tratamento de saúde, segundo etiologia - Rio Branco - AC, 2003 - 2007.

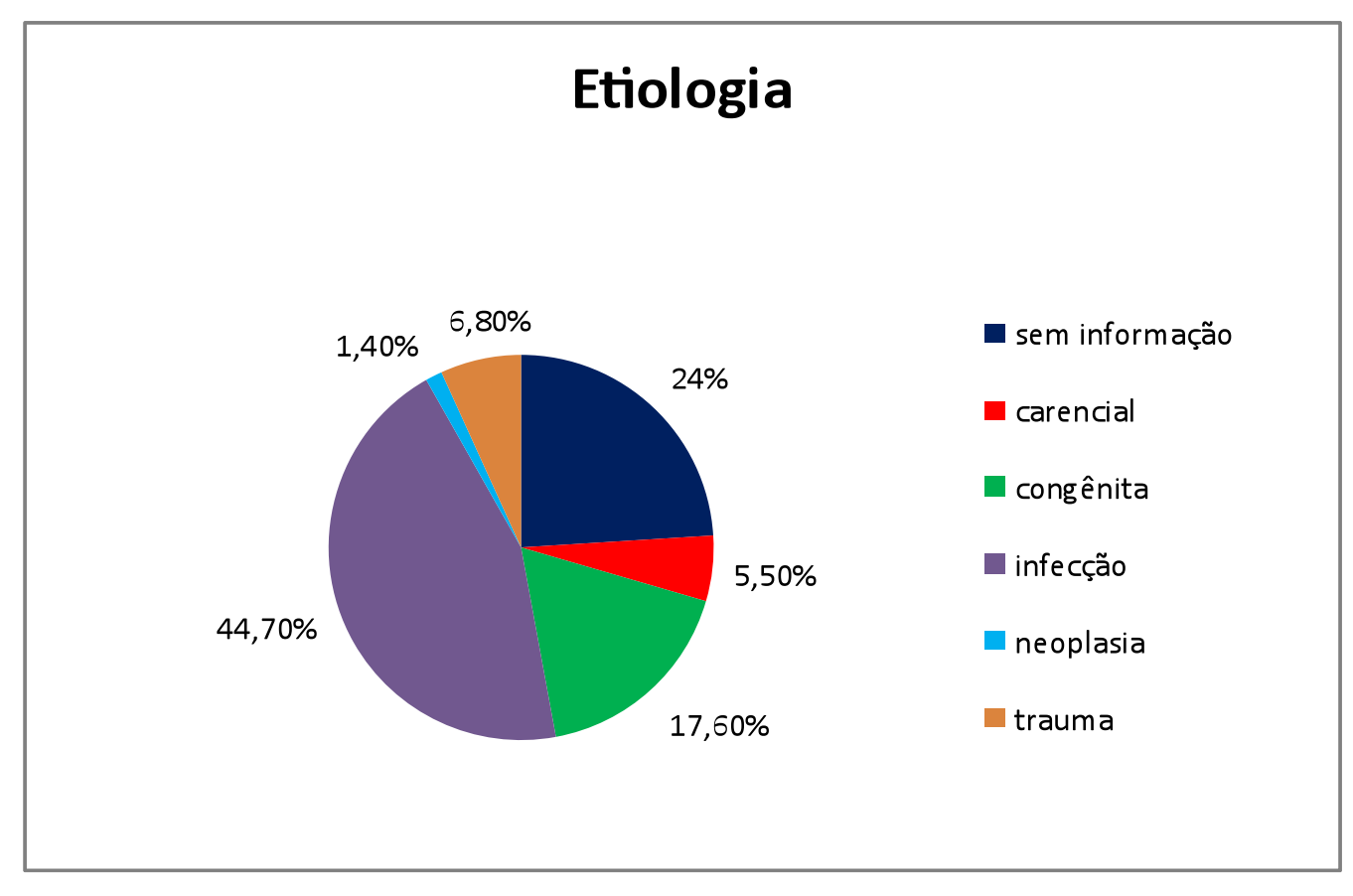

A tabela 4 mostra a distribuição percentual das causas de internação na CASAI de cada etnia, segundo a CID 10, permitindo comparação entre as etnias. Observa-se uma participação maior das doenças infecciosas e parasitárias, cap. I, na etnia Kaxararí, sendo responsável por um terço das internações, contrastando com os Yawanawá, onde o capítulo I correspondeu à apenas 5,9\% das internações. As doenças endócrinas, nutricionais e metabólicas, cap. IV, foram proporcionalmente mais frequentes entre os Ashaninka, correspondendo a um quarto das internações. Já 
nas doenças do aparelho respiratório, cap. X, chama atenção sua baixa freqüência entre os Jamamady, sendo responsáveis por pouco mais de $6 \%$ das internações, contrastando com as outras etnias, onde sua magnitude é mais pronunciada, correspondendo à causa de um sexto a um quarto das internações. As doenças da pele, cap. XII, são mais frequentes entre os Ashaninka, respondendo por um terço de todas as internações, seguidos pelos Apurinã com um quarto das internações. Entre os Apurinã e os Kulina, 30\% das internações não apresentavam registro sobre a causa, contrastando com os Ashaninka que tem informação sobre todas as internações, apesar de ser a etnia com o número mais reduzido de internações.

As etnias com menos de cinco internações não foram expostas na tabela para facilitar a visualização da mesma, e apresentaram os seguintes resultados: Arara, uma internação por doenças infecciosas e parasitárias cap. I; Poyanawa, com uma internação sem informação sobre a morbidade; Nukini, uma internação por causas externas, e Katukina, com quatro internações, uma por doenças infecciosas e parasitárias, cap. I, duas por causas externas, cap.XX, e uma sem informação sobre a morbidade. 
Tabela 4 - Distribuição percentual das causas de internação em crianças indígenas menores que 10 anos de idade encaminhadas para CASAI para tratamento de saúde, segundo etnia e grupo de doenças da Classificação Internacional de Doenças $10^{\mathrm{a}}$ revisão (CID 10) - Rio Branco - AC, 2003 - 2007.

\begin{tabular}{|c|c|c|c|c|c|c|c|c|c|c|}
\hline \multirow{2}{*}{$\begin{array}{l}\text { Capítulo } \\
\text { CID } 10\end{array}$} & \multicolumn{10}{|c|}{ Etnia } \\
\hline & Apurinã & Ashaninka & Jamamady & Jaminawa & Kaxararí & Kaxinawa & Kulina & Manchinery & Shanenawa & Yawanawá \\
\hline Cap. I & 9,9 & 8,3 & 25,0 & 16,1 & 34,6 & 13,8 & 17,4 & 27,4 & 11,1 & 5,9 \\
\hline Cap. II & & - & - & 7,1 & & 1,1 & & - & 7,4 & - \\
\hline Cap. III & 2,0 & - & - & 11,6 & 0,8 & 1,7 & 4,3 & 1,4 & 14,8 & 5,9 \\
\hline Cap. IV & 3,0 & 25,0 & - & 2,7 & - & 6,3 & 4,3 & 2,7 & - & 5,9 \\
\hline Cap. VI & 7,9 & 8,3 & - & - & 6,0 & 4,0 & - & 1,4 & - & 5,9 \\
\hline Cap. VII & - & - & - & - & 0,8 & 1,1 & - & 4,1 & 3,7 & - \\
\hline Cap. VIII & - & - & - & 0,9 & 4,5 & 2,3 & 4,3 & 1,4 & - & - \\
\hline Cap. IX & 2,0 & - & - & - & - & 1,1 & - & - & 7,4 & - \\
\hline Cap. X & 12,9 & 16,7 & 6,3 & 22,3 & 14,3 & 13,2 & 17,4 & 24,7 & 14,8 & 23,5 \\
\hline Cap. XI & 1,0 & - & - & 0,9 & 2,3 & 2,3 & - & - & - & 5,9 \\
\hline Cap. XII & 2,0 & 33,3 & 25,0 & 0,9 & 2.3 & 5,2 & - & 2,7 & - & - \\
\hline Cap. XIII & - & - & 12,5 & - & - & - & - & - & - & - \\
\hline Cap. XIV & 4,0 & - & - & 0,9 & 2,3 & 0,6 & - & - & 11,1 & - \\
\hline Cap. XVI & - & - & - & 2,7 & 0,8 & - & - & - & - & - \\
\hline Cap.XVII & 13,9 & - & - & 7,1 & 0,8 & 16,1 & 13,0 & 6,8 & 3,7 & 5,9 \\
\hline Cap.XVIII & 2,0 & - & 6,3 & - & 4,5 & 1,7 & - & 1,4 & 3,7 & 5,9 \\
\hline Cap. XIX & 7,9 & 8,3 & - & 1,8 & 4,5 & 6,3 & 4,3 & 6,8 & 3,7 & 5,9 \\
\hline Cap. XX & 1,0 & - & 12,5 & - & - & - & 4,3 & - & - & 17,6 \\
\hline $\begin{array}{l}\text { Sem } \\
\text { informação }\end{array}$ & 30,7 & - & 12,5 & 25,0 & 21,8 & 23,0 & 30,4 & 19,2 & 18,5 & 11,8 \\
\hline $\begin{array}{c}\text { Total } \\
\mathbf{N}\end{array}$ & $\begin{array}{l}100 \% \\
(101)\end{array}$ & $\begin{array}{r}100 \% \\
(12)\end{array}$ & $\begin{array}{r}100 \% \\
(16)\end{array}$ & $\begin{array}{l}100 \% \\
(112)\end{array}$ & $\begin{array}{l}100 \% \\
(133)\end{array}$ & $\begin{array}{l}100 \% \\
(174)\end{array}$ & $\begin{array}{r}100 \% \\
(23)\end{array}$ & $\begin{array}{r}100 \% \\
(73)\end{array}$ & $\begin{array}{r}100 \% \\
(27)\end{array}$ & $\begin{array}{r}100 \% \\
(17)\end{array}$ \\
\hline
\end{tabular}

Cap. I: Dças infecciosas e parasitárias; Cap. II: Neoplasias; Cap III: Dças sangue e imunitárias; Cap IV: Dças endócrinas, metabólicas e nutricionais; Cap VI: Dças sistema nervoso; Cap VII: Dças olho e anexos; Cap VIII: Dças ouvido, apófise e mastóide; Cap IX: Dças aparelho circulatório; Cap X: Dças aparelho respiratório; Cap XI: Dças aparelho digestivo; Cap XII: Dças pele e tecido celular subcutâneo; Cap XIII: Dças sistema osteomuscular; Cap XIV: Dças aparelho genitourinário; Cap XVI: Dças originadas no período neonatal; Cap XVII: Malformações congênitas e anormalidades cromossômicas; Cap XVIII: Sinais e sintomas; Cap XIX: Causas externas; Cap XX: Causas externas. 
A tabela 5, semelhante à tabela 4 , mostra a distribuição percentual das causas de internação na CASAI de cada Pólo-base, segundo a CID 10, permitindo comparação mais minuciosa entre eles. Observa-se a frequência maior das doenças infecciosas e parasitárias, cap. I, no Pólo-base de Sena Madureira, provavelmente pelo peso da etnia Kaxararí já abordada anteriormente no texto, sendo esta a causa de 27,5\% das internações oriundas do mesmo, e também no Pólo-base de Assis Brasil, correspondendo a 27,0\% das internações. As doenças da pele, cap. XII, foram mais frequentes em Feijó, responsáveis por 10,8\% das internações. As causas externas, cap. XIX, foram mais frequentes no Jordão, correspondendo à causa de $28,6 \%$ das internações, e proporcionalmente menos frequentes em Sena Madureira e Assis Brasil, apesar destas cidades serem mais próximas de Rio Branco. Os Pólos-base de Rio Branco e do Jordão foram os que encaminharam menos crianças para internação na CASAI, sendo apenas sete internações oriundas de cada um deles ao longo dos cinco anos analisados. 
Tabela 5 - Distribuição percentual das causas de internação em crianças indígenas menores que 10 anos de idade encaminhadas para CASAI para tratamento de saúde, segundo Pólo-base e grupo de doenças da Classificação Internacional de Doenças $10^{\mathrm{a}}$ revisão (CID 10) - Rio Branco - AC, 2003 - 2007.

\begin{tabular}{|c|c|c|c|c|c|c|c|c|c|}
\hline \multirow{2}{*}{$\begin{array}{l}\text { Capítulo } \\
\text { CID } 10\end{array}$} & \multicolumn{9}{|c|}{ Pólo-base } \\
\hline & $\begin{array}{l}\text { Assis } \\
\text { Brasil }\end{array}$ & $\begin{array}{c}\text { Boca } \\
\text { do Acre }\end{array}$ & Feijó & Jordão & $\begin{array}{l}\text { Manoel } \\
\text { Urbano }\end{array}$ & Pauini & $\begin{array}{c}\text { Rio } \\
\text { Branco }\end{array}$ & $\begin{array}{l}\text { Santa } \\
\text { Rosa }\end{array}$ & $\begin{array}{c}\text { Sena } \\
\text { Madureira }\end{array}$ \\
\hline Cap. I & 27,0 & 11,8 & 13,8 & 14,3 & 18,2 & 14,7 & 14,3 & 12,0 & 27,5 \\
\hline Cap. II & - & - & 3,1 & - & - & - & - & 1,7 & 4,2 \\
\hline Cap. III & 2,4 & 1,3 & 6,2 & 14,3 & 9,1 & 2,9 & - & 0,9 & 5,8 \\
\hline Cap. IV & 2,4 & 2,6 & 6,2 & - & 9,1 & - & 14,3 & 8,5 & 1,1 \\
\hline Cap. VI & 0,8 & 7,9 & 3,1 & 14,3 & - & 5,9 & - & 2,6 & 4,2 \\
\hline Cap. VII & 2,4 & - & 1,5 & - & - & - & - & 0,9 & 0,5 \\
\hline Cap. VIII & 1,6 & - & 3,1 & 14,3 & 9,1 & - & - & 0,9 & 3,2 \\
\hline Cap. IX & - & 2,6 & 4,6 & - & - & - & - & - & - \\
\hline Cap. X & 23,8 & 5,3 & 13,8 & 14,3 & 9,1 & 20,6 & 42,9 & 19,7 & 15,9 \\
\hline Cap. XI & - & - & - & - & - & 2,9 & - & 3,4 & 1,6 \\
\hline Cap. XII & 1,6 & 5,3 & 10,8 & - & - & 2,9 & - & 5,1 & 2,1 \\
\hline Cap. XIII & - & 2,6 & - & - & - & - & - & - & - \\
\hline Cap. XIV & - & 3,9 & 4,6 & - & - & - & 14,3 & 0,9 & 2,1 \\
\hline Cap. XVI & 2,4 & - & - & - & - & - & - & - & 0,5 \\
\hline Cap.XVII & 3,2 & 14,5 & 4,6 & - & 18,2 & 8,8 & 14,3 & 13,7 & 5,3 \\
\hline Cap.XVIII & 0,8 & 1,3 & 3,1 & - & - & 5,9 & - & 0,9 & 3,2 \\
\hline Cap. XIX & 4,0 & 5,3 & 6,2 & 28,6 & - & 11,8 & - & 6,0 & 3,7 \\
\hline Cap. XX & - & 2,6 & - & - & - & 2,9 & - & 0,9 & - \\
\hline $\begin{array}{l}\text { Sem } \\
\text { informação }\end{array}$ & 27,8 & 32,9 & 15,4 & - & 27,3 & 20,6 & - & 22,2 & 19,0 \\
\hline Total $\mathbf{N}$ & $\begin{array}{l}100 \% \\
(126)\end{array}$ & $\begin{array}{r}100 \% \\
(76) \\
\end{array}$ & $\begin{array}{r}100 \% \\
(65) \\
\end{array}$ & $\begin{array}{r}100 \% \\
(7) \\
\end{array}$ & $\begin{array}{r}100 \% \\
(11) \\
\end{array}$ & $\begin{array}{r}100 \% \\
(34) \\
\end{array}$ & $\begin{array}{r}100 \% \\
(7) \\
\end{array}$ & $\begin{array}{l}100 \% \\
(117) \\
\end{array}$ & $\begin{array}{l}100 \% \\
(189) \\
\end{array}$ \\
\hline
\end{tabular}

Cap. I: Dças infecciosas e parasitárias; Cap. II: Neoplasias; Cap III: Dças sangue e imunitárias; Cap IV: Dças endócrinas, metabólicas e nutricionais; Cap VI: Dças sistema nervoso; Cap VII: Dças olho e anexos; Cap VIII: Dças ouvido, apófise e mastóide; Cap IX: Dças aparelho circulatório; Cap X: Dças aparelho respiratório; Cap XI: Dças aparelho digestivo; Cap XII: Dças pele e tecido celular subcutâneo; Cap XIII: Dças sistema osteomuscular; Cap XIV: Dças aparelho genitourinário; Cap XVI: Dças originadas no período neonatal; Cap XVII: Malformações congênitas e anormalidades cromossômicas; Cap XVIII: Sinais e sintomas; Cap XIX: Causas externas; Cap XX: Causas externas. 
$\mathrm{Na}$ análise do total das morbidades registradas nos prontuários da CASAI, tanto morbidade principal como co-morbidades, nota-se que as mais freqüentes continuam sendo as doenças infecciosas e parasitárias, cap. I, com 234 (26,5\%) ocorrências, seguidas pelas doenças do aparelho respiratório, cap. X, com 197 $(22,4 \%)$ e as malformações congênitas com 99 (11,3\%) das 880 morbidades reportadas. Apesar da freqüência não ser a mesma da causa de internação, a ordem permanece igual. 


\section{DISCUSSÃO}

Moriyama 1979 (apud LAURENTI, 2004, p. 910) ressaltou a importância das estatísticas de morbidade para avaliação do panorama de saúde da população, descrevendo o crescente sentimento de necessidade de dados sobre morbidade para propósitos de saúde pública. Assim, mesmo incompletos, os dados da CASAI de Rio Branco são úteis para o conhecimento das necessidades das políticas públicas para os povos indígenas da região.

A guisa de orientação preliminar, cabe destacar que o estudo utiliza os preceitos dos estudos de demanda, já que analisa os casos referidos para a CASAI para serem atendidos na rede do SUS, ou seja, a demanda que chega ao SUS referenciada pelo Subsistema de Atenção à Saúde Indígena (SASI). Conforme ressalta YAZLLE ROCHA em estudo de 1985 sobre padrões de morbidade, as estatísticas de morbidade ambulatorial adquirem maior valor se o serviço atende toda a demanda populacional, como é o caso da CASAI de Rio Branco. Assim, seu resultado reflete as "necessidades" da população.

Para ajudar na apreciação das questões a discussão foi dividida em três tópicos:

Registros: São apresentadas considerações sobre a qualidade dos registros e possibilidades de seu uso para caracterizar a demanda dos serviços;

Perfil demográfico do atendimento: É feito um recorte analítico a partir das informações de sexo, idade e densidade de freqüência da demanda; 
Perfil nosológico: A discussão está dirigida à lógica da causalidade e distribuição geográfica e cultural das etnias;

\section{Registros:}

O presente estudo mostra que apesar do SIASI e dos esforços em se registrar as ocorrências de saúde e doença entre os povos indígenas, ainda existe uma lacuna muito grande no conhecimento sobre o perfil de morbidades desta população específica.

Uma das dificuldades de se realizar estudos populacionais com indígenas diz respeito ao acesso dos pesquisadores ao campo, uma vez que os levantamentos epidemiológicos com a população indígena têm restrições éticas, jurídicas e constitucionais (BRASIL, 1996 e 2000; FUNAI, 1973). Além disso, existem agravantes demográficos e geográficos, já que estes povos se dispersam por aldeias em locais remotos (GARNELO et al., 2003). Desta maneira, a possibilidade de analisar os prontuários disponíveis na CASAI torna-se um instrumento útil para complementar as informações de saúde dessa população. LAURENTI (2004), ao estudar a qualidade das informações dos registros médicos, atenta para o fato de que os registros são utilizados por governos, historicamente, há cerca de 400 anos - desde 1662 (Graunt, apud LAURENTI, 2004, p.910). Nesse estudo Laurenti faz restrições à qualidade dos registros, mas conclui que, apesar disso, sempre foram, continuam e continuarão sendo uma das principais fontes de dados em saúde pública. 
ESCOBAR (2003), analisando as causas de internação hospitalar em indígenas em Rondônia, encontrou elevada freqüência de prontuários incompletos e aponta falhas na qualidade dos registros da CASAI de Porto Velho, mas ressalta a importância deste tipo de estudo por ser uma forma pouco explorada de análise à cerca da saúde indígena. A autora sugere que os dados de morbidade indígena têm sido tratados burocraticamente pelo sistema, havendo prioridade pelos indicadores de produção (número de consultas, procedimentos, medicação dispensada) em detrimento aos dados epidemiológicos.

A dificuldade de registro dos dados de saúde no Brasil não se restringe à saúde indígena. É discutida por BERINGHS et al. em estudo de 2008 sobre a avaliação do preenchimento das declarações de nascidos mortos no Município de São Paulo. Foram observadas deficiências tanto na quantidade quanto na qualidade dos dados registrados, com repercussões nas análises epidemiológicas. Os autores correlacionam essas deficiências à pouca importância dada pelos profissionais de saúde ao preenchimento das notificações obrigatórias (BERINGHS et al., 2008).

MODESTO et al. (1992), durante avaliação da qualidade dos dados registrados nos prontuários médicos em um distrito sanitário da Bahia, encontraram elevada proporção $(76 \%)$ de prontuários caracterizados como insatisfatórios por estarem incompletos, ilegíveis ou mal preenchidos. Os autores ressaltam que apesar da melhora da qualidade das fichas e impressos, através da padronização dos mesmos, o preenchimento ainda se mantém aquém do esperado.

Neste estudo, apesar dos espaços dedicados para registro (Anexo 1), nenhum prontuário da CASAI estava completamente preenchido. As informações sobre 
eventos ocorridos durante as internações hospitalares, como por exemplo realização de procedimentos cirúrgicos, resultado de exames, e até possível óbito da criança, não foram encontrados em quase nenhum prontuário. Dessa maneira, como ressalta CARDOSO et al., 1995, LAURENTI et al., 2004, GARNELLO et al., 2005, BERINGHS et al., 2008, VASCONCELOS et al., 2008 e o relatório da FUNASA de 2006, são necessários esforços para a melhoria da qualidade dos registros de saúde, de modo particular, como aponta Garnello, as informações sobre o DSEI do Alto Rio Juruá, região com uma das piores estimativas de mortalidade infantil no Brasil (GARNELLO et al., 2005).

\section{Perfil demográfico do atendimento:}

O estudo não mostrou diferenças importantes quanto ao sexo, e embora todas as faixas etárias tenham contribuído com as internações, predominou a participação de menores de dois anos de idade e de maneira mais específica, o primeiro ano de vida. A elevada proporção de crianças menores de um ano assistidas na rede pública de saúde tem sido constatada em vários trabalhos (BARROS, 1981; LUNARDI et al., 2007). Segundo dados do DATASUS, cerca de $18 \%$ do total de atendimentos ambulatoriais de menores de 10 anos estão concentrados no primeiro ano de vida. SILVÉRIO (1997) em estudo sobre as crianças internadas no Hospital Universitário da UFSC, ESCOBAR et al. (2003) na avaliação da morbidade hospitalar em indígenas de Rondônia, e ORELLANA et al. (2007) analisando a morbidade 
hospitalar em crianças indígenas Suruí menores de 10 anos de idade de Rondônia, também reportam preponderância dos lactentes e em particular de crianças no primeiro ano de vida entre as internadas.

O Unicef (Fundo das Nações Unidas para o Desenvolvimento infantil) classifica o primeiro ano de vida como o mais vulnerável às condições ambientais e o mais importante no processo de desenvolvimento humano. Seja por questões maturacionais do aparelho neuro-motor, digestório, neuro-endócrino (LEONE e GALLO, 2009; MARCONDES, 1994) seja no aspecto imuno-biológico, ou psicosocial (SPTIZ, 1980), o fato é que a atenção à criança no primeiro ano de vida tem sido colocada em evidência pelos principais sistemas de saúde regionais e nacionais.

Ao adotar o ponto de vista da saúde coletiva para discussão da faixa etária, BACKETT et al. (1985) sugere uma leitura das vulnerabilidades da infância nos moldes do enfoque de risco. Segundo este autor os menores de dois anos de idade devem ser considerados grupo de risco para morbidades. Sua proposta para diminuir as desigualdades das condições de saúde e aumentar a efetividade dos cuidados primários é partir para uma diferenciação positiva, principalmente porque a população de lactentes indígenas pode ser considerada de grande necessidade e suscetível a mudança nos índices de morbidade com ações sanitárias relativamente simples.

Chama atenção o registro das internações de recém-nascidos ao longo dos cinco anos analisados no estudo. Ao todo apenas 27 recém nascidos (RN). Apesar das falhas de registro nas estatísticas vitais (LAURENTI et al., 2004, GARNELLO et al., 2005), é preciso considerar como elevada a taxa de natalidade que a população 
indígena apresenta (COIMBRA JUNIOR e SANTOS, 2001). No Dsei do Alto Rio Purus, que atende cerca de 7500 indígenas, foram registrados pela FUNASA 210 nascidos vivos em 2005 e 319 em 2006. Cerca de 90\% dos partos ocorrem na própria aldeia por meio de parteiras indígenas (FUNASA, 2006a).

O fato de se estimar uma média anual de 5,4 internações na CASAI de bebês recém nascidos sugere que muitos portadores de morbidades neonatais não estariam sendo assistidos pelos serviços de saúde do SUS. Este número, que traduz um coeficiente de internação hospitalar dos recém nascidos na ordem de 6,4 por mil nascimentos, subestima a magnitude da morbidade entre os $\mathrm{RN}$ indígenas do Acre.

ORELLANA et al. (2007), reporta a baixa ocorrência de internações causadas por afecções perinatais entre as crianças indígenas Suruí de Rondônia, atribuindo $3,2 \%$ das internações às afecções originadas no período perinatal (capítulo XVI do CID 10). CAETANO et al. (2002), analisando dados de internação de crianças residentes em município da região metropolitana de São Paulo, encontra 3,1\% das internações causadas por afecções perinatais. Neste sentido, os dados da CASAI de Rio Branco apresentam resultados de internação de RN bem mais modestos. O mesmo capítulo da CID é responsável por taxas, pelo menos, cinco vezes menores $(0,57 \%)$

Contribui para este quadro tanto a dificuldade de acesso dos indígenas aos referidos serviços de saúde, mas também as características sócio-culturais dessa população, que tem conceitos diferentes da população não-indígena no que se refere aos cuidados das gestantes e dos recém-nascidos doentes (FUNASA, 2006b). As 
malformações registradas como causa de internação foram principalmente aquelas que não levavam a risco de vida, como pé torto congênito e lábio leporino.

Esta questão pode suscitar um debate antropológico relevante acerca da legitimidade da intervenção pelo SUS nestes casos de morbidade perinatal (FUNASA, 2006b). Trata-se de discussão que foge aos objetivos deste estudo, mas é importante e pertinente para o planejamento das ações de saúde voltadas para esta parcela da população.

Quase a totalidade das crianças (95\%) reside em aldeias distantes das cidades, no interior ou próximo da floresta. Dado que realça a autonomia cultural dessas etnias, diferente de outros Estados da Federação, onde parte significativa dos indígenas se localiza nas áreas periféricas das cidades (GARNELLO et al., 2003; COIMBRA JUNIOR e SANTOS, 2000).

Dentre as 17 etnias atendidas pelos dois Dseis estudados foram encontradas internações de crianças indígenas pertencentes a 14 delas. As três ausentes são etnias "ressurgidas" (Nawa, Apolina-arara e Jaminawa-arara) que são menos populosas e provavelmente não organizadas nos anos iniciais do estudo, a ponto de influenciarem nos resultados apresentados. Este fato contribui para mostrar uma abrangência satisfatória do SASI, com ações de saúde alcançando todas as etnias propostas. Cabe, contudo, interrogar se as fazem com equidade. 


\section{Perfil nosológico:}

O risco de adoecimento entre as diversas etnias estudadas é heterogêneo. De acordo com a etnia avaliada, o peso proporcional de cada capítulo do CID 10 é diferente. A expressão da doença e seu significado podem variar conforme a cultura e a situação, sugerindo uma maior complexidade nos estudos de demanda com a população indígena (SCHRAMM e CASTIEL, 1992; ALVES e MINAYO, 1994, FUNASA, 2006b).

Este estudo evidencia que as principais causas de internação na CASAI são as doenças infecciosas e parasitárias (Capítulo I do CID 10), particularmente infecções gastrointestinais e malária, e em seguida as doenças do aparelho respiratório (Capítulo X do CID 10). De modo geral, as proporções das doenças encontradas na literatura em cada capítulo do CID se aproximam e são referidas tanto para crianças indígenas (ORELLANA et al., 2007; ESCOBAR et al., 2003; LUNARDI et al., 2007) quanto não indígenas (DATASUS; SILVERIO, 1997; YAZLLE ROCHA e NOGUEIRA, 1985; CARVALHO et al., 1994), sendo mais freqüentes as doenças do aparelho respiratório e em segundo lugar doenças infecciosas e parasitárias. Contudo, neste estudo é importante destacar a inversão da hierarquia. Dessa maneira o grupo mais freqüente de doenças está relacionado ao Capítulo I em detrimento das classificadas no capítulo X, que aqui aparece ocupando o segundo lugar.

A malária é reportada tanto por COIMBRA JUNIOR e SANTOS (2001) como por ESCOBAR et al. (2003), como sendo uma das principais parasitoses endêmicas nas populações indígenas da Amazônia. Neste estudo a malária 
isoladamente é responsável por cerca de $22 \%$ das internações classificadas no Capítulo I. Contudo, chama atenção que mesmo os valores sendo ajustados retirandose os casos de malária, o Capítulo I manteria no mínimo equivalência em magnitude ao Capítulo X. Fatos que confirmam a diferença no perfil epidemiológico das crianças da CASAI de Rio Branco do verificado em outros estudos de morbidade, na maioria dos quais, o risco das doenças respiratórias é cerca de duas vezes maior que o de doenças infecciosas e parasitárias (BARROS, 1981; SILVÉRIO, 1997; CAETANO et al., 2002; LUNARDI et al., 2007; ORELLANA et al., 2007).

$\mathrm{Na}$ análise do total das 880 morbidades registradas nos prontuários da CASAI, englobando tanto morbidade principal quanto co-morbidades, observa-se que apesar de o percentual proporcional não ser o mesmo do obtido para a causa de internação, a ordem de ocorrência se mantém igual. Permanecem as doenças infecciosas e parasitárias como o tipo de morbidade mais encontrada, seguido pelas doenças do aparelho respiratório e pelas malformações congênitas. Tem que se levar em conta nesta análise falhas de registro das co-morbidades no estudo.

As malformações congênitas foram responsáveis por cerca de um decil das internações, magnitude de difícil comparação dada a grande variabilidade verificada em outros trabalhos (BARROS,1981; SILVÉRIO,1997; ORELLANA et al. 2007). As malformações foram a causa mais comum de internação em duas etnias, a saber Apurinã e Kaxinawá, e podem estar relacionadas à consanguínidade nos relacionamentos - "na cultura Kaxinawá, etnia mais numerosa na região, o casamento consangüineo é preferido e estimulado pelas famílias” (UCHOA, 2003 p.79), A mesma justificativa, baseada na endogenia desses povos, também pode ser 
extendida ao povo Apurinã, uma vez que eles se organizam em apenas três aldeias (UCHOA, 2003; MINDLIN, 1992).

Observa-se, ao longo do período estudado, diminuição na freqüência das doenças infecciosas como causa de internação, e aumento na participação das doenças congênitas. A diminuição na ocorrência de doenças diarréicas em menores de dois anos de idade estaria relacionada à melhoria das condições socioeconômicas e sanitárias (VÁZQUEZ et al., 1999; CAMPOS et al., 1995; BENÍCIO e MONTEIRO, 2000.) Neste estudo, a menor participação do capítulo I no perfil epidemiológico pode estar relacionada tanto à melhora das condições sanitárias das aldeias, em particular do acesso à água potável, como às atividades de promoção de saúde e à maior resolutividade dos casos em nível primário de atenção, nos Pólosbase, sem necessidade de encaminhamento à capital (SILVA, 1989; FUNASA, 2006).

A análise comparativa da contribuição proporcional de cada morbidade para a internação na CASAI, ao longo dos anos do estudo, mostra certa redistribuição na magnitude das patologias. Contudo mesmo com estas redistribuições específicas no perfil epidemiológico, as doenças infecciosas e parasitárias continuam sendo o capítulo mais freqüente, seguidas das doenças do aparelho respiratório. Mas as modificações verificadas principalmente nos últimos dois anos do estudo talvez possam ser consideradas indicadoras precursoras do processo de transição epidemiológica (PRATA, 1992; MEDICI e BELTRÃO, 1993) na população indígena. 
Dado que doenças neoplásicas são raras em crianças (DATASUS), a pouca ocorrência destas entre as internações não chama atenção. Constata-se também pouca participação das doenças de pele, anemias, desnutrição e baixo peso como causas específicas de internação na CASAI.

Observa-se uma participação proporcionalmente expressiva das doenças de etiologia congênita como causa da internação na CASAI, quase um quinto das internações e cerca de metade da freqüência das causadas por etiologia infecciosa. Segundo TANAKA et al. (1989), a melhoria do pré-natal pode interferir positivamente nos índices destas doenças, o que sugere uma análise crítica sobre a qualidade do pré-natal.

$\mathrm{Na}$ análise do coeficiente de internação por mil crianças destaca-se a etnia Kaxararí, que apresenta valor cerca de 10 vezes maior quando comparado com as outras etnias; às custas das doenças infecciosas, principalmente malária, e das doenças respiratórias. Pode-se explicar essa diferença de freqüência através de uma sinergia de fatores, alguns agravando o coeficiente desta população específica, e outros diminuindo o coeficiente das outras etnias utilizadas para comparação. Entre os fatores agravantes destaca-se a proximidade desta comunidade com a cidade de Rio Branco, sendo o acesso realizado por estrada pavimentada de boas condições, facilitando o atendimento de casos menos complexos (AQUINO et al., 1992). Nas etnias e comunidades mais distantes de Rio Branco, de pior acesso, encontrou-se coeficientes de internação menores, talvez porque os casos não tenham conseguido chegar até a CASAI (PINHEIRO, 2002; FUNASA, 2006a). Além disso, as aldeias Kaxararí se localizam em área endêmica de malária (GARNELLO et al., 2005; 
SOUZA-SANTOS, 2002) e portanto, esta causa contribui para aumentar o coeficiente de internação desta etnia.

O padrão de utilização dos serviços de saúde de uma população está condicionado a uma série de fatores: a disponibilidade, o tipo e a quantidade de serviços e recursos; a localização geográfica, a cultura médica local, a ideologia do prestador (PINHEIRO, 2002). Apesar do Dsei do Alto Rio Juruá apresentar situação de saúde e indicadores mais críticos que o Dsei do Alto Rio Purus (FUNASA, 2006a), a distância geográfica e dificuldade de acesso às aldeias, junto aos fatores culturais (FUNASA, 2006b), podem explicar a menor participação entre as internações na CASAI (TRAVASSOS e MARTINS, 2004). Além disso, hospitais da região conseguem absorver parte da demanda (ESCOBAR et al., 2003).

Houve diferença na frequência das internações relacionada à época do ano, tendo sido notado um predomínio na época do verão amazônico, quando o acesso terrestre é facilitado e o fluvial dificultado. Isto pode ser explicado pela pequena participação dos indígenas do Dsei do Alto Rio Juruá entre as internações, já que esta região possui poucas estradas e o acesso as aldeias é realizado principalmente por via fluvial, sendo facilitado no período das chuvas (MARTINS e MENEZES, 1994). O Dsei do Alto Rio Purus, predominante na CASAI, contém mais estradas que se tornam trafegáveis durante o período da seca, assim aumentando a demanda nesta época do ano (FUNASA, 2006b).

Diferente de BERINGHS (2005), a influência sazonal nas internações é explicada, portanto, por questões de acessibilidade, e não por estar relacionado à maior incidência das morbidades segundo estação do ano. A demanda das 
morbidades é constante durante todo o ano, porém os indígenas não conseguem acesso aos serviços de saúde por dificuldades geográficas particulares da região (FUNASA, 2006a) demonstrando vulnerabilidade dos mesmos às forças naturais (COIMBRA JUNIOR e SANTOS, 2000). 


\section{CONCLUSÕES}

1. O perfil demográfico mostra que $95 \%$ dos indígenas atendidos na CASAI são aldeados.

2. Houve predomínio de internação em lactentes, principalmente no primeiro ano de vida, quando comparado com outras faixas etárias.

3. Apesar da alta taxa de natalidade da população indígena, a frequência de internação de recém-nascidos na CASAI é baixa, com registro de apenas 27 internações nos cinco anos estudados.

4. Com exceção das etnias ressurgidas (Nawa, Apolina-Arara e Jaminawa-Arara) e dos índios isolados, todas as outras etnias existentes nos dois Dseis estudados: Kaxinawá (Huni Kui), Ashaninka (Kampa), Manchineri, Kulina (Madijá), Katikina, Jaminawa, Shanenawa, Yawanawá, Arara (Shawãdawa), Poyanawa, Nukini, Jamamadi e Apurinã, estão presentes entre as internações na CASAI. Isso sugere uma abrangência satisfatória, mesmo que heterogênea, das ações do SASI no território dos distritos.

5. Existe diferença no coeficiente de internação na CASAI por mil crianças quando se compara os Dseis do Alto Rio Purus e do Alto Rio Juruá, sendo o primeiro quase oito vezes maior que o segundo. 
6. O perfil epidemiológico das crianças indígenas encaminhadas para a CASAI de Rio Branco se diferencia do reportado tanto para a população não indígena do Acre e do Brasil, quanto para a população indígena de outras regiões do país.

7. As morbidades mais freqüentes foram as doenças infecciosas e parasitárias (Capítulo I do CID 10), seguidas das doenças do aparelho respiratório (Capítulo $\mathrm{X}$ do CID 10).

8. A malária contribuiu com parcela importante das internações na CASAI, sendo a quinta causa mais frequente de internação.

9. Os últimos dois anos do estudo talvez possam ser considerados indicadores de um processo de transição epidemiológica na população indígena, com diminuição na frequência das doenças infecciosas como causam de internação, e aumento na participação das doenças congênitas.

10. As particularidades culturais de cada etnia, as experiências de interação com os não-índios e a dificuldade de acesso às aldeias são os principais fatores determinantes da demanda e do tipo de morbidade que chega a CASAI.

Além das conclusões acima citadas, que respondem diretamente aos objetivos propostos, cabe realçar que o estudo permite ainda algumas considerações:

11. Faltam estudos sistemáticos sobre o perfil de morbidades da população indígena da Amazônia Ocidental.

12. O registro de informações ainda é deficiente, tanto na FUNASA e principalmente nos hospitais do Estado do Acre, sinalizando necessidade de se empreender esforços para melhoria da qualidade dos registros. 
13. É necessária abordagem de enfoque de risco com a etnia Kaxararí, que apresenta coeficiente de internação por mil crianças muito superior as outras etnias. 


\section{REFERÊNCIAS BIBLIOGRÁFICAS}

ACRE. Governo do Estado do Acre. Terras Indígenas. Disponível em: $<$ http://www.ac.gov.br/> Acesso em: 13 maio 2008.

AlveS, P., C.; MINAYO, M., C., S. (org). Saúde e Doença: um olhar antropológico. Rio de Janeiro: editora Fiocruz, 1994.

AQUINO, E. M. L., MENEZES, G. M. S., AMOEDO, M. B. Gênero e Saúde no Brasil: considerações a partir da Pesquisa Nacional por Amostra de Domicílios. Revista de Saúde Pública, São Paulo, v. 26, n. 3, p. 195-202, 1992.

ATHIAS, R.; MACHADO, M. A saúde indígena no processo de implantação dos distritos Sanitários: temas críticos e propostas para um diálogo interdisciplinar. Cadernos de Saúde Pública, Rio de Janeiro, v. 17, n. 2, p. 425-31, 2001.

BACKETT, E. M.; DAVIES, A. M.; PETROS-BARVAZIAN, A. O enfoque de risco na assistência à saúde - com especial referência à saúde materno-infantil, inclusive planejamento familiar. OPAS (Organização Pan-Americana da Saúde). Publicação científica n. 491. Washington DC: 1985.

BARROS, M. B. A. Morbidade e mortalidade hospitalar de crianças menores de um ano, em Ribeirão Preto, SP (BRASIL), 1975. Revista de Saúde Pública, São Paulo, v. 15, p. $308-20,1981$. 
BASTA, P. C.; OELEMANN, M. A. C., OELEMANN, W. M. R.; FONSECA, L. S.; COIMBRA JUNIOR, C. E. A. Detection of Mycobacterium tuberculosis in sputum from Suruí Indian subjects, Brazilian Amazon. Memórias do Instituto Oswaldo Cruz, Rio de Janeiro, v. 101, n. 6, p. 581-84, 2006.

BENICIO, M. H. D’A.; MONTEIRO, C. A. M. Tendência secular da doença diarréica na infância na cidade de São Paulo (1984 - 1996). Revista de Saúde Pública, São Paulo, v. 34, n. 6, p. 83-90, 2000.

BRASIL. Conselho Nacional de Saúde. Comitê Nacional de Ética em Pesquisa. Resolução 196/96. Brasília, DF, 1996.

. Conselho Nacional de Saúde. Comitê Nacional de Ética em Pesquisa. Resolução 340/00. Brasília, DF, 2000.

. Ministério da Saúde. Fundação Nacional de Saúde. Política Nacional de Atenção à Saúde dos Povos Indígenas. 2 ed. Brasília, DF; 2002a.

- Ministério da Saúde. Fundação Nacional de Saúde. Ações de Saúde, Saneamento e Edificações de Saúde como promoção da Cidadania dos Povos Indígenas. Brasília, DF, $2002 b$.

. Conselho Nacional de Secretários de Saúde. Para entender gestão do

SUS. Brasília, DF, 2003. 
. Ministério da Saúde. Portaria 2656 de 17/10/2007. Brasília, DF, 2007.

BERINGHS, E. M.; GALLO P. R.; REIS, A. A. Mortalidade por asma no Município de São Paulo-Brasil: influência do clima. Sociedad Iberoamericana de Información Científica. Buenos Aires, Argentina, jan., 2005.

BERINGHS, E. M.; GALLO P. R.; REIS, A. A. Declarações de nascidos mortos no Município de São Paulo: avaliação descritiva do preenchimento. Revista Brasileira de Saúde Materno Infantil, Recife, v. 8, n. 3, p. 319-23, jul./set., 2008.

BRITO, G. S. Farmacologia Humana da Hoasca (chá preparado de plantas alucinógenas usado em contexto ritual no Brasil) In: LABATE, B. C.; ARAÚJO, W. S. (orgs). O uso ritual da Ayahuasca. Campinas: editora Mercado das Letras, 2002.

BUChIllet, D. Saúde e Povos Indígenas. Cadernos de Saúde Pública, Rio de Janeiro, v. 11, n. 2, p. 338-341, 1995.

BUCHILLET, D. Bibliografia crítica da saúde indígena no Brasil (1844 - 2006). Quito, Equador: editora Abya-Yala, 2007.

CAETANO, J. R. M.; BORDIN, I. A. S.; PUCCINI, R. F.; PERES, C. A.. Fatores associados à internação hospitalar de crianças menores de cinco anos, São Paulo, SP. Revista de Saúde Pública, São Paulo, v. 36, n. 3, p. 285-91, 2002. 
CAMPOS, G. J. V.; FILHO, S. A. R.; SILVA, A. A. M.; NOVOCHADIO, M. A. S.; SILVA, R. A.; GALVÃO, C. E. S. Morbimortalidade infantil por diarréia aguda em área metropolitana da região Nordeste do Brasil, 1986-1989*. Revista de saúde Pública, São Paulo, v. 29, n. 2, p.132-39, 1995.

CARDOSO, A. M.; SANTOS, R. V.; COIMBRA JUNIOR, C. E. A. Mortalidade infantil segundo raça/cor no Brasil: o que dizem os sistemas nacionais de informação? Cadernos de Saúde Pública, Rio de Janeiro, v. 21, n. 5, p.1602-608, set./out., 2005.

CARVALHO, M. S.; d'ORSI, E.; PRATES, E. C.; TOSCHI, W. D. M.; SHIRAIWA, T.; CAMPOS, T. P.; ELL, E.; GARCIA, N. L.; JUNQUEIRA, A. P.; SERRÃO, S. A.; TAVARES, E. L. A. Demanda ambulatorial em três serviços da rede pública do Município do Rio de Janeiro, Brasil. Cadernos de Saúde Pública, Rio de Janeiro, v. 10, n. 1, p. 17-29, jan./mar., 1994.

CESAR, C. L. G., FIGUEIREDO, G. M., WESTPHAL M. F., CARDOSO, M. R. A., COSTA, M. Z. A.; GATTÁS, V. L. Morbidade referida e utilização de serviços de saúde em localidades urbanas brasileiras: metodologia. Revista de Saúde Pública, São Paulo, v. 30, n. 2, p. 153-60, 1996.

COIMBRA JUNIOR, C. E. A.; SANTOS, R. V. Saúde, minorias e desigualdade: Algumas teias de inter-relações, com ênfase nos povos indígenas. Ciência \& Saúde Coletiva, Rio de Janeiro, v. 5, p. 125-132, 2000. 
. Perfil epidemiológico da população indígena no Brasil: considerações gerais. In: GOLDBAUN, M. (org.). Perfil epidemiológico da população brasileira. Brasília: editora CENEPI, 2001.

COIMBRA JUNIOR, C. E. A.; SANTOS, R. V, FLOWERS, N. M.. Hepatitis B epidemiology and cultural pratices in Amerindian populations of Amazônia: The Tupi-Mondé and the Xavante of Rondônia and Mato Grosso. Social Science and Medicine, vol. 42, p. 1738-1743, 1996.

CUNHA, M. C. Introdução a uma história indígena. In: CUNHA, M. C. (org) História dos índios do Brasil. São Paulo: editora Companhia das Letras, p. 9-24, 1992.

DATASUS. Departamento de Informática do SUS. Ministério da Saúde.

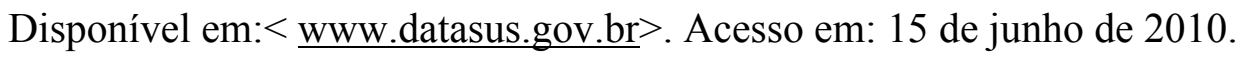

ESCOBAR, A L.; RODRIGUES, A. F.; ALVES, C. L. M; ORELlANA, J. D. Y.; SANTOS, R. V.; COIMBRA JUNIOR, C. E. A. Causas de internação hospitalar indígena em Rondônia. O Distrito Sanitário Especial Indígena Porto Velho (19982001) In: COIMBRA JUNIOR, C. E. A; SANTOS, R. V.; ESCOBAR, A. L. (org.). Epidemiologia e saúde dos povos indígenas no Brasil. Rio de Janeiro: editora Fiocruz, 2003. 
FUNAI. Lei 6.001 - Estatuto do Índio. Publicado no Diário Oficial da União em 21 de dezembro 1973.

FUNASA. Relatório anual Dsei Alto Purus. Rio Branco, 2005.

. Relatório anual Dsei Alto Purus. Rio Branco, 2006a.

_. Projeto: valorização e adequação dos projetos de parto tradicionais das etnias indígenas do Acre e do sul do Amazonas. Florianópolis e São Paulo, 2006b.

. Fundação Nacional de Saúde. Saúde Indígena. Disponível em: $<$ http://www.funasa.gov.br $>$ Acesso em: 24 junho 2008.

GARNELO, L.; MACEDO, G.; BRANDÃO, L.C. Os povos indígenas e a construção das políticas de saúde no Brasil. Brasília: Organização Pan-Americana da Saúde, 2003.

GARNELO, L.; BRANDÃO L.C., G.; LEVINO A. Dimensões e potencialidades dos sistemas de informação geográfica na saúde indígena. Revista de Saúde Pública, São Paulo, v. 39, n. 4, p. 634-40, 2005.

GOMES, M. P. Os Índios e o Brasil: Ensaio Sobre um Holocausto e Sobre uma Nova Possibilidade de Convivência. Petrópolis: editora Vozes, 1988. 
GONÇALVES, L. J. M. Entre culturas: uma experiência de intermediação em saúde indígena. Dissertação (Mestrado em Saúde Pública) - Faculdade de Saúde Pública, Universidade de São Paulo, São Paulo. 2007.

GUERRA, J. A. O.; BARROS, M. L.; FÉ, N. F.; GUERRA, M. V. F.; CASTELlON, E.; PAES, M. G.; SHERLOCK, I. A. Leishmaniose visceral entre índios no Estado de Roraima, Brasil. Aspectos clínicoepidemiológicos de casos observados no período de 1989 a 1993. Revista da Sociedade Brasileira de Medicina Tropical, Uberaba, v. 37, n. 4, 2004.

GUGELMIN, S. A.; SANTOS, R. V.; LEITE, M. S. Physical growth of five to ten year old Xavante indian children in Mato Grosso. Jornal de Pediatria, Rio de Janeiro, v. 77, n. 1, 2001.

IANELLI, R. V., COIMBRA JUNIOR, C. E. A. \& SANTOS, R. V. Perfil de morbimortalidade entre os índios Xavante de Mato Gross. Revista da Sociedade Brasileira de Medicina Tropical, Uberaba, v. 29, 1996. Suplemento 1.

ISA. Instituto Socioambiental. Disponível em <http://www.socioambiental.org>. Acesso em: 25 novembro 2008.

ISHAK, M. O. G.; ISHAK, R. O impacto da infecção por Chlamydia em populações indígenas da Amazônia brasileira. Caderno de Saúde Pública, Rio de Janeiro, v. 17, n. 2, 2001 . 
LEONE, C. ; GALLO, P. R. . Crescimento da Criança e do Adolescente. In: SILVA, L., R. (Org.). Diagnóstico em Pediatria. Rio de Janeiro: editora Guanabara Koogan S.A., p. 153-163, 2009.

LIMA, A. C. S. L. Um grande cerco de paz. Poder tutelar, indianidade e formação do Estado no Brasil. Petrópolis: editora Vozes, 1995.

LOTUFO, M., DUARTE, E., C. Avaliação dos serviços de saúde do Município de Cárceres, MT (Brasil): contribuições à programação local. Revista de Saúde Pública, São Paulo, v. 21, n. 5, p. 427-38, 1987.

LUNARDI, R.; SANTOS, R. V.; COIMBRA JUNIOR, C. E. A. Morbidade Hospitalar de Indígenas Xavante, Mato Grosso, Brasil (2000-2002). Revista Brasileira de Epidemiologia , São Paulo, v. 10, n. 4, p. 441-452, 2007.

MARTINS, S., J.; MENEZES, R. C. Evolução do estado nutricional de menores de cinco anos em aldeias indígenas da tribo Parakanã, na Amazônia Oriental Brasileira (1989-1991). Revista de Saúde Pública, São Paulo, v. 28, n. 1, 1994.

MARCONDES, E. Pediatria básica. São Paulo: editora Sarvier, 1994.

MEDICI, A., C.; BELTRÃO, K., I. Transição Demográfica no Brasil, uma agenda para pesquisa. IV Conferencia Latinoamericana de Poblacion, Cidade do México, 1993. 
MINDLIN, B. Amor e ruptura na aldeia indígena. In: PORCHAT, I. ; NETO, A. N. (org.). Amor, casamento e separação: a falência de um mito. São Paulo: editora Brasiliense, 1992.

MODESTO, M. G.; MOREIRA, E. C.; ALMEIDA-FILHO, N. Reforma Sanitária e Informação em Saúde: Avaliação dos registros Médicos em um Distrito Sanitário de Salvador, Bahia. Cadernos de Saúde Pública, Rio de Janeiro, v. 8, n. 1, p. 62-68, jan./mar., 1992.

OMRAM, A., R. The epidemiologic transition: a theory of the epidemiology of population change. The Milbank Quarterly, v. 83, n. 8, p. 731-57, 2005.

OMS (Organização Mundial da Saúde). Classificação Estatística Internacional de Doenças e Problemas Relacionados à Saúde. $10^{\mathrm{a}}$ revisão. São Paulo: Centro Colaborador da OMS para a Classificação de Doenças em Português, Faculdade de Saúde Pública, Universidade de São Paulo, 1995.

OPAS (Organización Panamericana de la Salud). La salud de los pueblos indígenas. La salud em las Américas. Publicación Científica n. 569. v. 1, p. 95-105. Washington DC : OPAS, 1998.

ORELLANA, J. D. Y.; COIMBRA JUNIOR, C. E. A . Nutritional status and anemia in Suruí Indian children, Brazilian Amazon. Jornal de Pediatria, Rio de Janeiro, v. 82, n. 5, p. 383-88, 2006. 
ORELLANA, J. D. Y.; BASTA P. C.; SANTOS R. V.; COIMBRA JUNIOR, C. E. A . Morbidade hospitalar em crianças indígenas Suruí menores de dez anos, Rondônia, Brasil: 200 a 2004. Revista Brasileira de Saúde Materno Infantil , Recife, v. 7, n. 3, p. 281-287, jul./set., 2007.

PAGLIARO, H.; AZEVEDO, M. M.; SANTOS, R. V. Demografia dos povos indígenas do Brasil: um panorama crítico. In: PAGLIARO, H.; AZEVEDO, M. M.; SANTOS, R. V. (org.). Demografia dos povos indígenas do Brasil. Rio de Janeiro: editora Fiocruz, 2005.

PINHEIRO, R. S.; VIACAVA, F.; TRAVASSOS, C.; BRITO, A. S. Gênero, morbidade, acesso e utilização de serviços de saúde no Brasil. Ciência \& Saúde Coletiva, Rio de Janeiro, v. 7, n. 4, p. 687-707, 2002.

PRATA, P., R. A transição epidemiológica no Brasil. Cadernos de saúde Pública, Rio de Janeiro, v. 8, n. 2, p. 168-75, 1992.

RICARDO, C. A. A sociodiversidade nativa contemporânea no Brasil. In: RICARDO, C. A. (org). Povos Indígenas no Brasil. São Paulo: Instituto Socioambiental, 1996.

RIOS, L.; CUTOLO, S. A.; GIATTI, L. L.; CASTRO, M.; ROCHA, A. A.; TOLEDO, R. F.; PELICIONI, M. C. F; BARREIRA, L. P.; SANTOS, J. G. Prevalência de Parasitos Intestinais e Aspectos Socioambientais em Comunidade 
Indígena no Distrito de Iauaretê, Município de São Gabriel da Cachoeira (AM), Brasil. Saúde e Sociedade, São Paulo, v. 16, n. 2, p. 76-86, 2007.

SALDANHA,C. T.; SILVA, A., M., C.; BOTELHO, C. Variações climáticas e uso de serviços de saúde em crianças asmáticas menores de cinco anos de idade: um estudo ecológico. Jornal Brasileiro de Pneumologia, Brasília, DF, v. 31, n. 6, p. 492-98, 2005.

SANTOS, R. V.; Crescimento físico e estado nutricional de populações indígenas brasileiras. Cadernos de Saúde Pública, Rio de Janeiro, v. 9, p. 46-57, 1993. Suplemento 1 .

SANTOS, R. V.; COIMBRA JÚNIOR, C. E. A. Cenários e tendências da saúde e da epidemiologia dos povos indígenas do Brasil. In: COIMBRA JUNIOR, C. E. A; SANTOS, R. V.; ESCOBAR, A. L. (org.). Epidemiologia e saúde dos povos indígenas no Brasil. Rio de Janeiro: editora Fiocruz, 2003.

SCHRAMM, F., R.; CASTIEL, L., D. Processo Saúde/Doença e Complexidade em Epidemiologia. Cadernos de Saúde Pública, Rio de Janeiro, v. 8, n. 4, p. 370-90, 1992.

SILVA, J., A. Avaliação da TRO em Nova Friburgo-RJ após 18 meses de sua implantação. Jornal de Pediatria, Rio de Janeiro, v. 65, n.8, p. 302-08, 1989. 
SILVÉRIO, A. Perfil dos pacientes internados na Divisão de Pediatria do Hospital Universitário da UFSC. Arquivos Catarinenses de Medicina, Florianópolis, v. 26, n. 1- 4, p. 31-5, jan./dez., 1997.

SOBRAL, C. A.; AMENDOEIRA, M. R. R.; ANTONIO TEVA, A.; PATEL, B. N.; KLEIN, C. H. Seroprevalence of infection with toxoplasma gondii in indigenous brazilian populations American Journal of Tropical Medicine and Hygiene, Ohio, EUA, v. 72, n. 1, 2005.

SOUZA-SANTOS, R. Distribuição sazonal de vetores da malária em Machadinho d'Oeste, Rondônia, Região Amazônica, Brasil. Cadernos de Saúde Pública, Rio de Janeiro, v. 18, n. 6, p. 1813-18, nov./dez., 2002.

SPITZ, R, A. O primeiro ano de vida. São Paulo: editora Martins Fontes, 1980.

TANAKA, A., C., A.; SIQUEIRA, A.,A., F.; BAFILE, P., N. Situação de saúde materna e perinatal no Estado de São Paulo, Brasil. Revista de Saúde Pública, São Paulo, vol. 23, n. 1, p. 67-75, 1989.

UCHOA, M. L. (org.). Índios no Acre, História e Organização. Rio Branco: Comissão Pró Índio, 2003.

VÁZQUEZ, M., L.; MOSQUEIRA, M.; CUEVAS, L. E.; GONZÁlES, E., S.; VERAS, I., C., L.; LUZ, E., O.; FILHO, M., B.; GURGEL, R. Q. Incidência e 
fatores de risco de diarréia e infecções respiratórias agudas em comunidades urbanas de Pernambuco, Brasil. Cadernos de Saúde Pública, Rio de janeiro, vol. 15, n. 1, p. 163-71, 1999.

VINNYA, A. L.; TEIXEIRA, G. A.; UCHOA, M. L. P. (org.). Costumes e Tradições do Povo Yawanawá. Belo Horizonte: FALE/UFMG : SECAD/MEC, 2007.

YAZLLE ROCHA, J. S. \& NOGUEIRA, J. L. Padrões de morbidade em assistência primária na Região de Ribeirão Preto, SP (Brasil). Revista de Saúde Pública, São Paulo, v. 19, p. 215-24, 1985. 


\section{ANEXO - 1: PRONTUÁRIO DA CASAI}

\section{Ministério da Saúde}

Fundação Nacional de Saúde

Coordenação Regional do Acre

Departamento de Saúde Indigena

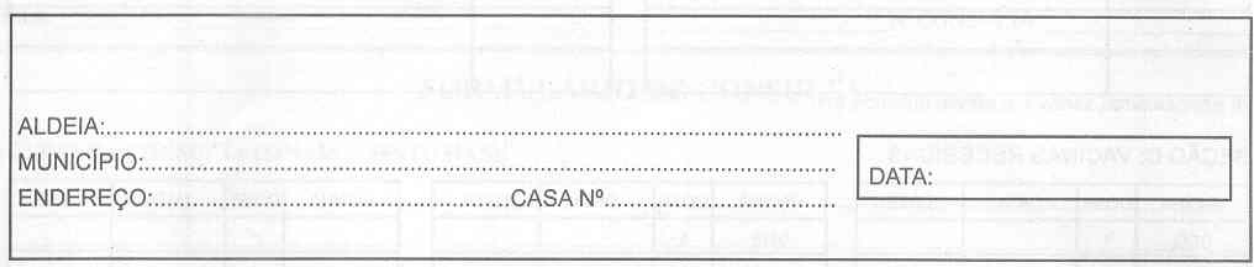

PRONTUÁRIO N

SEÇÃO A: DADOS DE IDENTIFICAÇÃO DO PACIENTE

POVO (ETNIA):

NOME COMPLETO

OUTRO NOME:

OUTRO NOME

DATA DE NASCIMENTO

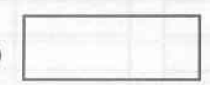

IDADE

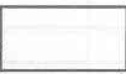

REAL

ESTIMADA SEXO

NOME DO PAI:

NOME DA MÃE:

NOME DO/A ESPOSO/A:

NOME DO/A ESPOSO/A

ALDEIA ONDE RESIDE:

PRINCIPAL ATIVIDADE DE TRABALHO OU SOBREVIVÊNCIA:

LINGUA MATERNA PORTUGUÊS:

FALA

LEE ESCREVE

SEÇÄO B: HISTORIA DE DOENÇAS:

\begin{tabular}{|l|l|l|l|}
\hline \multicolumn{1}{|c|}{ TIPO } & DATAS & MEDICAÇÃO ATUAL & SITUAÇĀOATUAL \\
\hline RUBÉOLA & & & \\
\hline PNEUMONIA & & & \\
\hline TBC & & & \\
\hline HANSENIASE & & & \\
\hline MALÁRIA & & & \\
\hline CHAGAS & & & \\
\hline LEISHMANIOSE & & & \\
\hline PARASTTAS & & & \\
\hline DST & & & \\
\hline AIDS & & & \\
\hline HIPERTENSÃOARTERIAL & & & \\
\hline DIABETES & & & \\
\hline ALCOOLISMO & & & \\
\hline TRANSTORNOS MENTAIS & & & \\
\hline CONVULSOES & & & \\
\hline & & & \\
\hline & & & \\
\hline & & & \\
\hline
\end{tabular}


REAÇÕES ADVERSAS OU ALÉRGICAS GRAVES (1)

DATA
\begin{tabular}{|l|l|}
\hline & \\
\hline & \\
\hline & \\
\hline & \\
\hline & \\
\hline
\end{tabular}

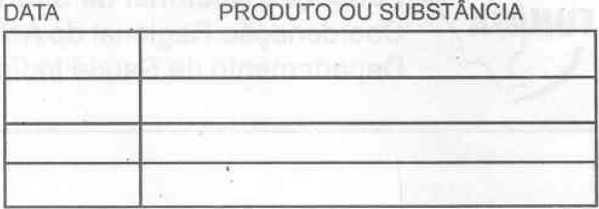

(1) MEDICAMENTOS, VACINAS, AUMENTO QUIMICOS, ETC.

SEÇÃO C: VACINAS RECEBIDAS

\begin{tabular}{|c|c|c|c|}
\hline VACINA & DOSE & DATA & LOTE \\
\hline BCG & 1 & & \\
\hline & 2 & & \\
\hline APO & 1 & & \\
\hline & 2 & & \\
\hline & 3 & & \\
\hline & 4 & & \\
\hline DTP & 1 & & \\
\hline & 2 & & \\
\hline & 3 & & \\
\hline & 4 & & \\
\hline VAS & 1 & & \\
\hline VFA & 1 & & \\
\hline & 2 & & \\
\hline
\end{tabular}

\begin{tabular}{|c|c|c|c|}
\hline VACINA & DOSE & DATA & LOTE \\
\hline VHB & 1 & & \\
\hline & 2 & & \\
\hline & 3 & & \\
\hline VHiB & 1 & & \\
\hline & 2 & & \\
\hline & 3 & & \\
\hline R & & & \\
\hline & & & \\
\hline & & & \\
\hline SR & & & \\
\hline & & & \\
\hline VTV & & & \\
\hline & & & \\
\hline
\end{tabular}

\begin{tabular}{|l|l|l|l|}
\hline VACINA & DOSE & DATA & LOTE \\
\hline & & & \\
\hline & & & \\
\hline & & & \\
\hline & & & \\
\hline & & & \\
\hline & & & \\
\hline & & & \\
\hline & & & \\
\hline & & & \\
\hline & & & \\
\hline & & & \\
\hline & & & \\
\hline & & & \\
\hline
\end{tabular}

SEÇÃO D: ENCAMINHAMENTO

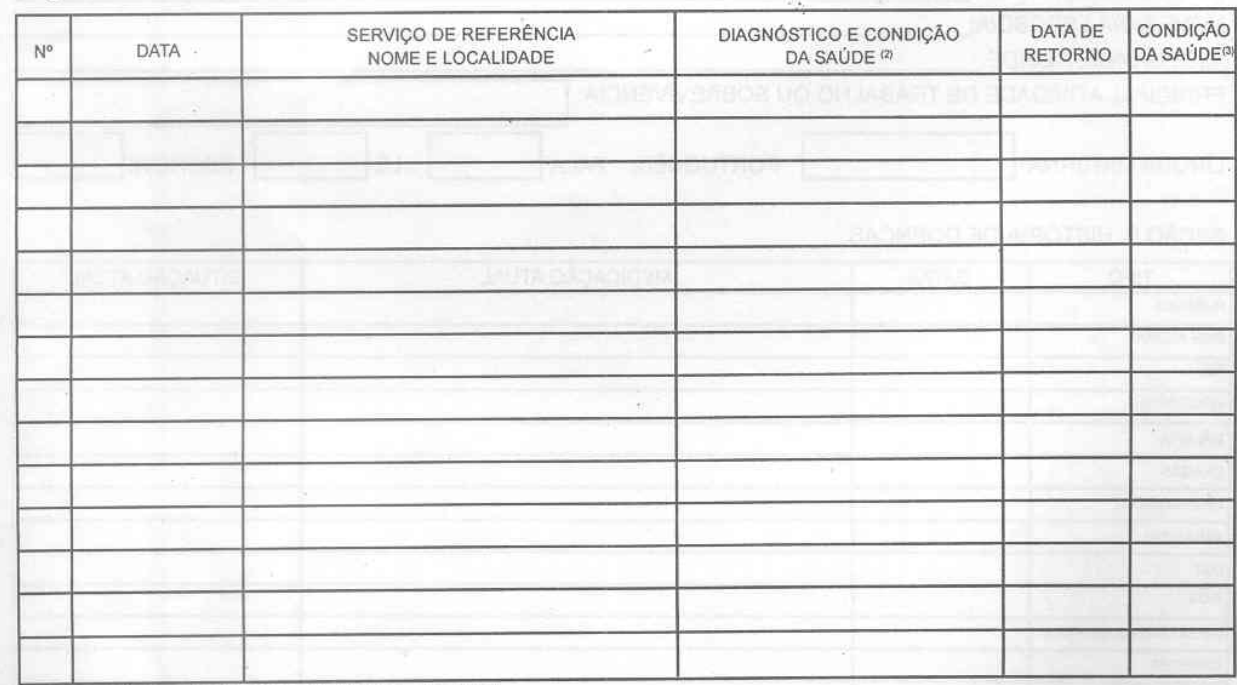

(2) $G=$ GRAVE, $R=$ REGULAR CM = CONSULTA MARCADA

(3) $C=C U R A D O, M=M E L H O R A D O, I=I G U A L, P=P I O R, O=O B I T O$

SEÇÃO E: ÓBITO

DATA DA MORTE

ATESTADO DE ÓBITO: SIM

NÃO

CAUSA DA MORTE

\begin{tabular}{|l}
\hline 1. \\
2.
\end{tabular}

SIASI - FORMULÁRIOS DE CONSULTAS - PÁGINA 
Ministério da Saúde

FUNASA Fundação Nacional de Saúde
Coordenação Regional do Acre

\begin{tabular}{ll} 
NOME COMPLETO: & DATA: \\
ALDEIA: & $N^{\circ}$ CONSULTA: \\
\hline
\end{tabular}

FORMULÁRIO DE CONSULTA

1. MOTIVO DA CONSULTA (SINAIS E SINTOMAS):

2. SUSPEITAS OU HIPÓTESE DIAGNÓSTICA

3. EXAME FÍSICO

PRESSÃO ARTERIAL
FREQUÊNCIA RESPIRATÓRIA

$\mathrm{mm} \mathrm{Hg}$ PULSO $\square$ bpm

Irpm ALTURA $\mathrm{m}$
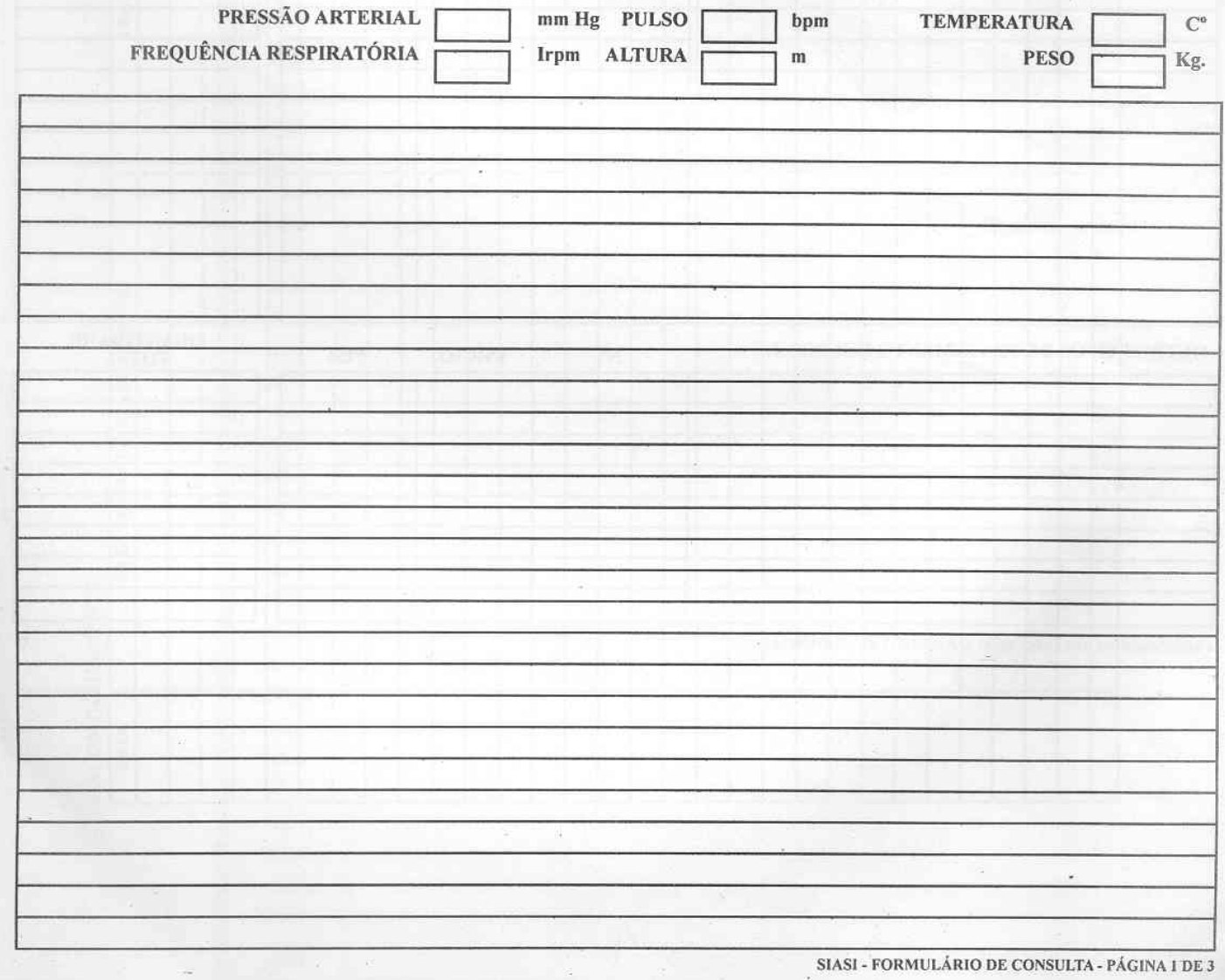
4. EXAMES DE LABORATÓRIO (TIPO E LUGAR)

\begin{tabular}{|l|l|l|}
\hline DATA & EXAME & RESULTADO \\
\hline & & \\
\hline & & \\
\hline & & \\
\hline & & \\
\hline & & \\
\hline & & \\
\hline & & \\
\hline & & \\
\hline & & \\
\hline & & \\
\hline & & \\
\hline & & \\
\hline
\end{tabular}

5. INDICAÇOEES DO TRATAMENTO

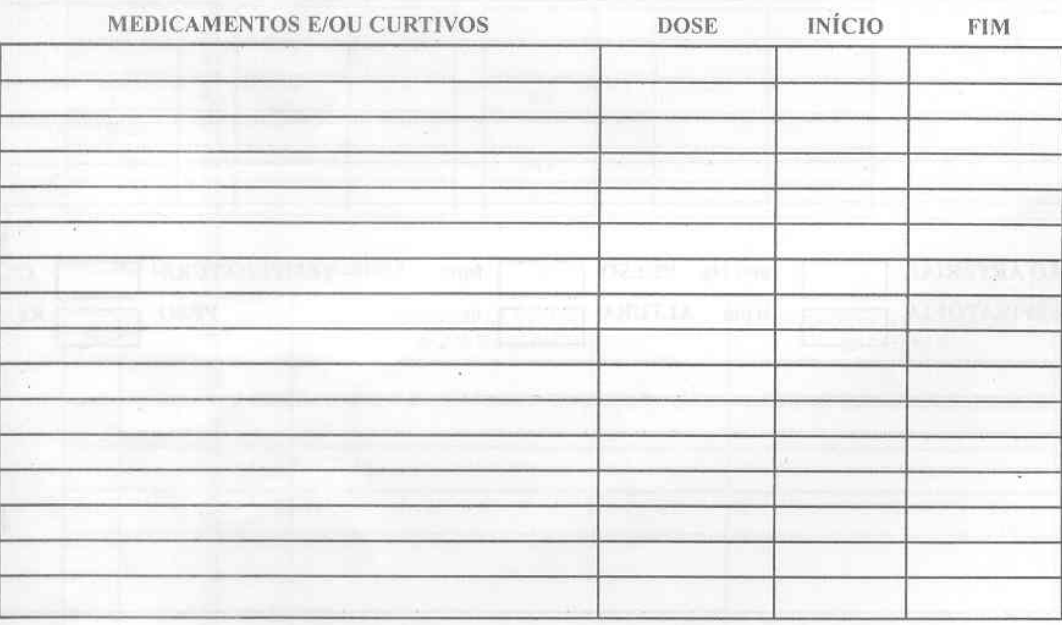

OUTROS TIPOS DE TRATAMENTO USADOS(4)

\begin{tabular}{|l|l|l|l|}
\hline & & & \\
\hline & & & \\
\hline & & & \\
\hline & & & \\
\hline & & & \\
\hline & & & \\
\hline & & & \\
\hline
\end{tabular}

T. MEDICAMENTOS POPULAKAS ERVAS. RITLALS DECUIRA CERIMONIAS ETC

QUANTIDADE

QUANTIDADE

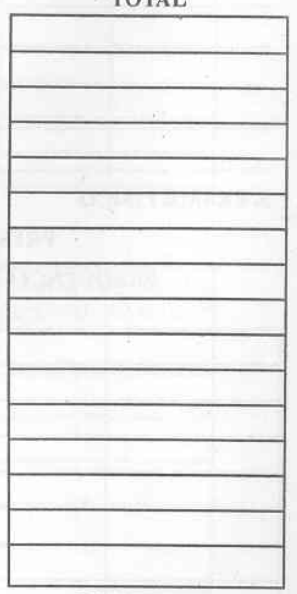

TOTAL

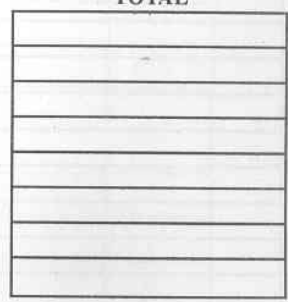

SIASI - FORMULÁRIO DE CONSULTA - PAGINA2 DE 


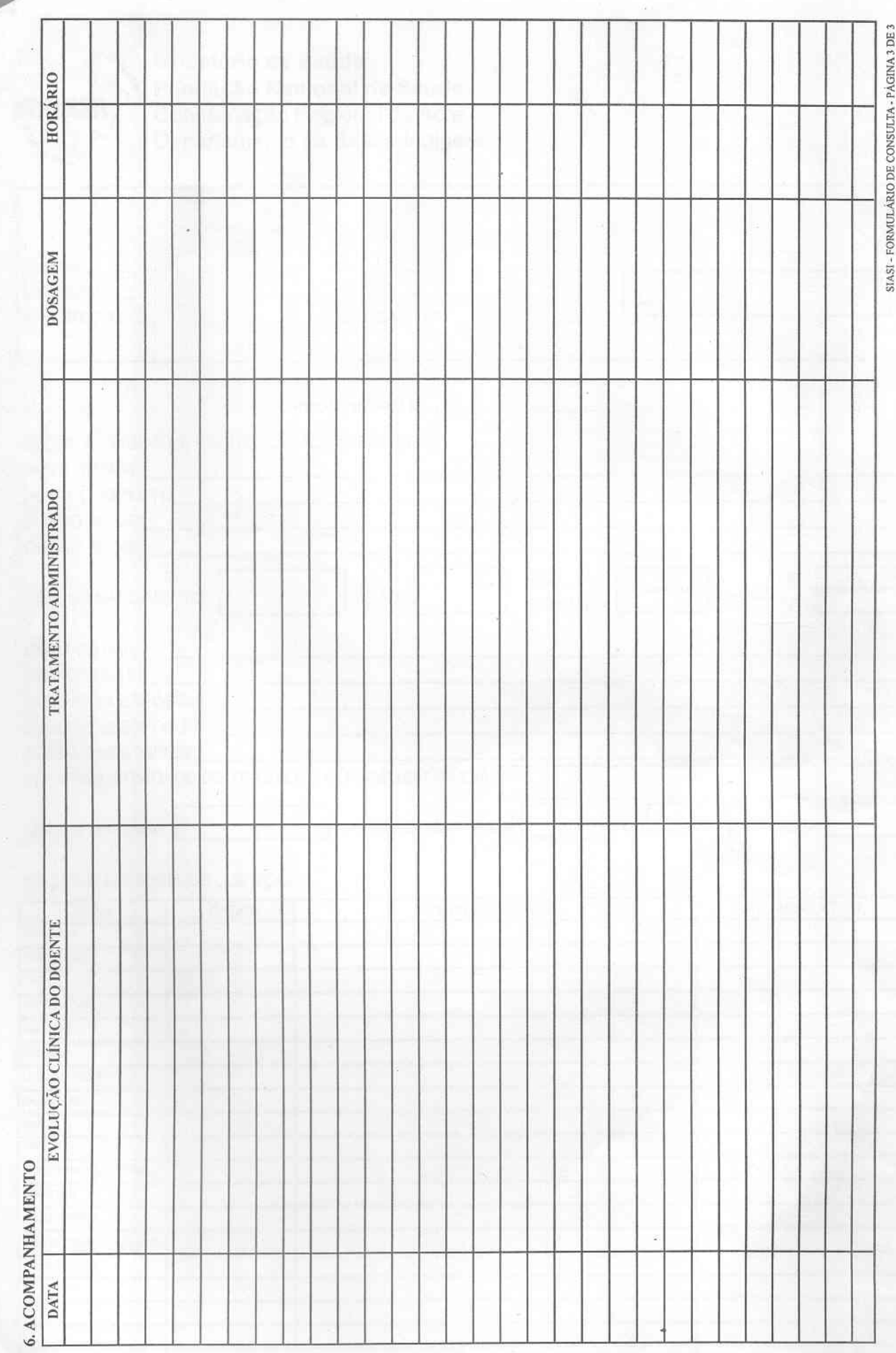




\begin{abstract}
ANEXO - 2
Instrumento de coleta de dados

PERFIL DE MORBIDADE DA POPULAÇÃO INDÍGENA INFANTIL REFERENCIADA PARA A CASA DE SAÚDE INDÍGENA DE RIO BRANCO
\end{abstract}

Nome:

No: letra:

Sexo:

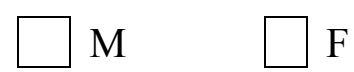

Data de nascimento: sem certidão:

Etnia:
Aldeado

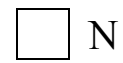
$\square \mathrm{S}$
Aldeia:

Pólo-base:

Estado:

Data de admissão na CASAI:

Idade de admissão na CASAI:

Data de alta CASAI: 1 $\mathrm{N}^{\mathrm{o}}$ dias na CASAI:

Causa da internação:

Hospital de internação:

Prontuário:

Data internação:

$1 \quad 1 \quad$ Data alta:
1

$\mathrm{N}^{\mathrm{o}}$ dias internado:

Causa da internação:

Patologias associadas:

Congênita

Adquirida
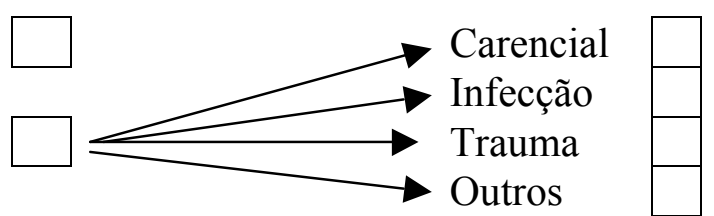

Hospital de internação:

Prontuário:

Data internação: data alta:

$\mathrm{N}^{\mathrm{o}}$ dias internado:

Causa da internação:

Patologias associadas: 


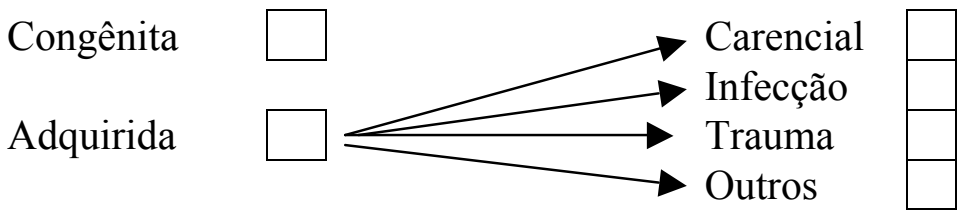

Hospital de internação:

Prontuário:

Data internação: I data alta:

No dias internado:

Causa da internação:

Patologias associadas:

Congênita

Adquirida

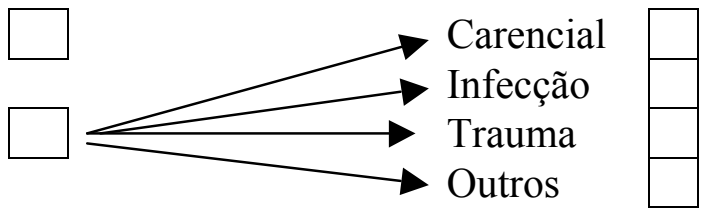

Cirurgia realizada:

Hospital:

especialidade: neuro

geral

Data:

ortopedia

\begin{tabular}{|r|r|}
\hline & plástica \\
vascular & \\
outros & \\
\hline
\end{tabular}

Cirurgia realizada:

Hospital:

especialidade: neuro

geral

Data:

ortopedia

\begin{tabular}{r|r|} 
plástica & \\
vascular & \\
outros &
\end{tabular}

Cirurgia realizada:

Hospital:

especialidade: neuro

geral

Data:

ortopedia

plástica

vascular outros

Obs: 
ANEXO - 3: PARECER DO CONEP

\section{PARECER $N^{\circ}$ 239/2008}

Registro CONEP: 14622 (Este $n^{\circ}$ deve ser eitado nas correspondências referentes a este projeto)

Registro no CEP: näo consta

Processo $n^{\circ}$ 25000.022756/2008-04 Projeto de Pesquisa: "Perfil de morbidades da populaçăo indigena infantil referenciada para Casa do Indio de Rio Branco".

Pesquisador Responsável: Dra. Femanda Lage Lima Dantas Instituiçáo: Casa de Saúde do Índio de Rio Branco - CASAI

CEP de origem: CEP/Fundação Hospital Estadual do Acre

Area Temática Especial: População indígena

Patrocinador: náo se aplica

Sumário geral do protocolo

A populaçäo indigena brasileira apresenta um quadro de saúde caracterizado por alta ocorrência de doenças infecto-contagiosas e relacionadas a baixas condiçóes de saneamento ambiental, assim como alta prevalência de anemia e desnutrição. Ressalta-se ainda que os indicadores de saúde da populaçäo indigena do Acre são ainda piores, com índice de mortalidade infantil quase três vezes maior que o encontrado para o restante do país. Aproximadamente $50 \%$ da população indigena é menor que 15 anos de idade com elevado o índice de natalidade.

A assistência d̀ saúde indigena é responsabilidade da FUNASAMS que dividiu o país em trinta e quatro Distritos Sanitário Especial Indigena - DSEls, sendo cada um composto de vários postos de saúde nas aldeias, ligados a um pólo base e à Casa de Saúde do índio-CASAl.

A CASAI funciona como unidade de apoio ao tratamento de saúde na rede referenciada do Sus, e fica localizada geralmente na principal cidade da regiāo. A CASAl de Rio Branco recebe todos os indígenas referenciados do DSEI do Alto Purus $\theta$ do DSEI do Alto Juruá, abrangendo a totalidade do território do Acre e também regiōes vizinhas.

Nesse contexto e se propondo a contribuir com os estudos da saúde dos povos indígenas, a presente pesquisa tem como objetivo principal, descrever e analisar a ocorrencia das morbidades na populaçāo indigena infantil referenciada para Casa do índio de Rio Branco, englobando os DSEI do Alto Purus e do Alto Juruá, no periodo compreendido de janeiro de 2003 a dezembro 2007. Propöe-se ainda descrever a populaçāo estudada no que se refere às suas caracteristicas biológicas (sexo, idade) e sócio-culturais (aldeado ou năo, etnia, aldeia, município), local, tempo e causa de internação; classificar as morbidades segundo etiologia (congénita ou adquirida, trauma, infeccão), e segundo aparelhos e sistemas conforme classificação internacional de doenças CID 10; descrever as morbidades secundárias mais encontradas na população; a freqüência da necessidade de intervençăo cirúrgica, as patologias encontradas e classificar a especialidade da cirurgia realizadá (neurocirúrgica, pediátrica, ortopédica, plástica, buco-maxilar, etc); descrever ainda as complicacóes ocorridas e o desfecho do caso (favorável, desfavorável, óbito); comparar os indicadores de saúde dos DSEls entre si, e com aqueles encontrados na populaçăo nãoindígena das macro-regióes e unidades federadas que sediam os DSEIs; aferir a qualidade dos dados coletados nas respectivas instituicōes.

Caracteriza-se como estudo epidemiológico seccional descritivo e retrospectivo. Serăo estudados os dados secundários obtidos a partir dos prontuários das crianças até dez anos incompletos admitidas na CASAI de Rio Branco e também os prontuários hospitalares das unidades de internaçáo por onde essas crianças passaram no periodo de janeiro de 2003 a dezembro 2007 . Esse limite de cinco anos é devido o tempo que o prontuário hospitalar fica disponível para consultas com acesso facilitado.

Serāo coletados, também, dados gerais sobre a população indígena atendida pelos DSEls do Alto Purus e do Alto Juruá, disponiveis na forma de relatórios anuais elaborados pela FUNASA 
Cont Parest CONEP 239raos.

do Acre. Os inatrumentos de coleta de dados as varietveis a serem estudadas encontram-be anexadog e descritas devidamente.

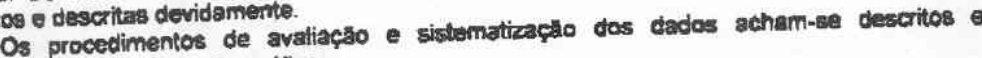
justificados 08 parametros de analise.

\section{Local do reallzagilo}

A peaguian in dos livros de registros e prontudrios enquanto que a Santa Juliann onde sera coletados serb́o realizadas na UFAC \& USP.

análise e eiztematizaghio dos

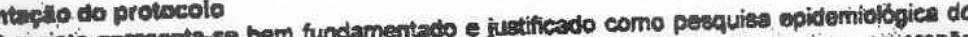
O projeto apresenta-se bem fundamentado e justificado como pesquiza opideniojogjea do

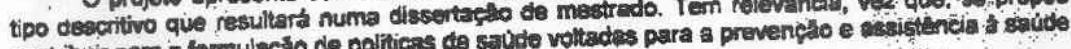
contribuir para a formulaça de políticas de saude

da populacho indigens infantil do Estado do Acre. o orçamento-apresentado estima ums despess tecal no valor da Rs

cinquenteg reaib) relativo ao material de consumo que sera assumse peta pesidos ad protocolo.

Os currículos da pesquisadors e de oriented or encontram-se anexsidos

\section{R Reiomendacónes}

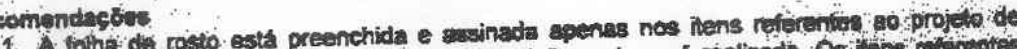

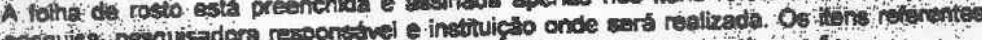

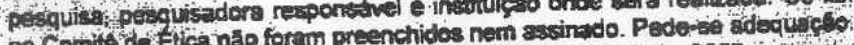

ao Comite de Eticanalo foram preenchides nem assinado. Pedorse sday cofolusto finat em

2. O cronograma estabelece o inicio de pesquisa em abri de 2008 e concusao ina outulur de 2009 . Solicita-se que o cronegrams seja atualizad

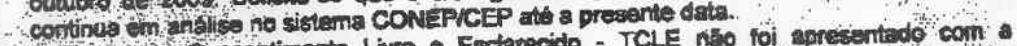

3. O Termo de Consentimento Livre Esclarecido - TCLE niso foi apresentado Com a

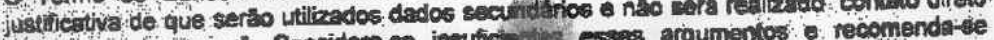

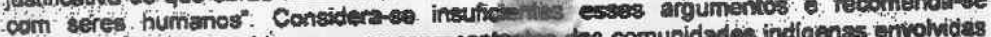

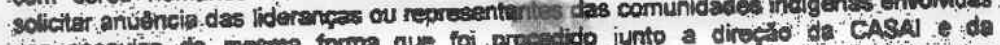
nas pesquiga da mesma forma que foi proesclido junto a dirojto ds. CAsal do

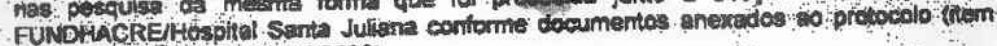
iv: 1 da Resoluca cNS $304 / 2000$ ).

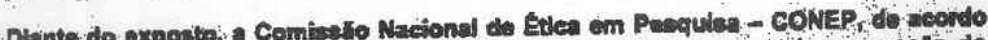

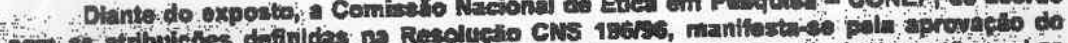

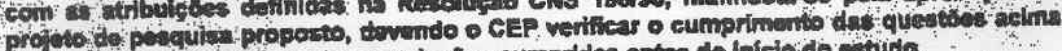

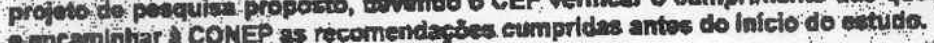

Situesto: Protocolo aprovede cem rieenendapilo.

Braslitis 20 de maio de 2008

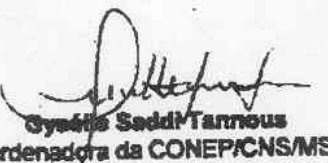

cocordenadgre da CONEPRCNSMS 


\section{ANEXO - 4 \\ TERMO DECONSENTIMENTO LIVRE E ESCLARECIDO}

Título do Projeto: PERFIL DE MORBIDADE DA POPULAÇÃO INDÍGENA INFANTIL REFERENCIADA PARA A CASA DE SAÚDE INDÍGENA DE RIO BRANCO Pesquisador Responsável: Fernanda Lage Lima Dantas

Este projeto tem o objetivo de traçar um perfil das morbidades (doenças) mais freqüentes nas crianças indígenas menores que 10 anos de idade encaminhadas para a Casa do Índio de Rio Branco entre 2003 e 2007, buscando relacionar com sua idade, etnia e local de moradia.

Para tanto será necessário realizar os seguintes procedimentos: analisar os prontuários de internação destas crianças na Casa do Índio de Rio Branco e nos hospitais, para colher dados sobre as crianças e as doenças.

Durante a execução do projeto serão analisados somente os dados existentes nos registros das instituições, não havendo qualquer contato com as crianças, ou risco de causar qualquer prejuízo para as crianças indígenas. Será preservado o sigilo das informações individuais, trabalhando-se com o grupo como um todo.

Após ler e receber explicações sobre a pesquisa, e ter meus direitos de:

1. receber resposta a qualquer pergunta e esclarecimento sobre os procedimentos, riscos, benefícios e outros relacionados à pesquisa;

2. retirar o consentimento a qualquer momento e deixar de participar do estudo;

3. não ser identificado e ser mantido o caráter confidencial das informações relacionadas à privacidade.

4. procurar esclarecimentos com o Comitê de Ética em Pesquisa da Faculdade de Saúde Pública da Universidade de São Paulo, no telefone 11 3061-7779 ou Av. Dr. Arnaldo, 715 - Cerqueira César, São Paulo - SP, em caso de dúvidas ou notificação de acontecimentos não previstos.

Declaro estar ciente do exposto e desejar que meu povo seja incluído na

pesquisa.

Rio Branco, de de

Nome da liderança responsável:

Etnia/aldeia: 
Assinatura:

Eu, Fernanda Lage Lima Dantas, declaro que forneci todas as informações referentes ao projeto ao participante e/ou responsável.

Telefone : (68) 8113-1148

Data:

- 
ANEXO - 5: TABELA COM TODOS OS CÓDIGOS DA CLASSIFICAÇÃO INTERNACIONAL DE DOENÇAS 10 REVISÃO (CID 10) ENCONTRADOS NA PESQUISA.

\begin{tabular}{|c|c|c|}
\hline CID principal & $\mathbf{N}$ & $\%$ \\
\hline Sem informação & 161 & 23,2 \\
\hline A09 & 53 & 7,6 \\
\hline A16 & 5 & 0,7 \\
\hline A37 & 1 & 0,1 \\
\hline A63 & 3 & 0,4 \\
\hline A63.0 & 6 & 0,9 \\
\hline A71 & 1 & 0,1 \\
\hline B01 & 1 & 0,1 \\
\hline B15 & 5 & 0,7 \\
\hline B16 & 1 & 0,1 \\
\hline B19 & 2 & 0,3 \\
\hline B37.3 & 1 & 0,1 \\
\hline B37.7 & 1 & 0,1 \\
\hline B41 & 4 & 0,6 \\
\hline B50 & 4 & 0,6 \\
\hline B51 & 3 & 0,4 \\
\hline B54 & 22 & 3,2 \\
\hline B58 & 4 & 0,6 \\
\hline B83.9 & 12 & 1,7 \\
\hline B86 & 3 & 0,4 \\
\hline $\mathrm{C} 95$ & 10 & 1,4 \\
\hline D18 & 2 & 0,3 \\
\hline D53.9 & 21 & 3,0 \\
\hline D69 & 5 & 0,7 \\
\hline E03 & 1 & 0,1 \\
\hline E25 & 5 & 0,7 \\
\hline $\mathrm{E} 43$ & 5 & 0,7 \\
\hline E46 & 12 & 1,7 \\
\hline E86 & 1 & 0,1 \\
\hline G00 & 1 & 0,1 \\
\hline G04 & 1 & 0,1 \\
\hline G40 & 10 & 1,4 \\
\hline G80 & 13 & 1,9 \\
\hline G93.2 & 1 & 0,1 \\
\hline $\mathrm{H} 10$ & 5 & 0,7 \\
\hline H52 & 2 & 0,3 \\
\hline H66 & 13 & 1,9 \\
\hline I00 & 1 & 0,1 \\
\hline I01 & 1 & 0,1 \\
\hline I09.9 & 1 & 0,1 \\
\hline
\end{tabular}




\begin{tabular}{|c|c|c|}
\hline CID principal & $\mathbf{N}$ & $\%$ \\
\hline $\mathrm{I} 27.0$ & 1 & 0,1 \\
\hline I50 & 2 & 0,3 \\
\hline J02 & 1 & 0,1 \\
\hline J03.9 & 1 & 0,1 \\
\hline J06.9 & 29 & 4,2 \\
\hline $\mathrm{J} 18$ & 76 & 10,9 \\
\hline $\mathrm{J} 20$ & 3 & 0,4 \\
\hline $\mathrm{J} 21$ & 2 & 0,3 \\
\hline J45 & 3 & 0,4 \\
\hline K04 & 4 & 0,6 \\
\hline $\mathrm{K} 40$ & 4 & 0,6 \\
\hline K62.3 & 1 & 0,1 \\
\hline K73 & 1 & 0,1 \\
\hline L02.3 & 1 & 0,1 \\
\hline L08 & 12 & 1,7 \\
\hline L10 & 11 & 1,6 \\
\hline L30 & 1 & 0,1 \\
\hline M86 & 2 & 0,3 \\
\hline N04 & 3 & 0,4 \\
\hline N05 & 1 & 0,1 \\
\hline N10 & 6 & 0,9 \\
\hline N43 & 1 & 0,1 \\
\hline N47 & 1 & 0,1 \\
\hline P07.3 & 2 & 0,3 \\
\hline P36 & 1 & 0,1 \\
\hline P37.1 & 1 & 0,1 \\
\hline Q01 & 2 & 0,3 \\
\hline Q02 & 1 & 0,1 \\
\hline Q03 & 8 & 1,2 \\
\hline Q04 & 3 & 0,4 \\
\hline Q04.9 & 7 & 1,0 \\
\hline Q05 & 4 & 0,6 \\
\hline Q21 & 1 & 0,1 \\
\hline Q24.9 & 5 & 0,7 \\
\hline Q25.0 & 4 & 0,6 \\
\hline Q34.9 & 1 & 0,1 \\
\hline Q36 & 1 & 0,1 \\
\hline Q37 & 11 & 1,6 \\
\hline Q64.4 & 1 & 0,1 \\
\hline Q66 & 9 & 1,3 \\
\hline Q80 & 3 & 0,4 \\
\hline R04 & 1 & 0,1 \\
\hline R07 & 1 & 0,1 \\
\hline R10 & 2 & 0,3 \\
\hline R11 & 1 & 0,1 \\
\hline R17 & 2 & 0,3 \\
\hline R19.0 & 1 & 0,1 \\
\hline
\end{tabular}




\begin{tabular}{lrr} 
CID principal & N & \% \\
\hline R50 & 2 & 0,3 \\
R51 & 1 & 0,1 \\
R55 & 1 & 0,1 \\
R56 & 2 & 0,3 \\
R58 & 1 & 0,1 \\
S00.9 & 2 & 0,3 \\
S02.6 & 1 & 0,1 \\
S05 & 2 & 0,3 \\
S09.9 & 1 & 0,1 \\
S22 & 1 & 0,1 \\
S42 & 10 & 1,4 \\
S43 & 1 & 0,1 \\
S61 & 1 & 0,1 \\
S72 & 1 & 0,1 \\
S79 & 1 & 0,1 \\
S82 & 3 & 0,4 \\
S92 & 1 & 0,1 \\
T07 & 5 & 0,7 \\
T16 & 2 & 0,3 \\
T17 & 1 & 0,1 \\
T20 & 1 & 0,1 \\
T30 & 2 & 0,3 \\
X20 & 2 & 0,3 \\
X95 & 3 & 0,4 \\
X99 & 3 & 0,4 \\
\hline Total & 695 & $100 \%$ \\
\hline
\end{tabular}


ANEXO - 6: TABELAS COM TODAS AS ALDEIAS ENCONTRADAS NA PESQUISA.

\begin{tabular}{|c|c|c|}
\hline Nome da aldeia & $\mathbf{N}$ & $\%$ \\
\hline indeterminada & 11 & 2,2 \\
\hline 18 Praias & 5 & 1,0 \\
\hline 7 de setembro & 1 & 0,2 \\
\hline Água Preta & 2 & 0,4 \\
\hline Água Viva & 2 & 0,4 \\
\hline Aldeia 27 & 1 & 0,2 \\
\hline Alto Bonito & 2 & 0,4 \\
\hline Alves Rodrigues & 4 & 0,8 \\
\hline Ananai & 8 & 1,6 \\
\hline Barrinha & 5 & 1,0 \\
\hline Belo Monte & 3 & 0,6 \\
\hline Betel & 12 & 2,4 \\
\hline Boa União & 1 & 0,2 \\
\hline Boa Vista & 1 & 0,2 \\
\hline Boca do Caramari & 1 & 0,2 \\
\hline Boca do Mamoadate & 5 & 1,0 \\
\hline Bom Jesus & 3 & 0,6 \\
\hline Brasiléia & 1 & 0,2 \\
\hline Buenos Aires & 7 & 1,4 \\
\hline Camapã & 3 & 0,6 \\
\hline Camarapú & 3 & 0,6 \\
\hline Camicuã & 13 & 2,6 \\
\hline Campina & 1 & 0,2 \\
\hline Capanã & 2 & 0,4 \\
\hline Cardoso & 1 & 0,2 \\
\hline Carolina & 1 & 0,2 \\
\hline Castanheira & 2 & 0,4 \\
\hline Caucho & 9 & 1,8 \\
\hline Centrinho & 1 & 0,2 \\
\hline Chaparral & 2 & 0,4 \\
\hline Cocameira & 1 & 0,2 \\
\hline Cocuaçu & 3 & 0,6 \\
\hline comunidade boliviana & 1 & 0,2 \\
\hline Cumarú & 1 & 0,2 \\
\hline Dois Irmãos & 2 & 0,4 \\
\hline Estirão Jaminawa & 5 & 1,0 \\
\hline Extrema & 23 & 4,5 \\
\hline Extrema Caetés & 6 & 1,2 \\
\hline Floresta & 1 & 0,2 \\
\hline Formoso & 3 & 0,6 \\
\hline Foz do Nilo & 1 & 0,2 \\
\hline
\end{tabular}




\begin{tabular}{|c|c|c|}
\hline Nome da aldeia & $\mathbf{N}$ & $\%$ \\
\hline Goiânia & 1 & 0,2 \\
\hline Grota & 1 & 0,2 \\
\hline Guajará & 11 & 2,2 \\
\hline Ipiranga & 1 & 0,2 \\
\hline Jagunço II & 2 & 0,4 \\
\hline Jatobá & 4 & 0,8 \\
\hline Kaiapucá & 14 & 2,8 \\
\hline Kanamari & 6 & 1,2 \\
\hline Katispero & 4 & 0,8 \\
\hline Lago Novo & 3 & 0,6 \\
\hline Laranjeira & 1 & 0,2 \\
\hline Lourdes & 1 & 0,2 \\
\hline Maloca & 1 & 0,2 \\
\hline Manhaê & 7 & 1,4 \\
\hline Maria Monteza & 2 & 0,4 \\
\hline Mariene & 2 & 0,4 \\
\hline Marmelinho & 39 & 7,7 \\
\hline Maronawa & 2 & 0,4 \\
\hline Martins & 2 & 0,4 \\
\hline Mipirí & 1 & 0,2 \\
\hline Morada Nova Kaxi & 5 & 1,0 \\
\hline Morada Nova Sha & 12 & 2,4 \\
\hline Mucuripe & 1 & 0,2 \\
\hline Mutun & 1 & 0,2 \\
\hline não aldeado & 17 & 3,4 \\
\hline Nawá & 1 & 0,2 \\
\hline Nazaré & 1 & 0,2 \\
\hline Nova & 4 & 0,8 \\
\hline Nova Aldeia & 1 & 0,2 \\
\hline Nova Aliança & 10 & 2,0 \\
\hline Nova Esperança & 11 & 2,2 \\
\hline Nova Fortaleza & 4 & 0,8 \\
\hline Nova Fronteira & 17 & 3,4 \\
\hline Nova Moema & 9 & 1,8 \\
\hline Nova Olinda & 2 & 0,4 \\
\hline Nova Santarém & 1 & 0,2 \\
\hline Nova União & 1 & 0,2 \\
\hline Nova Vida Kaxi & 2 & 0,4 \\
\hline Nova Vida Sha & 1 & 0,2 \\
\hline Novo Ipiranga & 1 & 0,2 \\
\hline Novo Lugar & 3 & 0,6 \\
\hline Novo Marinho & 1 & 0,2 \\
\hline Novo Recreio & 8 & 1,6 \\
\hline Paredão & 1 & 0,2 \\
\hline Paroá & 14 & 2,8 \\
\hline Paxiúba & 22 & 4,3 \\
\hline Pedreira & 24 & 4,7 \\
\hline
\end{tabular}




\begin{tabular}{lcc} 
Nome da aldeia & N & \% \\
\hline Peri & 2 & 0,4 \\
Porto Alegre & 1 & 0,2 \\
Porto Rico & 5 & 1,0 \\
Raimundo Vale & 1 & 0,2 \\
República & 2 & 0,4 \\
Santa Cruz & 3 & 0,6 \\
Santa Júlia & 3 & 0,6 \\
Santa Rosa & 5 & 1,0 \\
Santo Amaro & 5 & 1,0 \\
Santo Antônio & 8 & 1,6 \\
São Francisco & 2 & 0,4 \\
São Joaquim & 1 & 0,2 \\
São José Katpari & 1 & 0,2 \\
São José Tacaquiri & 4 & 0,8 \\
São Lourenço & 7 & 1,4 \\
São Paulino & 3 & 0,6 \\
Senegal & 3 & 0,6 \\
Simpatia & 1 & 0,2 \\
Sítio Bimi & 2 & 0,4 \\
Timbaúba & 1 & 0,2 \\
Três Cachoeiras & 6 & 1,2 \\
\hline Total & 507 & $100 \%$ \\
\hline
\end{tabular}


ANEXO - 7: TABELAS BIVARIADAS DE CAUSA DE INTERNAÇÃO POR ETNIA

\section{Apurinã}

\begin{tabular}{lrr}
\hline Grupo causas afins & $\mathbf{N}$ & \multicolumn{1}{c}{$\%$} \\
\hline Malformação & 14 & 13,9 \\
Infecção respiratória & 10 & 9,9 \\
Trauma & 8 & 7,9 \\
Epilepsia & 6 & 5,9 \\
Desnutrição & 3 & 3,0 \\
Anemia & 2 & 2,0 \\
Diarréia & 2 & 2,0 \\
ITU & 2 & 2,0 \\
Malária & 2 & 2,0 \\
Sinais sintomas & 2 & 2,0 \\
Ac. ofídico & 1 & 1,0 \\
Hérnia & 1 & 1,0 \\
Parasitose & 1 & 1,0 \\
Pênfigo & 1 & 1,0 \\
Sem informação & 46 & 45,5 \\
\hline Total & 101 & $100 \%$ \\
\hline
\end{tabular}

\section{Ashaninka}

\begin{tabular}{lrr}
\hline Grupo causas afins & N & \% \\
\hline Pênfigo & 4 & 33,3 \\
Desnutrição & 3 & 25,0 \\
Infecção respiratória & 2 & 16,7 \\
Diarréia & 1 & 8,3 \\
Epilepsia & 1 & 8,3 \\
Trauma & 1 & 8,3 \\
\hline Total & 12 & $100 \%$ \\
\hline
\end{tabular}




\section{Jamamadi}

\begin{tabular}{llr}
\hline Grupo causas afins & \% & N \\
\hline Diarréia & 4 & 25,0 \\
Pênfigo & 3 & 18,8 \\
Ac. ofídico & 1 & 6,3 \\
Infecção respiratória & 1 & 6,3 \\
Lesão arma fogo & 1 & 6,3 \\
Lesão infecciosa pele & 1 & 6,3 \\
Sinais sintomas & 1 & 6,3 \\
Sem informação & 4 & 25,0 \\
\hline Total & 16 & $100 \%$ \\
\hline
\end{tabular}

\section{Jaminawa}

\begin{tabular}{lrr}
\hline Grupo causas afins & N & \% \\
\hline Infecção respiratória & 25 & 22,3 \\
Diarréia & 9 & 8,0 \\
Anemia & 8 & 7,1 \\
Malformação & 8 & 7,1 \\
Neoplasia & 8 & 7,1 \\
Hepatite & 5 & 4,5 \\
Desnutrição & 3 & 2,7 \\
Parasitose & 3 & 2,7 \\
Trauma & 2 & 1,8 \\
ITU & 1 & 0,9 \\
Lesão infecciosa pele & 1 & 0,9 \\
Otite & 1 & 0,9 \\
Sem informação & 38 & 33,9 \\
\hline Total & 112 & $100 \%$ \\
\hline
\end{tabular}




\section{Katukina}

\begin{tabular}{lcc}
\hline Grupo causas afins & N & \% \\
\hline Infecção respiratória & 2 & 50,0 \\
Diarréia & 1 & 25,0 \\
Sem informação & 1 & 25,0 \\
\hline Total & 4 & $100 \%$ \\
\hline
\end{tabular}

\section{Kaxararí}

\begin{tabular}{lrr}
\hline Grupo causas afins & N & \% \\
\hline Malária & 23 & 17,3 \\
Infecção respiratória & 18 & 13,5 \\
Diarréia & 13 & 9,8 \\
Paralisia cerebral & 7 & 5,3 \\
Otite & 6 & 4,5 \\
Parasitose & 6 & 4,5 \\
Sinais sintomas & 6 & 4,5 \\
Trauma & 5 & 3,8 \\
Lesão infecciosa pele & 3 & 2,3 \\
ITU & 2 & 1,5 \\
Tuberculose & 2 & 1,5 \\
Anemia & 1 & 0,8 \\
Conjuntivite & 1 & 0,8 \\
Epilepsia & 1 & 0,8 \\
Hepatite & 1 & 0,8 \\
Malformação & 1 & 0,8 \\
Queimadura & 1 & 0,8 \\
Sem informação & 36 & 27,1 \\
\hline Total & 133 & $100 \%$ \\
\hline
\end{tabular}




\section{Kaxinawá}

\begin{tabular}{lrr}
\hline Grupo causas afins & N & \% \\
\hline Malformação & 28 & 16,1 \\
Infecção respiratória & 23 & 13,2 \\
Trauma & 11 & 6,3 \\
Diarréia & 9 & 5,2 \\
Lesão infecciosa pele & 5 & 2,9 \\
Desnutrição & 4 & 2,3 \\
Malária & 4 & 2,3 \\
Otite & 4 & 2,3 \\
Paralisia cerebral & 4 & 2,3 \\
Pênfigo & 4 & 2,3 \\
Anemia & 3 & 1,7 \\
Parasitose & 3 & 1,7 \\
Sinais sintomas & 3 & 1,7 \\
Epilepsia & 2 & 1,1 \\
Hérnia & 2 & 1,1 \\
Tuberculose & 2 & 1,1 \\
DST & 1 & 0,6 \\
Hepatite & 1 & 0,6 \\
ITU & 1 & 0,6 \\
Sem informação & 60 & 34,5 \\
\hline Total & 174 & $100 \%$ \\
\hline
\end{tabular}

Kulina

\begin{tabular}{lrr}
\hline Grupo causas afins & N & \% \\
\hline Infecção respiratória & 4 & 17,4 \\
Diarréia & 3 & 13,0 \\
Malformação & 3 & 13,0 \\
Anemia & 1 & 4,3 \\
Desnutrição & 1 & 4,3 \\
Lesão arma fogo & 1 & 4,3 \\
Otite & 1 & 4,3 \\
Trauma & 1 & 4,3 \\
Tuberculose & 1 & 4,3 \\
Sem informação & 7 & 30,4 \\
\hline Total & 23 & $100 \%$ \\
\hline
\end{tabular}


Manchinery

\begin{tabular}{lrr}
\hline Grupo causas afins & N & \% \\
\hline Infecção respiratória & 17 & 23,3 \\
Diarréia & 9 & 12,3 \\
DST & 9 & 12,3 \\
Malformação & 5 & 6,8 \\
Conjuntivite & 3 & 4,1 \\
Trauma & 3 & 4,1 \\
Desnutrição & 2 & 2,7 \\
Lesão infecciosa pele & 2 & 2,7 \\
Queimadura & 2 & 2,7 \\
Anemia & 1 & 1,4 \\
Hepatite & 1 & 1,4 \\
Otite & 1 & 1,4 \\
Paralisia cerebral & 1 & 1,4 \\
Sinais sintomas & 1 & 1,4 \\
Sem informação & 16 & 21,9 \\
\hline Total & 73 & $100 \%$ \\
\hline
\end{tabular}

Nukini

\begin{tabular}{lcc}
\hline Grupo causas afins & $\mathbf{N}$ & $\mathbf{\%}$ \\
\hline Lesão arma fogo & 1 & 100 \\
\hline Total & 1 & $100 \%$ \\
\hline
\end{tabular}

Shanenawa

\begin{tabular}{lcc}
\hline Grupo causas afins & N & \multicolumn{1}{c}{$\%$} \\
\hline Anemia & 4 & 14,8 \\
Infecção respiratória & 4 & 14,8 \\
Neoplasia & 2 & 7,4 \\
Parasitose & 2 & 7,4 \\
Conjuntivite & 1 & 3,7 \\
Diarréia & 1 & 3,7 \\
Malformação & 1 & 3,7 \\
Sinais sintomas & 1 & 3,7 \\
Trauma & 1 & 3,7 \\
Sem informação & 10 & 37,0 \\
\hline Total & 27 & $100 \%$ \\
\hline
\end{tabular}




\section{Yawanawá}

\begin{tabular}{lrr} 
Grupo causas afins & $\mathbf{N}$ & $\mathbf{\%}$ \\
\hline Infecção respiratória & 4 & 23,5 \\
Lesão arma branca & 3 & 17,6 \\
Anemia & 1 & 5,9 \\
Desnutrição & 1 & 5,9 \\
Diarréia & 1 & 5,9 \\
Hérnia & 1 & 5,9 \\
Malformação & 1 & 5,9 \\
Paralisia cerebral & 1 & 5,9 \\
Sinais sintomas & 1 & 5,9 \\
Trauma & 1 & 5,9 \\
Sem informação & 2 & 11,8 \\
\hline Total & 17 & $100 \%$ \\
\hline
\end{tabular}


ANEXO - 8: TABELAS BIVARIADAS DE CAUSA DE INTERNAÇÃO POR PÓLO-BASE

\section{Assis Brasil}

\begin{tabular}{lrr}
\hline Grupo causas afins & N & \% \\
\hline Infecção respiratória & 29 & 23,0 \\
Diarréia & 14 & 11,1 \\
DST & 9 & 7,1 \\
Hepatite & 6 & 4,8 \\
Malformação & 4 & 3,2 \\
Trauma & 4 & 3,2 \\
Anemia & 3 & 2,4 \\
Conjuntivite & 3 & 2,4 \\
Desnutrição & 3 & 2,4 \\
Parasitose & 3 & 2,4 \\
Lesão infecciosa pele & 2 & 1,6 \\
Otite & 2 & 1,6 \\
Paralisia cerebral & 1 & 0,8 \\
Queimadura & 1 & 0,8 \\
Sinais sintomas & 1 & 0,8 \\
Sem informação & 41 & 32,5 \\
\hline Total & 126 & $100 \%$ \\
\hline
\end{tabular}

\section{Boca do Acre}

\begin{tabular}{lrr}
\hline Grupo causas afins & N & \multicolumn{1}{c}{$\%$} \\
\hline Malformação & 11 & 14,5 \\
Epilepsia & 5 & 6,6 \\
Diarréia & 4 & 5,3 \\
Infecção respiratória & 4 & 5,3 \\
Trauma & 4 & 5,3 \\
Pênfigo & 3 & 3,9 \\
Desnutrição & 2 & 2,6 \\
ITU & 2 & 2,6 \\
Ac. ofídico & 1 & 1,3 \\
Anemia & 1 & 1,3 \\
Lesão arma fogo & 1 & 1,3 \\
Lesão infecciosa pele & 1 & 1,3 \\
Malária & 1 & 1,3 \\
Sinais sintomas & 1 & 1,3 \\
Sem informação & 35 & 46,1 \\
\hline Total & 76 & $100 \%$ \\
\hline
\end{tabular}




\section{Cruzeiro do Sul}

\begin{tabular}{lrr}
\hline Grupo causas afins & N & \% \\
\hline Infecção respiratória & 2 & 50,0 \\
Diarréia & 1 & 25,0 \\
Epilepsia & 1 & 25,0 \\
\hline Total & 4 & $100 \%$ \\
\hline
\end{tabular}

\section{Feijó}

\begin{tabular}{lrr}
\hline Grupo causas afins & N & \% \\
\hline Infecção respiratória & 9 & 13,8 \\
Anemia & 4 & 6,2 \\
Desnutrição & 4 & 6,2 \\
Pênfigo & 4 & 6,2 \\
Trauma & 4 & 6,2 \\
Diarréia & 3 & 4,6 \\
Lesão infecciosa pele & 3 & 4,6 \\
Malformação & 3 & 4,6 \\
Parasitose & 3 & 4,6 \\
Neoplasia & 2 & 3,1 \\
Otite & 2 & 3,1 \\
Sinais sintomas & 2 & 3,1 \\
Conjuntivite & 1 & 1,5 \\
DST & 1 & 1,5 \\
Epilepsia & 1 & 1,5 \\
Paralisia cerebral & 1 & 1,5 \\
Sem informação & 18 & 27,7 \\
\hline Total & 65 & $100 \%$ \\
\hline
\end{tabular}

\section{Jordão}

\begin{tabular}{lcc}
\hline Grupo causas afins & N & \% \\
\hline Trauma & 2 & 28,6 \\
Anemia & 1 & 14,3 \\
Diarréia & 1 & 14,3 \\
Infecção respiratória & 1 & 14,3 \\
Otite & 1 & 14,3 \\
Paralisia cerebral & 1 & 14,3 \\
\hline Total & 7 & $100 \%$ \\
\hline
\end{tabular}


Mâncio Lima

\begin{tabular}{lrr}
\hline Grupo causas afins & N & \% \\
\hline Lesão arma fogo & 1 & 33,3 \\
Sem informação & 2 & 66,7 \\
\hline Total & 3 & $100 \%$ \\
\hline
\end{tabular}

\section{Manoel Urbano}

\begin{tabular}{lrr}
\hline Grupo causas afins & N & \% \\
\hline Diarréia & 2 & 18,2 \\
Malformação & 2 & 18,2 \\
Anemia & 1 & 9,1 \\
Desnutrição & 1 & 9,1 \\
Infecção respiratória & 1 & 9,1 \\
Otite & 1 & 9,1 \\
Sem informação & 3 & 27,3 \\
\hline Total & 11 & $100 \%$ \\
\hline
\end{tabular}

\section{Pauiní}

\begin{tabular}{lrr}
\hline Grupo causas afins & N & \% \\
\hline Infecção respiratória & 6 & 17,6 \\
Trauma & 4 & 11,8 \\
Malformação & 3 & 8,8 \\
Diarréia & 2 & 5,9 \\
Sinais sintomas & 2 & 5,9 \\
Ac. ofídico & 1 & 2,9 \\
Anemia & 1 & 2,9 \\
Epilepsia & 1 & 2,9 \\
Hérnia & 1 & 2,9 \\
Malária & 1 & 2,9 \\
Parasitose & 1 & 2,9 \\
Pênfigo & 1 & 2,9 \\
Sem informação & 10 & 29,4 \\
\hline Total & 34 & $100 \%$ \\
\hline
\end{tabular}


Rio Branco

\begin{tabular}{lrr} 
Grupo causas afins & N & \% \\
\hline Desnutrição & 1 & 14,3 \\
Diarréia & 1 & 14,3 \\
Infecção respiratória & 1 & 14,3 \\
Malformação & 1 & 14,3 \\
Sem informação & 3 & 42,9 \\
\hline Total & 7 & $100 \%$ \\
\hline
\end{tabular}

